SERVICODE POS-ORAIUUACAOODO ICMC-USP

Data de Depósito: $\quad 25 / 02 / 20012$

Assinatura $i_{2}$ lo

\title{
Teste de Mutação: subsidios para a redução do custo de aplicação
}

Rodrigo Funabashi Jorge

Orientador: Prof. Dr. Márcio Eduardo Delamaro

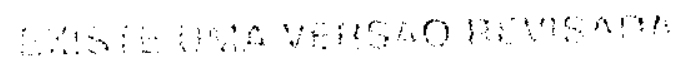

Dissertação apresentada ao Instituto de Ciências Matcmáticas e de Computação - ICMC-USP. como parte dos requisitos para obtenção do titulo de Mestre en Ciências de Computação e Matemática Computacional.

USP São Carlos

Fevereiro/2002 


\section{A Conissão Julgadora:}

Prof. Dr. Márcio Eduardo Delamaro

Prof Dr. Paulo ('esar Masiero

Profa. Dra. Sandra ('amargo P'mto lierraz Iabhri
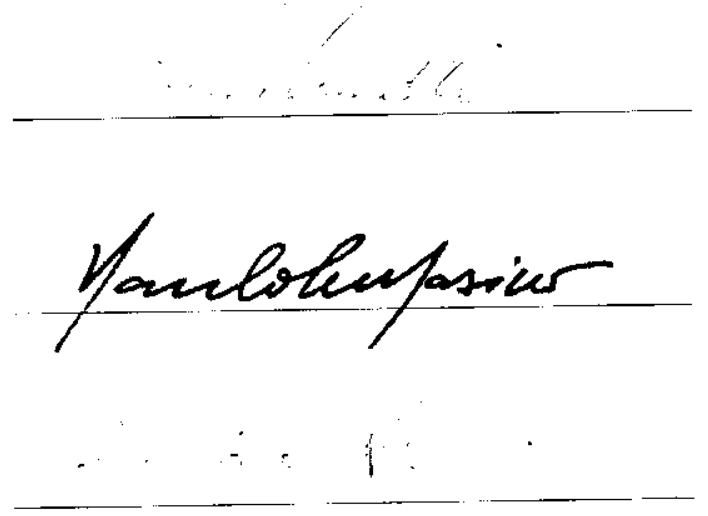
Ao meu fitho Pedro Paulo, aos meus pais, Elcio e Sônia,

e a minha irmã Patrícia 


\section{Agradecimentos}

Agradeço inicialmente a DEUS, pelo dom da vida e por me acompanhar em todos os momentos.

Ao meu orientador, Prof. Dr. Márcio Eduardo Delamaro, pela orientação e profissionalismo durante todo o periodo deste trabalho.

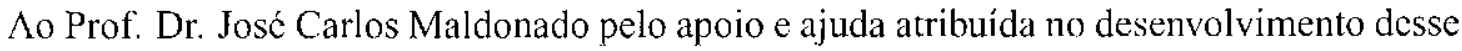
trabalho e pela revisão da disscrtação.

Fm especial ao Auri, pela grande amizade e por estar sempre disposto a ajudar, mesmo $\mathrm{cm}$ momentos dificeis.

Aos meus pais, Elcio e Sônia, e minha irmã Patrícia, pelo amor, incentivo e constante apoio em todos os momentos da minha vida.

Ao meu filho Pedro Paulo, por "entender" a minha ausência para que esse trabalho pudesse ser desenvolvido, e a Fábia por sempre se esforçar para que eu pudesse estar com nosso filho, as vezes deixando seus compromissos de lado.

Aos demais Professores do grupo de Engenharia de Software e ao Prof. Dr. Dorival Lcão Pinto Júnior pela contribuição no desenvolvimento desse trabalho.

Aos meus amigos: Adenilso (Ades), Andrea (Colaboradora), Ana (Banana), Aline, Camilo, Elisa, Ellen (Cachorrona), Emerson, Érica, Fernando (Tranqüilo), Gelza, Erald (Holandês), Luciana (DTI), Luciano, Marcelo, Maria Istela, Mayb, Matheus, Rejane, Richard, Rogério, Rosana, Silvio, Simone, Thaise, Tatiana (Ninja), Vangrei e Vivianc (Vivi) .

Aos companheiros de República: André (Maluquinho), Gustavo (Amebão), Kleber, Reginaldo (Ré) c Ricardo (Mininim) ${ }^{\dagger}$, pelos bons momentos que passamos juntos e que sempre estarão guardados $\mathrm{cm}$ meu coração.

Aos funcionários do ICMC, pela disposição c atenção.

A todos aqueles que, de certa forma, me apoiaram neste trabalho.

Ao CNPq e à Fapesp pelo apoio financeiro.

\footnotetext{
in Memoriam.
} 
1 Introdução 1

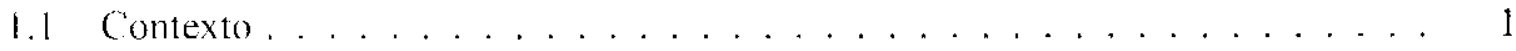

1.2 Motivaçăo . . . . . . . . . . . . . . . . . . . . 3

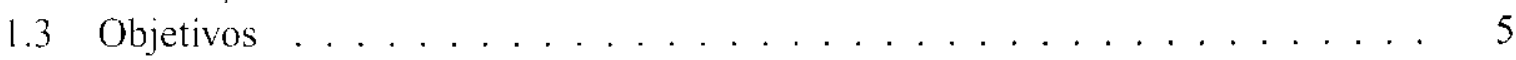

1.4 Organizaçăo do Trabalho . . . . . . . . . . . . . . . 6

2 Revisão Bibliográfica 7

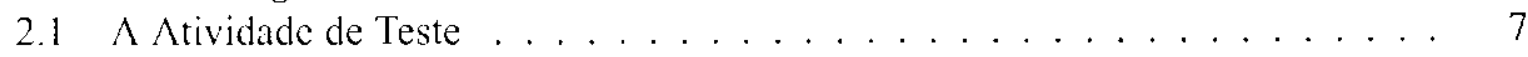

2.2 Técnicas e Critérios de Teste de Software . . . . . . . . . . . . . . 8

2.2 .1 Teste Funcional . . . . . . . . . . . . . . . . . . . . . . . 9

2.2 .2 Teste Estrutural . . . . . . . . . . . . . . . . . . . 10

2.2 .3 Teste Bascado $\mathrm{cm}$ Erros . . . . . . . . . . . . . . . . . 11

2.3 Teste de Mutação . . . . . . . . . . . . . . . . . . . . . . 13

2.3 .1 Aspectos Históricos . . . . . . . . . . . . . . . . 13

2.3.2 Passos para Aplicação do Teste de Mutação . . . . . . . . . . . . . . . . . 14

2.3.2.1 Geração dos Mutantes . . . . . . . . . . . . . . . . 15

2.3.2.2 Execução do Programa Original . . . . . . . . . . . . . 18

2.3.2.3 Execução dos Mutantes . . . . . . . . . . . . . . . . . 18

2.3.2.4 Análise dos Mutantes Vivos . . . . . . . . . . . . . . . 19

2.3 .3 Teste de Integração . . . . . . . . . . . . . . . . . . . . . 20

2.3.3.1 Erros de Integração . . . . . . . . . . . . . . 21

2.3.3.2 Critérios para o Teste em Nivel de Integração . . . . . . . . 23

2.3 .3 .3 o critério Mutação de Interface . . . . . . . . . . . . 23

2.4 Ferramentas para o Teste de Mutação . . . . . . . . . . . . . . . . 26

2.5 Estudos Empíricos . . . . . . . . . . . . . . . . . . . 27

2.5.1 Redução do Número de Mutantes Gerados . . . . . . . . . . . . . . . 28

2.5.2 Determinação de Mutantes equivalentes ................. 31

2.6 Considerações Finais . . . . . . . . . . . . . . . 37

3 Operadores de Mutação: Uma Avaliação Empírica 39

3.1 Descrição dos Operadores de Mutação . . . . . . . . . . . . . . . . . . . . 40

3.1.1 Teste de Unidade - Proteum . . . . . . . . . . . . . . . 41 
3.1 .2 Teste de Integração - PROTRMMIIM . . . . . . . . . . . 46

3.2 Descriçào do Experimento . . . . . . . . . . . . . . . . 50

3.2 .1 Seleçào dos Programas . . . . . . . . . . . . . . . . . . 51

3.2 .2 Seleção de Ferramentas de Teste . . . . . . . . . . . . . . . . . . . 53

3.2 .3 Geração dos Conjuntos de Casos de Teste . . . . . . . . . . . . . 54

3.2 .4 Colcta e Análise dos Dados . . . . . . . . . . . . . . . 56

3.3 Avaliação dos Operadores de Mutação . . . . . . . . . . . . . . . . . 57

3.3 .1 Operadores de Mulação para o Teste Unidade . . . . . . . . . . . . . . 60

3.3.2 Operadores de Mutação para o Teste de Integração . . . . . . . . . . . 73

3.4 Considerações Finais . . . . . . . . . . . . . . . . . . . . . . . . . . . 79

4 Estabelecimento de Estratégias de Teste para Aplicação dos Operadores de Muta$\begin{array}{lr}\text { ção } & \mathbf{8 0}\end{array}$

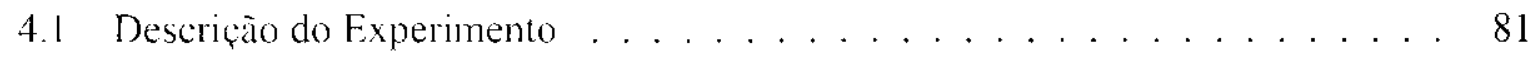

4.1.1 Coleta e Análise dos Dados . . . . . . . . . . . . . . 81

4.1 .2 Modelo de Ordem Estocástica . . . . . . . . . . . . . . . . 83

4.1.2.1 Algoritmo Matemático de Newton Raphson . . . . . . . . . 86

4.2 Fstratégias Baseadas no Número de Mutantes Equivalentes . . . . . . . . . . . 89

4.2 .1 Estratégia ESECUS: Teste de Unidade . . . . . . . . . . . . . . 90

4.2 .2 Estratégia LSECIS: Teste de Integração . . . . . . . . . . . . . . . . 91

4.3 Estratégias que Priorizam os Operadores Essenciais . . . . . . . . . . . . . . 95

4.3.1 Estratégia SESECUS: Teste de Unidade . . . . . . . . . . . . . . . 95

4.3 .2 Estratégia SESECIS: Teste de Integração f . . . . . . . . . . . . . . . . . 96

4.4 Comparação com Outras Estratégias . . . . . . . . . . . . . . . 97

4.5 Considerações Finais . . . . . . . . . . . . . . . . . . . . . . . . . . . . . . . 99

5 Conclusões e Trabalhos Futuros 101

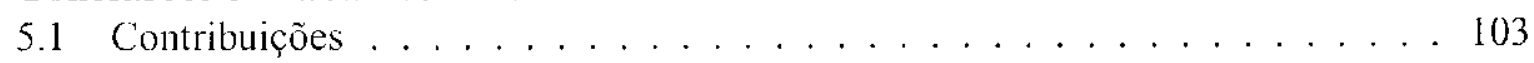

5.2 Trabalhos Futuros . . . . . . . . . . . . . . . 103 
2.1 Passos para $\Lambda$ plicação do Teste de Mutação. . . . . . . . . . . . . . . 16

2.2 Exemplo de Mutante. . . . . . . . . . . . . . . . . . . . . . . . 17

2.3 Excmplo de Mutante Equivalente. . . . . . . . . . . . . . . . . . . . . 19

2.4 Exemplo de Mutante Quase-Equivalente. . . . . . . . . . . . . . . . . 20

2.5 Modelo de Falhas causadas por Lrros de Integração: (A) Tipo 1; (B) Tipo 2;

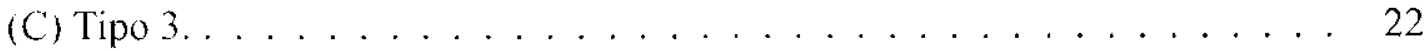

2.6 Representação do Conjunto de Mutantes Requeridos no Teste da Conexão $F-C_{r}$. 24

2.7 Mutantes $\Lambda$ ssociados às Chamadas de $G$ e $F \ldots \ldots \ldots . \ldots . \ldots 25$

2.8 Conexão entre as unidades $F$ e $G \ldots \ldots \ldots \ldots \ldots$

2.9 Processo do Teste de Mutação com Dependência de Associações e Análise de Restrições (Harman et al., 2000). . . . . . . . . . . . . . . . 37

3.1 Classificação dos Operadores de Mutação de Constantes . . . . . . . . . . . 42

3.2 Classificação dos Operadores de Mutação de Comandos . . . . . . . . . . . . 43

3.3 Classificação dos Operadores de Mutação de Operadores . . . . . . . . . . . . . 45

3.4 Classificação dos Operadores de Mutação de Variáveis . . . . . . . . . . . . 46

3.5 Classificação dos Operadores de Mutação de Interface - Grupo I . . . . . . 50

3.6 Classificação dos Operadores de Mutação de Interface - Grupo II . . . . . . . . 51

3.7 Cardinalidade dos Conjuntos de Casos de Teste AM-adequado e Ml-adequado 56 
2.1 Detecção de Mutantes Equivalentes - 15 Programas (Offutt \& Craft, 1994) . . 33

2.2 Deteç̧ão de Mutantes Equivalentes - 3 Programas (Offutt \& Craft, 1994) . . . 33

2.3 Mutantes Equivalentes por Operador - Mothra (Offutt \& Craft, 1994) . . . . . . 33

2.4 Deteção de Mutantes Equivalentes - 11 Programas (Offutt \& Pan, 1997) . . . 35

2.5 Detecção de Pontos não Executáveis (Offutt \& Pan, 1997) . . . . . . . . . . 36

3.1 Operadores de Mutação de Constantes . . . . . . . . . . . . . . . . . . . . 42

3.2 Operadores de Mutação de Comandos . . . . . . . . . . . . . . . . . . . . 42

3.3 Classilicação dos Operadores Binários em C . . . . . . . . . . . . . 43

3.4 Operadores de Mutação de Operadores . . . . . . . . . . . . . . . . . . . . . 44

3.5 Operadores de Mutação de Variáveis . . . . . . . . . . . . . . . . 45

3.6 Siglas que Formam os Nomes dos Operadores de Mutação para o Teste de Interface . . . . . . . . . . . . . . . . . . . . 47

3.7 Conjunto de Constantes Requeridas - Mutação de Interfáce . . . . . . . . . . 49

3.8 Operadores de Mutação de Interface - Grupo I . . . . . . . . . . . . . . . . . . . . 49

3.9 Operadores de Mutação de Interface - Grupo II . . . . . . . . . . . . . . . 50

3.10 Conjunto de Programas Utilizados no Experimento . . . . . . . . . . . . . . 52

3.11 Complexidade dos Programas: Ferramenta Proteum . . . . . . . . . 52

3.12 Complexidade dos Programas: Ferramenta PROTEM M LM . . . . . . . 52

3.13 Número de Casos de Teste Utilizados por Programa . . . . . . . . . . . . . . 55

3.14 Construçòes Típicas de Mutantes Equivalentes . . . . . . . . . . . . . . . . . 59

3.15 Conjunto de Constantes Requeridas - Mutação de Unidade . . . . . . . . . . . 60

3.16 Tabela Lógica - Operadores $\& \&$ e $\&$. . . . . . . . . . . . . . . . 63

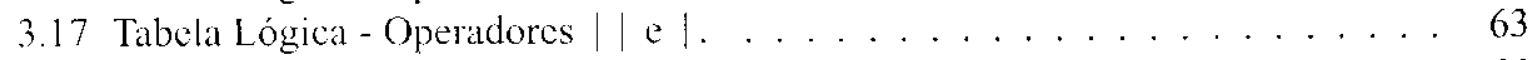

3.18 Análise de Inclusão Entre os operadores STRP c SSWM . . . . . . . . . . 66

3.19 Funções Utilizadas pelo Operador VDTR . . . . . . . . . . . . . . . 67

3.20 Complexidade dos Operadores de Mutação: Ferramenta Proteum . . . . . . . 70

3.21 Operadores de Mutaçào de Lnidade mais Custosos: (a) Mutantes Gerados, (b) Mutantes Lquivalentes e (c) Mutantes Q-Equivalentes . . . . . . . . . . . . . 73

3.22 Complexidade dos Operadores de Mutação: Ferramenta FROTUM/IM . . . . . 77

3.23 Operadores de Mutação de Interface mais Custosos: (a) Mutantes Gerados, (b) Mutantes Fquivalentes e (c) Mutantes Q-Equivalentes . . . . . . . . . . . 78 
4.1 Porcentagem de Casos de Teste Necessárias para Matar os Mutantes de cada Operador para um conjunto AM-adequado: Programa Cal . . . . . . . . . . . . . 82

4.2 Média para os 11 conjuntos AM-adequados: Programa Cal . . . . . . . . . 83

4.3 Média da Porcentagem de Casos de Teste Necessárias para Matar os Mutantes de cada Operador: 5 Programas . . . . . . . . . . . . . . . . . . . 83

4.4 Definiçôes para Aplicação do Algoritmo . . . . . . . . . . . . . . . . 84

4.5 Aplicação do Algoritmo de Vewton Raphson: Operadores de Unidade . . . . . 87

4.6 Aplicação do Algoritmo de Vewton Raphson: Operadores de Interface . . . . . 88

4.7 Dados Coletados para um Conjunto de Casos de Teste AM-adequado: Programa Cal. . . . . . . . . . . . . . . . . . . 89

4.8 Aplicação da Estratégia ESECUS: Primeiro Passo . . . . . . . . . . . . . . . 91

4.9 Aplicação da Estratégia ESECUS: Último Passo . . . . . . . . . . . . . . . . . . . . . . 92

4.10 Aplicação da Estratégia ESECIS: Primeiro Passo . . . . . . . . . . . . 93

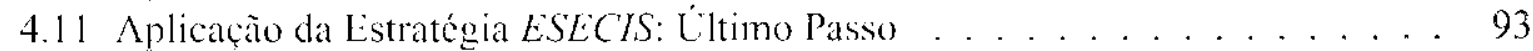

4.12 Aplicação da Estratégia SESEC US: Ĺltimo Passo . . . . . . . . . . . . . . . . . . . 96

4.13 Aplicação da Estratégia SESECIS: Último Passo . . . . . . . . . . . . . . . 97

4.14 Conjunto de Casos de Teste Quase Adequado - (Escore de Mutação maior ou igual a $0,991 \ldots \ldots \ldots \ldots$. . . . . . . . . . . . . . . . . 98

4.15 Conjunto de Casos de Teste Adequado - (Escore de Mutação igual a 1,00) . . 98 
D ARA sistematizar os testes e contornar as restrições de tempo e custo a ele associadas, diversas técnicas, critérios e ferramentas têm sido descnvolvidas. Além disso, visando ao estabelecimento de uma estratégia de teste que apresente baixo custo de aplicação e alta eficácia em revelar a presença de erros, estudos teóricos e empíricos vêm sendo conduzidos pela comunidade de teste. Os critérios de teste, Análise de Mutantes c Mutação de Interface, apresentam problemas de custo relacionados ao grande número de mutantes gerados e equivalentes, sendo de fundamental importância o desenvolvimento de abordagens que viabilizem a sua aplicação prática. O presente trabalho está inserido nesse contex to $\mathfrak{e}$ tem como objetivo analisar os operadores de mutação implementados nas lerramentas Proteum e $\mathcal{P R O T R M} / \mathcal{I} M$, que apóiam a aplicação dos critérios Análise de Mutantes e Mutação de Interface, respectivamente, levando em consideração não só o número de mutantes gerados mas também o esforço requerido na identificação e eliminação de mutantes equivalentes e mutantes que morrem facilmente. Tal análise permitiu a determinação de heurísticas para eliminação de mutantes equivalentes e o estabelecimento de cstratégias incrementais para aplicação dos operadores de mutação, reduzindo com isso o custo do teste em nivel de unidade e de integração sem comprometer sua qualidade e contribuindo para a evolução dessas ferramentas para a sua aplicação em ambientes industriais de produção de software. 
$\mathrm{T}$ O systematize testing and to outline the constraints of time and cost associated to testing activity, several techniques, criteria and tools have been developed. Besides, aiming at establishing testing strategies of low cost and high effectiveness in revealing the presence of errors, theoretical and empirical studies have been carried out by the testing community. Testing criteria such as, Mutation Analysis and Interface Mutation, present cost problems related to the large number of mutants and equivalency, being of fundamental importance the development of approaches to make possible their practical application. In this context, the present work aims at analyzing the mutant operators implemented in the Proteum and PROTEMM/IM lools, that support the application of the Mutation Analysis and Interface Mutation, respectively, considering not only the number of generated mutants but also the effort required in the identification and elimination of equivalent mutants and mutants that die easily. Such analysis allowed the determination of heuristics for elimination of equivalent mutants and the development of incremental strategies to apply mutant operators, reducing the cost of unit and integration testing without compromising quality. This work might also contribute to the evolution of these testing tools and to their application in software production industrial environments. 
ESTE capítulo são apresentados o contexto dentro do qual este trabalho está inserido, desenvolvimento. No final do capítulo também é apresentada uma visão geral da organização desta dissertação.

\subsection{Contexto}

Sistemas baseados em computação têm sido utilizados $\mathrm{cm}$ todas as árcas da atividade humana e, como conseqüência, tem-se exigido uma melhor qualidade do software, adicionando aspectos de qualidade e produtividade à dificuldade e complexidade da alividade de desenvolvimento de software (Maldonado, 1991).

Mesmo com as atividades de garantia de cualidade conduzidas durante todo o processo de desenvolvimento do software, verifica-se que muitos erros permanecem no software pronto. Segundo Harrold (2000), o teste é uma dessas atividades e pode consumir, em alguns casos, cerca de 40 a $50 \%$ do custo de desenvolvimento do softwarc. Desse modo é necessário determinar quais casos de teste utilizar a fim de que a maioria dos erros existentes possa ser encontrada e que o número de casos de teste utilizados não seja tão grande a ponto de ser impraticável.

$\mathrm{Na}$ tentativa de reduzir os custos e aumentar a qualidade da atividade de teste, várias técnicas e critérios têm sido propostos. A diferença entre essas técnicas está na origem da informação 
que é utilizada para avaliar ou construir conjuntos de casos de teste, sendo que cada técnica possui uma variedade de critérios para esse fim. $\mathrm{Na}$ Técnica Funcional (caixa preta) os requisitos de teste são obtidos a partir da especificação; na Técnica Estrutural (caixa branca) derivam-se os requisitos a partir da implementação do softwarc; e na Técnica Baseada em Erros os elementos requeridos para caracterizar a atividade de teste são baseados $\mathrm{cm}$ crros comuns que podem ocorrer durante o processo de desenvolvimento de software.

Dentro do contexto da Engenharia de Software, a atividade de teste, do ponto de vista procedimental, pode ser considerada como uma seqüencia de três passos. O primeiro deles é o teste de unidade, no qual cada unidade do software é testada individualmente, buscando-se evidências de que ela funcione adcquadamente. O próximo passo, o teste de integração, é uma atividade sistemática para integrar as unidades componentes da estrutura do software, visando a identificar erros de interação entre elas. Finalizando, o teste de sistema verifica se todos os elementos do sistema combinam-se adequadamente e se a função/desempenho global do mesmo é atingida (Pressman, 2000).

Existem mecanismos para a seleção sistemática de um subconjunto do domínio de entrada do programa em teste, de modo que este seja eficaz na deteç̧ão dos crros existentes, conhecidos como critérios de teste. Em geral, a partir de um dado critério de teste podem-se obter infinitos subconjuntos de casos de teste adequados ao programa em questão.

Segundo (Maldonado, 1991), as técnicas e teste devem ser vistas como complementares e a questão que se coloca está cm como utilizá-las de forma que as vantagens de cada uma sejam melhor exploradas em uma estratégia de teste que leve a um teste de boa qualidade, ou seja, eficaz em revelar a presença de crros e de baixo custo. As técnicas c critérios de teste fornecem ao desenvolvedor uma abordagem sistemática $\mathrm{c}$ tcoricamente fundamentada, além de constituírem um mecanismo de auxílio para avaliar a qualidade e adequação da atividade de teste.

Para que os testes sejam conduzidos de forma satisfatória e livre de erros que possam ser introduzidos devido à intervenção humana, o desenvolvimento de ferramentas que buscam automatizar cssa atividade é fundamental. Além disso, a disponibilidade de ferramentas de teste oferece recursos para o desenvolvimento de estudos empíricos de forma a avaliar o custo e a eficácia das técnicas e critérios de teste nos quais as ferramentas se baseiam. Pode-se identificar um grande esforço da comunidade de teste nessa dirç̧ão (Mathur \& Wong, 1993; Offutt et al., 1993; DeMillo et al., 1995; Offutt \& Craft, 1994; Offutt \& Lee, 1994; Wong et al., 1994a,b; Offutt et al., 1996a,b; Souza, 1996; Offutt \& Pan, 1997; Wong et al., 1997; Barbosa, 1998; Vincenzi, 1998; Harman et al., 2000; Maldonado et al., 2000; Delamaro et al., 2001; Jorge et al., 2001; Vincenzi et al., 2001)

Uma das linhas de atuação do Grupo de Engenharia de Software do ICMC/USP, em colaboração com o Grupo de Teste do DCA/FEEC/UNICAMP c o Laboratório de Engenharia de 
Software do DIN/UFM, é o estudo de principios, estratégias, métodos c critérios de teste e validação na produção de software, bem como na especificação e implementação de ferramentas que apóiem a realização das atividades de teste c viabilizem a avaliação do aspecto complementar dos critérios, por meio de estudos teóricos e empíricos.

Dentro desse contexto, algumas das ferramentas de teste desenvolvidas são: a Poketool (Maldonado et al., 1989; Chaim, 1991), a Proteum (Delamaro, 1993; Delamaro \& Maldonado. 1993) e a $\mathcal{F R O T E M M} / \mathcal{M}$ (Delamaro, 1997)- que apóiam os critérios Potenciais-Usos (Maldonado, 1991), Análise de Mutantes (DeMillo et al., 1978) e Mutação de Interface (Delamaro et al., 2001), respectivamente. A implementação dessas ferramentas viabilizou o início de trabalhos comparativos entre os critérios de teste Funcional, Estrutural c Bascado em Erros, bem como o estudo e avaliação de variantes para o Teste de Mutação (Souza, 1996; Delamaro, 1997; Wong et al., 1997; Barbosa, 1998; Vincenzi, 1998; Fondazzi, 1999; Sugeta, 1999; Simão, 2000; Delamaro et al., 2001).

\subsection{Motivação}

Dentre os critérios de teste que tem se destacado estão os critérios Baseados em Fluxo de Dados e os critérios Baseados em Mutação (Teste de Mutação). Neste trabalho ênfase é dada ao Teste de Mutação.

O Teste de Mutação surgiu na década de 70 na Yale University e Georgia Institute of Technology (DeMillo et al., 1978) e vários trabalhos empíricos e teóricos têm indicado que o Teste de Mutação é atrativo para o teste de programas devido a sua eficácia em revelar a presença de crros (Budd ct al., 1980; Mathur, 1991; Mathur \& Wong, 1993; Wong, 1993; Wong \& Mathur, 1995a,b; Offutt et al., 1996a,b; Barbosa, 1998: Vincenzi, 1998; Delamaro et al., 2001). Além da eficácia em revelar a presença de erros, outra qualidade do Teste de Mutação é sua flexibilidade no sentido de poder ser estendido para diversas entidades executáveis: programas (DeMillo et a1., 1978; Delamaro, 1997) e especificações (Fabbri et al., 1993; Woodward, 1993; Fabbri et al., 1994, 1995; Fabbri, 1996; Sugeta, 1999; Simão, 2000; Sridhanan et al., 2000). Essa flexibilidade vem do fato de que, para se aplicar o Teste de Mutação, é necessária a existência de um modelo que seja executável c que aceite uma entrada e produza uma saída que possa ser comparada com a saída do mutante. Além disso, é necessária a definição de um conjunto de operadores de mutação responsável pcla representação do modelo de erros correspondente à entidade executável em questão.

Especificamente para o teste de programas, o Teste de Mutação pode ser utilizado no teste de unidade (denominado Análise de Mutantes) e no teste de integração (denominado Mutação de Interface). 
Nessa Dissertação, quando nenhuma distinção for necessária, o termo Teste de Mutação é utilizado para referenciar ambos os critérios.

Basicamente, a idéia do Teste de Mutação é criar a confiança de que um programa $P$ está correto, produzindo-se por meio de pequenas alterações sintáticas, um conjunto de programas chamados de mutantes semelhantes a $P$, e construindo-se casos de teste capazes de provocar diferenças de comportamento entre $P$ e seus mutantes. Essas alterações são feitas com base em um conjunto de operadores de mutação. A cada operador pode-se associar um tipo ou uma classe de erros que se pretende revelar. A aplicação do critério consiste de quatro etapas principais:

1. Geração de mutantes;

2. Execução do programa $P$ com um conjunto de casos de teste $T$;

3. Execução dos mutantes com $T$; e

4. Análise dos mutantes.

O objetivo é achar um conjunto de casos de teste ' $I$ ' que consiga matar todos os mutantes não equivalentes à $P$, ou seja, fazer com que esses mutantes tenham um comportamento distinto de $P$ com algum caso de teste de $T$. Tais conjuntos são considerados adequados para o teste de $P$, no sentido de que ou $P$ está correto ou contém algum erro sutil e incsperado, o que deve ser raro se as modificações usadas para criar os mutantes forem cuidadosamente escolhidas.

O Teste de Mutação fornece uma medida objetiva do nível de confiança da adequação dos casos de teste analisados. Com base no escore de mutação, que relaciona o número de mutantes gerados com o número de mutantes mortos, pode-se avaliar a adequação dos casos de teste usados e, como conseqüência, a confiabilidade do programa testado.

As ferramentas Proteum (Delamaro, 1993; Delamaro \& Maldonado, 1993) e $\mathcal{P R O T a M}$ MM (Delamaro, 1997) foram desenvolvidas no Instituto de Ciências Matemáticas e de Computação - ICMC/USP e apóiam o Teste de Mutação em nivel de unidade e de integração, respectivamente. Estas ferramentas foram utilizadas no desenvolvimento desse trabalho por serem as únicas ferramentas existente atualmente que apóiam o Teste de Mutação para programas escritos em linguagem $C$. Para o nível de unidade, a Proteum possui um conjunto de 71 operadores de mutação. Para o teste de integração foram definidos e implementados 33 operadores de mutação na ferramenta $P R O T G M / T M$.

O principal problema para a aplicação de critérios baseados em mutação está relacionado com o seu custo. O primeiro aspecto deste problema está diretamente relacionado com o grande número de mutantes que pode ser gerado mesmo para programas simples. Entre as pesquisas para contornar este aspecto de custo dos critérios, têm sido investigadas abordagens para a 
redução do número de mutantes gerados. Uma linha interessante é a caracterização de um subconjunto de operadores de mutação que apresente o mesmo grau de adequação e eficácia, mas a um custo menor. Os critérios caracterizados por esses subconjuntos têm sido denominados de Mutação Restrita (Constrained Mutation) (Wong, 1993; Offutt et al., 1996a; Barbosa, 1998). Também tem sido objetivo dessas pesquisas o cstabelecimento de estratégias de teste incrementais que explorem as diversas características dos critérios, partindo-se inicialmente de critérios "mais fracos" e talvez menos eficazes para a avaliação da adequação do conjunto de casos de teste, e em função da disponibilidade de orçamento e de tempo, incrementalmente, procurandose satisfazer critérios mais "fortes" c eventualmente mais eficazes, porém, cm geral, mais caros (Vincenzi, 1998).

O segundo aspecto restritivo quanto ao custo de aplicação dos critérios refere-se ao esforço para a determinação dos mutantes equivalentes que, em geral, requer a intervenção do testador ou a elaboração de heurísticas (Offutt \& Craft, 1994; Offutt \& Pan, 1997; Harman ct al., 2000). Assim, a determinação de um conjunto essencial de operadores deve lcvar cm consideração não somente aspectos de cobertura e eficácia mas tambćm o custo associado à probabilidade de criação de mutantes equivalentes.

Este trabalho está em consonância com os trabalhos desenvolvidos pelo Grupo de Engenharia de Soltware do ICMC, e objetiva contribuir para a determinação de formas alternativas e de baixo custo para a aplicação dos critérios bascados $\mathrm{cm}$ mutação. E também está inserido no contexto do projeto de pesquisa - CNPq: Teste de Mutação: Análise e Definição de Estratégias de Teste e Validação de Software.

\subsection{Objetivos}

O trabalho tem como objctivo analisar teórica e empiricamente os operadores de mutação implementados nas ferramentas Proteum c $\mathcal{P R O T E M} / \mathcal{L}$, visando a diminuir o custo de aplicação dos critérios Análise de Mutantes e Mutação de Interface. Especificamente, são investigados dois aspectos: 1) determinação de mutantes equivalentes, por meio de inclusão de operadores e definição de heurísticas; 2 ) efetividade dos operadores, determinando quais operadores geram mutantes que morrem facilmente, ou seja, mutantes que morrem com grande quantidade de casos de teste. Com base nesses dados, são estabelecidas estratégias incrementais para aplicação dos operadores de mutação mantendo-se a eficácia e reduzindo-se o custo dos critérios baseados $\mathrm{cm}$ mutação $\mathrm{cm}$ relação ao número de mutantes equivalentes.

Devido aos problemas de custo, tanto em relação ao grande número de mutantes gerados quanto à determinação de mutantes equivalentes, o desenvolvimento de estratégias para aplicação dos operadores de mutação, levando-se em consideração esses dois aspectos, é de funda- 
mental importância para viabilizar a aplicação dos mesmos em ambientes reais de descnvolvimento de software.

\subsection{Organização do Trabalho}

Neste capítulo foi apresentado o contexto no qual cste trabalho se insere, as motivações para a sua realização e seus objetivos. No Capítulo 2 são apresentadas as fases da atividade de teste e as principais técnicas e critérios de teste existentes. Também são aprescntados os critérios Análise de Mutantes e Mutação de Interface, ferramentas para aplicação de testes baseados em mutação c alguns estudos empíricos que têm como objetivo reduzir o custo de aplicação desses critérios. No Capítulo 3 é apresentado o experimento para a avaliação dos operadores de mutação para o teste de unidade e integração com o estabelecimento de heurísticas para determinação de mutantes equivalentes. No Capítulo 4 são definidas estratégiás incrementais para aplicação dos operadores de mutação dos critério Análise de Mutantes e Mutação de Interface baseadas no número de mutantes equivalentes e na dificuldade de distinguir os mutantes gerados por um determinado operador de mutação e o Capítulo 5 apresenta as contribuições deste trabalho e perspectivas para trabalhos futuros. 


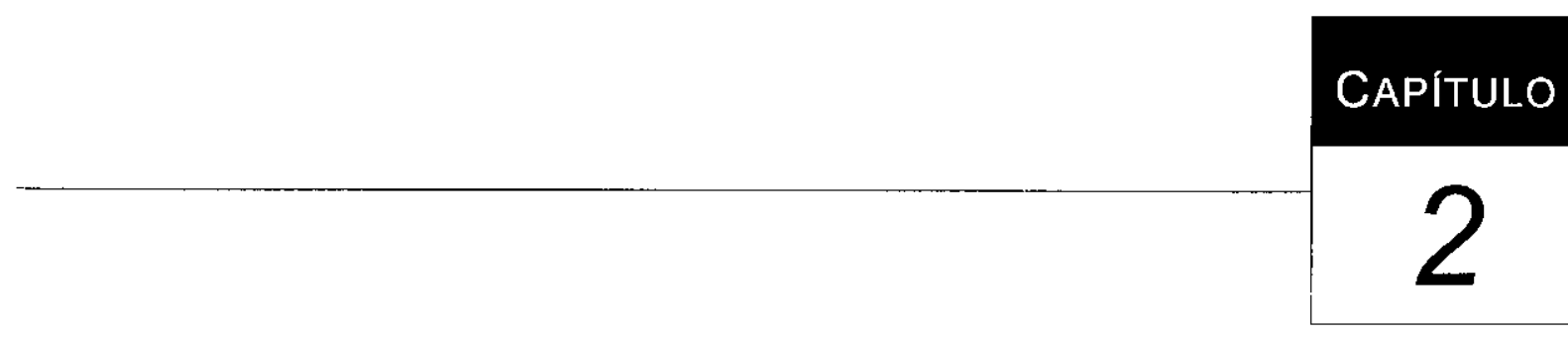

\section{Revisão Bibliográfica}

$\mathrm{N}$ ESTE capítulo são apresentados alguns conceitos envolvendo a atividade de teste. Inicialmente, são feitas considerações a respeito da importância do teste durante o processo de desenvolvimento, em seguida são apresentadas as fases do teste e as principais técnicas e critérios que podem ser utilizadas em cada uma delas. Os critérios Análise de Mutantes e Mutação de Interface, dois critćrios da Técnica Baseada em Lrros, também são descritos por constituírem o alvo do presente trabalho. A importância da existência de ferramentas automatizadas que auxiliem na condução dos testes também é discutida e identificadas as principais ferramentas para a atividade de teste que utilizam técnicas baseadas cm mutação.

Finalmente ć apresentada uma síntese dos principais estudos empíricos utilizando-se os critérios baseados em mutação, cujos resultados motivam a realização deste trabalho.

\subsection{A Atividade de Teste}

O processo de desenvolvimento de software envolve uma série de atividades nas quais, apesar dos métodos, técnicas e ferramentas empregados, erros ainda podem ocorrer. Com isso, a atividade de teste é de fundamental importância para a identificação e eliminação de erros que persistem, representando a última revisão da especificação, projeto e codificação (Pressman, $2000)$.

Segundo Myers (1979), a atividade de teste é o processo de executar um programa com a intenção de encontrar um erro; um bom caso de teste é aquele que tem alta probabilidade de 
revelar erros e um teste bem sucedido é aquele que detecta a existência de um erro ainda não descoberto.

A realização dos testes é composta das seguintes etapas: construção dos casos de teste, cxecução do programa $P$ com esses casos de teste e análise do comportamento de $P$ a fim de determinar se o mesmo cstá correto ou não. Tal procedimento se repete até que o testador tenha confiança de que $P$ comporta-se conforme o espcrado com o mínimo de erros possível ou até que um erro seja descoberto (Souza, 1996).

Segundo Pressman (2000), a atividade de teste deve ser conduzida $\mathrm{cm}$ três fases: teste de unidade, teste de integração e teste de sistema. O teste de unidade concentra-se no esforço de verificação da menor parte de projeto de software chamada de módulo ou unidade ${ }^{1}$. O teste de integração ć uma atividade sistemática para a construção da estrutura de programa, visando à descobrir erros associados às interações entre as unidades. O objetivo é, a partir dos módulos testados no nível de unidade, construir a estrutura de programa que foi determinada pelo projeto. O teste de sistema, realizado após a integração do sistema, visa a identificar erros de funções e características de desempenho que não estejam de acordo com a especificação.

Um dos pontos críticos da atividade de teste é a escolha dos casos de teste a serem aplicados. O programa, para ser demonstrado correto, deveria ser exercitado com todos os valores possíveis do domínio de entrada. Sabe-se, entretanto, que o teste exaustivo é impraticável devido a restrições de tempo c custo para realizá-lo, sendo necessário determinar um conjunto de casos de teste que seja eficaz em encontrar erros cuja cardinalidade seja reduzida (Mycrs, 1979). Com esse objetivo várias técnicas e critérios de teste têm sido elaborados.

\subsection{Técnicas e Critérios de Teste de Software}

$\mathrm{Na}$ tentativa de reduzir os custos associados ao teste, é fundamental a aplicação de técnicas que indiquem como testar o software e de critérios que respondam quando parar os testes, de forma que essa atividade possa ser conduzida de modo planejado e sistemático (Demillo, 1980).

Critérios de teste têm sido elaborados com o objetivo de fornecer uma maneira sistemática e rigorosa para selecionar um subconjunto do domínio de entrada e ainda assim ser eficaz para revelar a presença de erros, respeitando as restrições de tempo e custo associados a um projeto de software. Esses critérios são classificados em três técnicas de testes: Técnica Funcional, Técnica Estrutural e a Técnica Baseada em Erros. A diferença entre as três técnicas é a origem da informação usada para avaliar ou para construir conjuntos de casos de teste (Maldonado, 1991).

Segundo Pressman (2000), nenhuma das técnicas de teste ć completa, no sentido que nenhuma delas é, em geral, suficiente para garantir a qualidade da atividade de teste. Essas diferentes

\footnotetext{
${ }^{1}$ Usaremos neste trabalho o termo unidade.
} 
técnicas são complementares e devem ser aplicadas em conjunto para assegurar um teste de boa qualidade.

Apesar das limitações da atividade de testc, sua aplicação de maneira sistematizada e bem planejada pode garantir ao software algumas características mínimas que são importantes no estabclccimento da qualidade do produto e relevantes também para o seu processo de evolução. Além disso, é importante lembrar que o teste é, em geral, apenas uma atividade de validação e que sua utilização isolada não é suficiente para alcançar um produto de boa qualidade. Outras técnicas, tais como: inspeção, "walkthrough" e verificação formal, devem ser utilizadas em conjunto com a atividade de teste.

\subsubsection{Teste Funcional}

Essa técnica é também conhecida como teste de caixa preta pelo fato de tratar o software como uma caixa na qual o conteúdo é desconhecido e da qual só é possível visualizar o lado externo, ou seja, os dados de entrada fornecidos e as respostas produzidas como saída.

Nesta técnica são verificadas as funções do sistema sem se preocupar com detalhes de implementação. Para isto, Coward (1988) distingue no teste funcional dois passos principais:

1. Identificar as funções esperadas do software; e

2. Criar casos de teste que chequem a realização das funções determinadas.

Segundo Pressman (2000), o teste de caixa preta é uma abordagem que procura revelar erros das seguintes categorias:

- Funções incorretas ou ausentes;

- Erros de interface;

- Erros nas estruturas de dados ou no acesso a banco de dados externos;

- erros de desempenho; c

- erros de inicialização e término.

As funções que o software possui são identificadas a partir de sua especificação, sendo cssencial para o teste funcional uma especificação correta e de acordo com os requisitos do usuário (Demillo, 1987).

Os critérios de teste funcional mais conhecidos são: 
- Particionamento em Classes de Equivalência é um critério de teste funcional que divide o domínio de entrada de um programa em classes, a partir das quais os casos de teste podem ser selecionados. O objetivo é minimizar o número de casos de teste, obtendose somente casos de teste essenciais. O uso de particionamento permite examinar os requisitos com mais detalhes e restringir o número de casos de teste;

- Análise do Valor Limite (BVA-Boundary Value Analysis) é um complemento ao critério Particionamento cm Classes de Equivalência. Em vez de sclecionar qualquer elemento de uma classe de equivalência, a BVA leva à seleção de casos de teste nas "extremidades" da classe. Em vez de se concentrar somente nas condições de entrada, a BVA deriva os casos de teste também do domínio de saída (Myers, 1979);

- Grafo de Causa e Efeito é utilizado quando se necessita testar o efeito combinado de dados de entrada. Causas e efeitos são identificados e combinados $\mathrm{cm}$ um grafo. Esse grafo é convertido em uma tabela de decisão que é utilizada na construção dos casos de teste; e

- Error Guessing é um outro critério funcional, onde os possíveis erros são listados e casos de teste são construídos baseados nesta lista.

Em geral, o teste funcional é uma técnica de validação de programas na qual os casos de teste são gerados a partir da especificação dos requisitos, tornando-se uma técnica sujeita às inconsistências que podem ocorrer na especificação (Demillo, 1987). Outro problema encontrado com a utilização dessa técnica é a dificuldade de quantificar a atividade de teste, visto que não se pode garantir que partes essenciais ou críticas do programa sejam executadas.

\subsubsection{Teste Estrutural}

Essa técnica de teste também é conhecida como teste de caixa branca, pois os requisitos de teste inspecionados por esta são baseados na implementação.

Segundo Pressman (2000), o teste de caixa branca do software baseia-se em um minucioso exame dos detalhes procedimentais. O "status do programa" pode ser examinado em vários pontos para determinar se o status esperado ou estabclecido corresponde ao "status real". Esta técnica de teste é baseada no conhecimento da estrutura interna da implementação; a maioria dos critérios dessa técnica utiliza uma representação de programa conhecida como grafo de fluxo de controle ou grafo de programa. Um grafo de fluxo de controle é um grafo orientado onde cada vértice representa um bloco indivisível de comandos e cada aresta representa um desvio de um bloco para outro. Um bloco desse tipo tem as seguintes características: não existem desvios para o meio do bloco e uma vez que o primeiro comando do bloco seja executado, todos 
os demais comandos do bloco são executados seqüencialmente. Através do grafo de programa escolhem-se as estruturas que devem ser executados.

Como exemplos de critérios de teste estrutural têm-se (Pressman, 2000):

- Critérios Baseados na Complexidade: utilizam informações sobre a complexidade do programa para determinar os requisitos de teste. Um critério bastante conhecido desta classe é o critćrio de McCabe que utiliza a complexidade ciclomática para derivar os requisitos de teste. Essencialmente, esse critério requcr que seja executado um conjunto de caminhos linearmente independente do grafo de programa (Pressman, 2000).

- Critérios Baseados em Fluxo de Controle: utilizam apenas características de controle de execução do programa, como comandos ou desvios, para determinar quais estruturas são necessárias. Os mais conhecidos são os critérios Todos-Arcos, Todos-Nós e TodosCaminhos. Os critérios Todos-Nós e Todos-Arcos exigem que a execução do programa passe pelos menos uma vez em cada vértice do grafo de fluxo (ou que cada comando do programa seja executado pelo menos uma vez), e que cada aresta do grafo (cada desvio do programa) seja exercitado pelo menos uma ve $\%$, respectivamente. Já o critćrio Todos-Caminhos que, em geral, é impraticável, requer que todos os caminhos possiveis do programa sejam exccutados (Pressman, 2000). Um caminho é exccutável se existe um conjunto de valores que possa ser atribuído às variáveis de entrada do programa e que causa a exccução desse caminho; caso contrário, esse caminho é dito não executável (Frankl, 1987).

- Critérios Baseados em Fluxo de Dados: utilizam informações do fluxo de dados do programa para derivar os requisitos de teste. Lsses critérios selecionam caminhos de teste de um programa de acordo com as localizações das definições (pontos em que as variáveis reccbem um valor) e usos (pontos em que os valores das variávcis são utilizados) de variáveis no programa. Exemplos dessa classe de critérios são os critérios de (Rapps \& Weyuker, 1982, 1985) e os critérios Potenciais-Usos (Maldonado, 1991).

\subsubsection{Teste Baseado em Erros}

A técnica de teste baseada em erros utiliza informações sobre os crros mais freqüentes cometidos no processo de desenvolvimento de software e sobrc os tipos específicos de erros que se desejam localizar (Demillo, 1987). A ênfase da técnica cstá nos crros que o programador ou projetista pode cometer durante o desenvolvimento e nas abordagens que podem ser usadas para detectar a sua ocorrência.

Semeadura de Erros (Error Seeding), Análise de Mutantes (Mutation Analysis) e Mutação de Interface (Interface Mutation) são critérios típicos que se concentram em erros. 
No critério Semeadura de Erros, uma quantidade conhecida de erros é semeada artificialmentc no programa. Após o teste, do número total de crros encontrados verificam-se quais são naturais e quais são artificiais. Usando estimativas de probabilidade, o número de erros naturais ainda existentes no programa pode ser calculado (Budd, 1981).

Dentre os problemas para a aplicação deste critério estão:

1. Os erros artificiais podem interagir com os naturais fazendo com que os crros naturais sejam "mascarados" pelos erros semeados;

2. Para obter-se um resultado estatístico não questionável é necessário o uso de programas capazes de conter 10.000 erros ou mais; e

3. É preciso assumir que os erros estão distribuídos pelo programa de mancira uniforme, o que, cm geral, não é verdade. Programas reais apresentam longos trechos de programas com código simples e poucos erros, e pequenos trechos com alta complexidade e alta concentração de erros (Budd, 1981).

O Teste de Mutação, também baseado em erros, utiliza um conjunto de programas ligeiramente modificados (mutantes) obtidos a partir do programa em teste. O objetivo é encontrar um conjunto de casos de teste capaz de revelar as diferenças existentes entre o programa original e seus mutantes (Demillo, 1987).

Considerando o critério Análise de Mutantes, dois outros critérios que podem ser derivados são a Mutação Fraca (Weak Mutation) (Howden, 1982) e a Mutação Firme (Firm Mutation) (Woodward \& Halewood, 1988). A idéia básica dos critérios Mutação Fraca, Mutação Firme e Mutação Forte (como usa Howden (1982) para se referir à Análise de Mutantes) é a mesma, ou seja, uma pequena mudança no programa é realizada e os resultados da versão original são comparados com os da versão modificada. A diferença está no momento da criação do mutante e no momento em que se comparam os resultados obtidos para decidir se o mutante "morre" ou continua "vivo". Na Mutação Fraca cria-se o mutante imediatamente antes da execução de um comando e os resultados são comparados logo após o término da execução do comando. $\mathrm{Na}$ Mutação Forte geram-se os mutantes antes do inicio da exccução do programa e comparam-se os resultados após o término de sua execução. Já a Mutação Firme, definida como um critério entre a Mutação Fraca c a Mutação Forte, realiza alterações no programa e introduz pontos nos quais os estados do programa original e do programa mutante são comparados antes do final da cxecução (Woodward \& Halewood, 1988). 


\subsection{Teste de Mutação}

Este sessão apresenta dois critérios baseados em erros: Análise de Mutantes e Mutação de Interface, que permitem a aplicação do Teste de Mutação em nível de unidade e de integração, respectivamente.

\subsubsection{Aspectos Históricos}

O Teste de Mutação surgiu na década de 70 na YALE University c no Georgia Institute of Technology, possuindo um forte relacionamento com um método clássico para deteç̧ão de erros lógicos em circuitos digitais, conhecido como modelo de teste de falha única (DeMillo et al., 1978; Budd ct al., 1980; Demillo, 1980; Budd, 1981).

Segundo Demillo (1987), um conjunto de teste pode ser considerado adequado se o programa funciona corretamente quando executado com os casos de teste e se todos os programas incorretos têm um comportamento não esperado em relação a algum caso de teste. Dessa forma, o objetivo inicial do Teste de Mutação é de servir como um meio de medir o quanto um conjunto de casos de teste é adequado a um determinado programa, sendo também demonstrado por DeMillo et al. (1978), sua eficácia na detecção de erros.

Observou-se no final dos anos 80 uma intensificação de trabalhos na área, iniciando com o desenvolvimento da ferramenta conhecida como Mothra (DeMillo et al., 1988; Choi et al., 1989) que é um ambiente de teste para programas na linguagem Fortran-77, no qual existem 22 operadores de mutação implementados para o testc de unidade (Análise de Mutantes). A interface utilizada é baseada em janelas, o que facilita a realização dos testes; permite incorporar outras ferramentas como gerador de casos de teste, verificador de equivalência e oráculo.

Em 1991, DeMillo \& Offutt (1991) desenvolveram uma ferramenta para geração automática de dados de teste chamada Godzilla, a qual gera dados de teste próximos da adequação, utilizando um esquema de restrições (constraint-based automatic test data generation). Essa ferramenta hoje se encontra acoplada à ferramenta de teste Mothra.

Outro avanço na área foi o descnvolvimento da ferramenta Proteum (Delamaro, 1993; Delamaro \& Maldonado, 1993) que realiza teste em programas desenvolvidos na linguagem $C$ em nível de unidade.

Vários critérios têm sido propostos a fim de avaliar a qualidade dos casos de teste, podendose citar os critérios de Fluxo de Dados e critérios Bascados em Mutação como alguns dos mais promissores nesse aspecto. A maioria desses critérios, no entanto, estava restrita ao teste de unidade (Harrold \& Soffa, 1991), sendo que no teste de integração, em geral, aplica-se apenas o teste funcional. Porém, em 1997 Delamaro propôs o critério Mutação de Interface (Delamaro, 1997; Delamaro et al., 2001) que possui as mesmas características do critério Análise de 
Mutantes para o teste de integração. Para apoiar a aplicação do critério Mutação de Interface, Delamaro desenvolveu a ferramenta $\mathcal{F R O T E M} / I M$ (Delamaro, 1997) que testa a interação entre as unidade de programas desenvolvidos na linguagem $C$.

Hoje as ferramentas Proteum e $\mathcal{R O T I G M} / \mathcal{M}$ estão integradas em um único ambientes denominado $\mathcal{R R O T E M}$ TIM 2.0 (Delamaro et al., 2000). Essa ferramenta aplica tanto o teste de unidade quanto o teste de integração.

Com essas ferramentas hoje tem-se investido muito em estudos empíricos para avaliar c aprimorar os critérios Análise de Mutantes e Mutação de Interface (Mathur \& Wong, 1993; Offutt et al., 1993; DeMillo et al., 1993; Offutt \& Lee, 1994; Wong et al., 1994a,b; Offutt ct al., 1996b; Offutt \& Craft, 1994; Offutt ct al., 1996a; Souza, 1996; Offutt \& Pan, 1997; Wong et al., 1997; Barbosa, 1998; Vincenzi. 1998; Fondazzi, 1999; Harman et al., 2000; Maldonado et al., 2000; Barbosa et al., 2001; Delamaro et al., 2001; Jorge et al., 2001; Vincenzi et al., 2001)

\subsubsection{Passos para Aplicação do Teste de Mutação}

A idéia básica da técnica apresentada por DeMillo et al. (1978), conhecida como hipótese do programador competente (competent programmer hypothesis), assume que programadores expcricntes escrevem programas próximos do correto. Considerando a validade dessa hipótese, pode-se alirmar que crros são introduzidos nos programas através de pequenos desvios sintáticos que alteram a semântica do programa e, conseqüentemente, conduzem o programa a um comportamento incorreto. Para revelar tais crros, o Teste de Mutação identifica os desvios sintáticos mais comuns e, através da aplicação de pequenas transformações sobre o programa em teste, encoraja o testador a construir casos de testes que mostrem que tais transformações levam a um programa incorreto (Agrawal et al., 1989).

Uma outra hipótese explorada na aplicação do Teste de Mutação é o efeito de acoplamento (coupling effect) (DeMillo et al., 1978), a qual assume que crros complexos estão relacionados a erros simples. Dessa forma, espera-se, e alguns estudos já confirmaram esta hipótese (Budd et al., 1980; Wah, 2000), que conjuntos de casos de teste capazes de revelar erros simples sejam também capazes de revelar erros complexos.

Primeiramente o testador deve fornecer um programa $P$ a ser testado e um conjunto de casos de teste $T$ cuja adequação deseja-se avaliar. O programa é executado com $T$ e, se apresentar resultados incorretos, então um erro foi revelado e o teste termina. Caso contrário, o programa ainda pode conter erros que o conjunto $T$ não conseguiu revelar. $O$ programa $P$ sofre então pequenas alterações, dando origem aos programas $P 1, P^{2} \ldots$ Pn, que são mutantes de $P$, diferindo deste apenas pela ocorrência de crros simples, ou seja, cada mutante contém apenas uma mutação. 
A seguir, os mutantes são executados com o mesmo conjunto de casos de teste $T$. Os mutantes que apresentam resultados diversos de $P$, para algum caso de teste, é dito "morto". Os demais são considerados vivos e entre estes existem os mutantes equivalentes, para os quais não existe um valor do domínio de entrada que diferencie seu resultado de $P$.

Através do escore de mutação (mutation score), que relaciona o número de mutantes mortos com o número de mutantes gerados, o Teste de Mutação fornece uma medida objctiva do nível de adequação dos casos de teste analisados. O escore de mutação é calculado da seguinte forma:

$$
m s(P, T)=\frac{D M(P, T)}{M(P)-E M(P)}
$$

Sendo:

$D M(P, T)$ : total de mutantes mortos pelo conjunto de casos de teste $T$;

$M(P)$ total de mutantes gerados a partir do programa $P$;

$E M(P):$ total de mutantes equivalentes ao programa $P$.

O cscore de mutação varia no intervalo $[0,1]$ sendo que, quanto maior o escore, mais adequado é o conjunto de casos de teste para o programa sendo testado. Percebe-se com essa fórmula que apenas $D M(P, T)$ depende do conjunto de casos de testc utilizado e que $E M(P)$ é obtido à medida que se decide que determinado mutante vivo é equivalente. Em geral, a equivalência entre programas é uma questão indecidível; no entanto, alguns métodos e heurísticas têm sido propostos para determinar a cquivalência de programas em uma grande porcentagem dos casos de interessc (Offutt \& Craft, 1994; Offuit \& Pan, 1997; Harman et al., 2000).

Dados um programa $P$ e um conjunto de casos de teste $T$ cuja qualidade deseja-se avaliar, pode-se aplicar o Teste de Mutação através dos seguintes passos:

1. Gcração dos Mutantes;

2. Exccução do Programa Original $(P)$;

3. Execução do Mutantes; e

4. Análise dos Mutantes Vivos.

A Figura 2.1 ilustra a relação entrc cada um dos passos apresentados para a aplicação do Teste de Mutação que serão melhor detalhados a seguir.

\subsubsection{Geração dos Mutantes}

O sucesso da aplicação do Teste de Mutação depende do conjunto de mutantes gerados a partir de determinado programa $P$. Segundo Delamaro (1993) esse conjunto deve apresentar as seguintes características: 


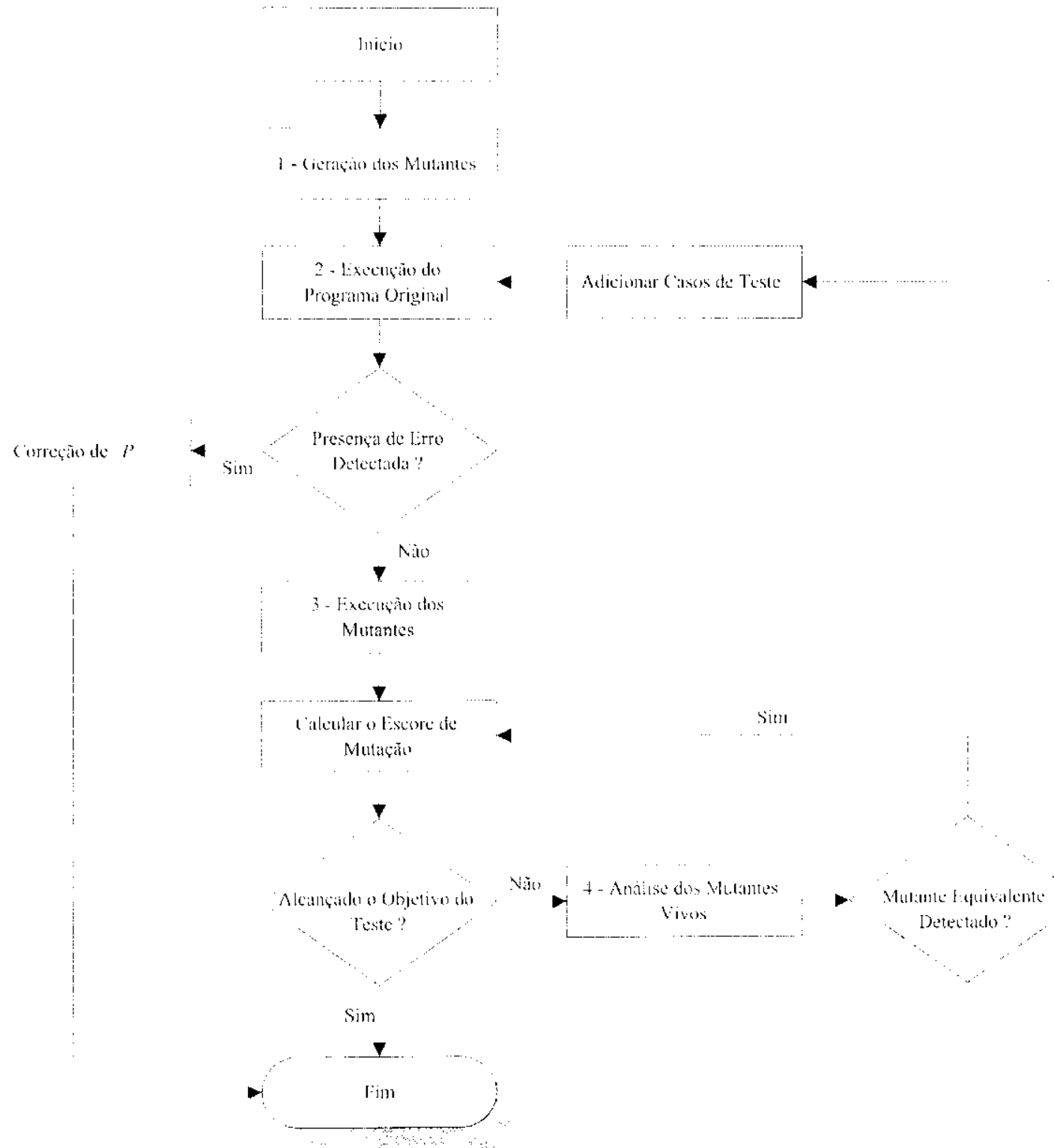

Figura 2.1: Passos para Aplicação do Teste de Mutação.

- Ser abrangente, de modo que um conjunto de casos de teste que satisfaça o Teste de Mutação, ou em outras palavras, que seja adequado para $\Gamma^{\prime}$ em relação a $F\left(I^{\prime}\right)$, consiga revelar a maior parte dos erros de $P$; e

- Ter cardinalidade pequena, para que o problema de gerar ou verificar se um conjunto de casos de teste é ou não adequado, seja tratável.

Os mutantes são gerados através da aplicação de operadores de mutação no programa $P$ sendo testado. Lintende-se por operador de mutação (mutant operators) as regras que definem as alterações que devem ser aplicadas no programa original $P$. A aplicação de um operador de mutação gera, na maioria das vezes, mais que um mutantc, visto que $P$ pode conter várias 
entidades que estão no domínio de um operador e, desse modo, o operador é aplicado a cada uma dessas entidades, uma de cada vez.

Os operadores de mutação são construídos para satisfazer um entre dois propósitos (Offutt et al., 1996a):

1. Induzir mudanças sintáticas simples com base nos erros típicos cometidos pelos programadores (como trocar o nome de uma variável); ou

2. Forçar determinados objetivos de teste (como executar cada arco do programa).

Além dos tipos de erros que se desejam revelar e da cobertura que se quer garantir, a escolha de um conjunto de opcradores de mutação depende fortemente da linguagem em que os programas a serem testados estão escritos. Em (DeMillo et al., 1988) encontra-se a relação de 22 operadores de mutação utilizados por um sistema de mutação, chamado Mothra, para programas em Fortran-77. Já para a linguagem $C$, a ferramenta Proteum conta com 71 operadores de mutação e, para o teste de programas $C$ em nível de integração, a ferramenta $\operatorname{RROTEM}$ M/LM possui 33 operadores de mutação.

A Figura 2.2 apresenta um trecho de programa, utilitário do sistema opcracional UNIX chamado sort, e um exemplo de mutante gerado a partir da aplicação de um operador de mutação.

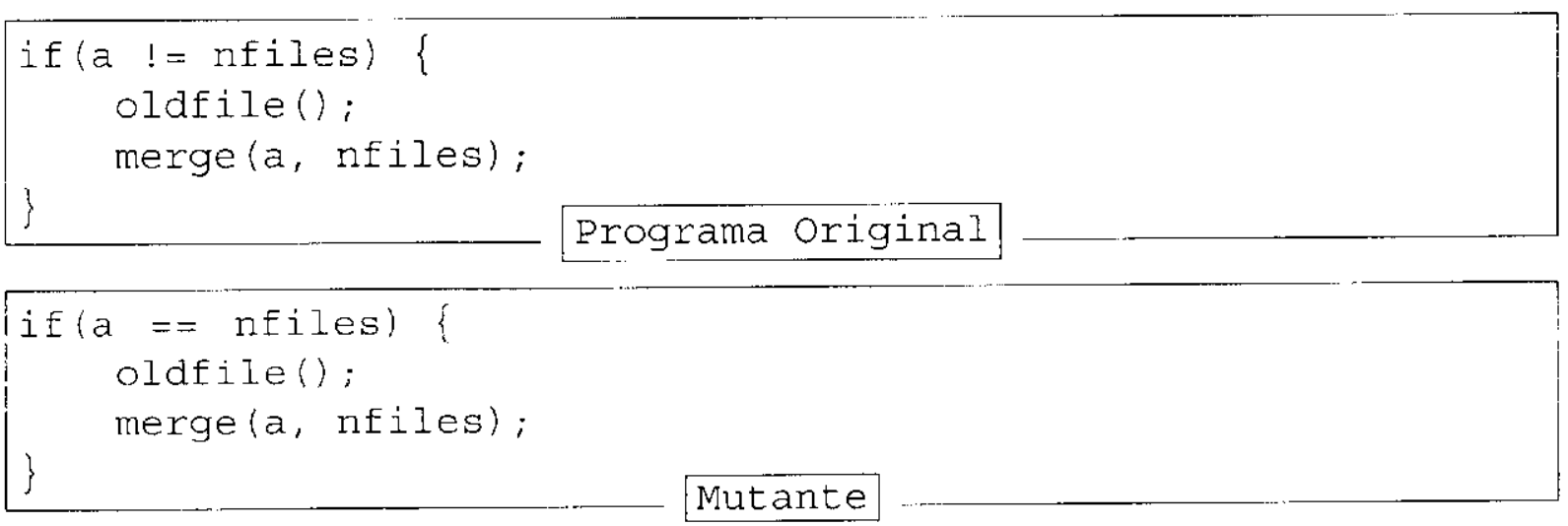

Figura 2.2: Exemplo de Mutante.

A princípio, é possível a aplicação de mais de um operador de mutação de uma só vez para a geração de mutantes. Mutantes gerados a partir de $k$ alterações simultâneas no programa $P$ em teste são ditos mutantes de ordem $k$. O estudo realizado por Budd et al. (1980) mostra que mutantes de ordem superior a 1 , além de não contribuírem de forma significativa para a construção de casos de teste melhores, têm um custo de geração e execução demasiadamente alto. Dessa maneira, apenas mutantes de primeira ordem têm sido utilizados no Teste de Mutação. 


\subsubsection{Execução do Programa Original}

Deve-se executar o programa original $P$ para os casos de teste selccionados e verificar se o resultado é o esperado. Caso o programa apresente um comportamento diferente para algum caso de teste, então um erro foi descoberto e o processo termina. Se nenhum caso de teste revelar erro, o teste continua no passo scguinte. A tarefa de oráculo, que ć decidir se o resultado está correto ou não, geralmente é desempenhada pelo testador.

\subsubsection{Execução dos Mutantes}

Neste passo, cada um dos mutantes é executado usando os casos de teste de $T$. Se um mutante $M$ apresenta resultado diferente de $P$, isto significa que os casos de teste utilizados são sensíveis e conseguiram expor a diferença entre $P$ e $M$; nestc caso, $M$ ć dito estar morto e é descartado. Por outro lado, se $M$ apresenta comportamento igual a $P$, isto indica ou uma fraqueza de $T$, pois não conseguiu distinguir $P$ de $M$, ou indica que $P$ e $M$ são equivalentes; neste caso, diz-se que $M$ continua vivo.

Existem alguns problemas relacionados com este passo do Teste de Mutação. Um deles é decidir se um mutante está morto ou vivo. Mais precisamente, determinar quais entidades devem ser comparadas para decidir se o comportamento do mutante e do programa original são os mesmos.

A opção mais simples é capturar as seqüências de caracteres enviadas pelos programas para os dispositivos de saida e comparar as seqüências produzidas pelo prograna original e pelos mutantes.

Além disso, outros pontos podem ser usados para tentar distinguir o comportamento dos programas. O código de retorno, que corresponde ao valor que indica se a execução terminou normalmente ou qual foi a causa do termino, é também usado com esse propósito.

Se o tempo de execução de um mutante ultrapassa muito o tempo de execução do programa original, isso pode indicar que a alteração fez com que o mutante entrasse em um laço infinito. Então, nesse caso o mutante deve também ser considerado morto por "timeout".

Assim, decidir quais "saídas" deven ser monitoradas é mais uma questão de implementação do sistema de mutação do que uma característica intrínseca do Teste de Mutação. Não são bem claras quais são as conseqüências de escolher-se como parâmetro de decisão, essa ou aquela entidade.

Nas ferramentas utilizadas neste trabalho, os mutantes podem ser mortos por quatro razões (Delamaro et al., 1996):

1. Stdout: quando a saida do mutante é diferente do programa original; 
2. RetCode: quando o código de retorno é diferente do programa original;

3. Timeout: quando o tempo de execução do mutante excede o tempo de exccução do programa original sendo esse tempo definido por uma constante; e

4. Trap: quando a execução atingi alguma "armadilha" (função trap) ${ }^{2}$.

Com certeza, um dos principais problemas na aplicação do Teste de Mutação diz respeito à complexidade da execução dos mutantes. Muitas vezes o número de mutantes criados é muito alto, fazendo com que a complexidade computacional da sua exccução scja proibitiva.

Outro problema estão nas dificuldades associadas em capturar casos de teste e compará-los às saídas quando o programa em teste utiliza como input uma interface gráfica por exemplo. A natureza das aplicações com GUI (Graphical User Interface), seu modo assíncrono de operação, entrada e saída não tradicionais e a estrutura hierárquica de interação com o usuário tornam o teste significativamente mais complexo em comparação com o teste de software "tradicional".

\subsubsection{Análise dos Mutantes Vivos}

Essa é a fase do Teste de Mutação que requer mais intervenção humana. Primeiramente, é necessário analisar os mutantes que sobreviveram à exccução com os casos de teste disponíveis. O mutante $M$ pode ter ficado vivo devido a:

- O conjunto $T$ não ser suficiente (adequado) para distinguir o comportamento de $P$ e $M$ e, nesse caso, podem ser incluídos novos casos de teste no conjunto $T$;

- $M$ ser equivalente a $P$. Para qualquer dado do domínio de entrada não existe diferença entre o comportamento dos dois programas. Um exemplo de mutante equivalente é apresentado na Figura 2.3;

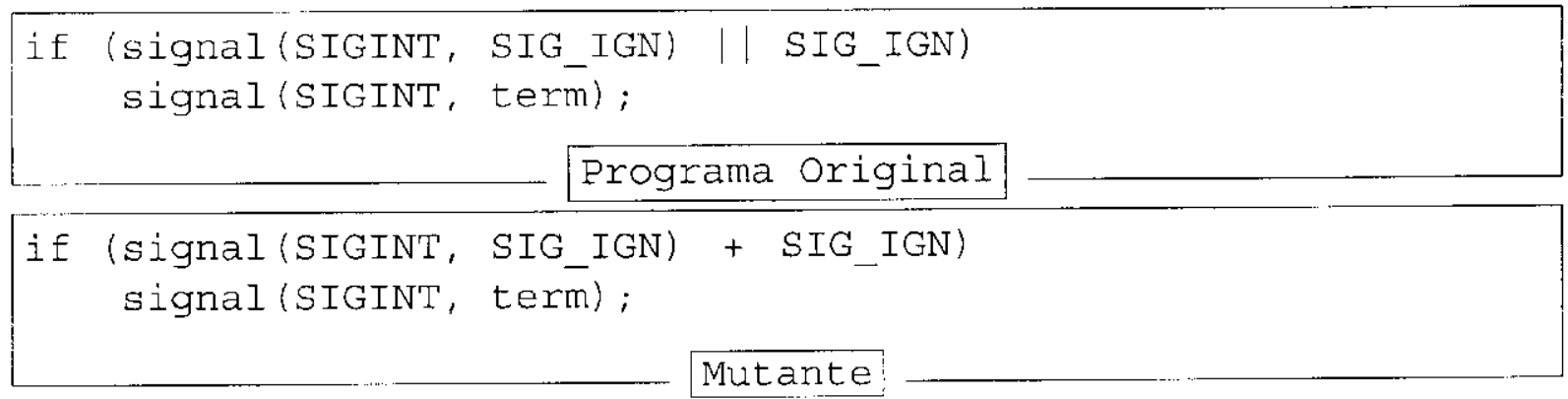

Figura 2.3: Exemplo de Mutante Equivalente.

\footnotetext{
${ }^{2}$ Alguns operadores aplicam a mutação incluindo a função trap ("trap function") no programa em teste (operadores "instrumentados"). Os mutantes gerados por esse tipo de operador são mortos quando a função trap é executada, ou seja, apenas os mutantes gerados por esse tipo de operador podem ser mortos por trap.
} 
Nas seções 2.3.3.1 e 2.3.3.2 são apresentados, respectivamente, os tipos de falhas que caractcrizam erros de integração e alguns trabalhos relacionados ao teste de integração. O critério Mutação de Interface proposto por Delamaro (Dclamaro, 1997; Delamaro \& Maldonado, 1997a, 1999) é descrito na Seção 2.3.3.3.

\subsubsection{Erros de Integração}

Segundo Haley \& Zweben (1984), os erros de integração podem ser classificados em erros de integração computacional ${ }^{3} \mathrm{c}$ erros de domínio ${ }^{4}$. Dada uma função $F$ que chama $G$, o primeiro ocorre quando um erro computacional em $G$ produz um valor incorreto que é passado para $F^{\prime}$ que, por sua vez, produz uma saída incorreta. O segundo ocorre quando um erro de domínio em $G$ causa uma saída incorreta $\mathrm{em} F$. Em ambos os casos existem algum valor incorreto passado entre as unidades que os levam a produzir uma saída incorreta.

Considerando esses aspectos, Delamaro (1997) classificou os erros de integração em três categorias.

Suponha-se um programa $P$ e um caso de teste $t$ para $P$. Suponha que em $P$ existam funções $F$ e $G$ tal que $F$ chama $G$. Define-se $S I(G)$ como o conjunto de valores passados para $G$ e $S O(G)$ os valores retornados por $G$. Ao exccutar $P$ com o caso de teste $t$, identifica-se uma falha causada por um erro de integração das unidades $F$ e $G$ em uma das seguintes situações (Delamaro, 1997):

- Tipo 1 (Figura 2.5 (a)): os valores contidos $\mathrm{cm} S I(G)$ não são os esperados por $G$, influenciando a produção de saídas erradas antes do retorno de $G$. Esse tipo de erro ocorre, por exemplo, quando uma função é chamada com parâmetros incorrctos ou um flag global possui um valor incorreto, fazendo com que a função chamada produza uma saida incorreta;

- Tipo 2 (Figura 2.5 (b)): os valores contidos em $S I(G)$ não são os esperados por $G$, desse modo, $S O(G)$ assume algum valor incorreto levando a uma saída incorreta (uma falha) após o retorno de $G$. Um crro desse tipo pode ocorrer, por exemplo, quando um parâmetro incorrcto passado para a função for utilizado para calcular o valor de retorno. Uma entrada incorreta pode levar a um valor de retorno incorreto que, por sua vez, pode gerar uma saída incorreta; e

- Tipo 3 (Figura 2.5 (c)): os valores contidos em $S I(G)$ são os esperados por $G$, mas valores incorretos em $S O(G)$ são produzidos dentro de $G$ c esses valores influenciam saídas

\footnotetext{
${ }^{3} \mathrm{Um}$ erro computacional ocorre quando o caminho correto é executado mas o valor computado é incorreto (Howden, 1978).

${ }^{4} \mathrm{Um}$ erro de dominio ocorre quando um caminho incorreto é executado (Howden, 1978).
} 
erradas após o retorno de $G$. Esse tipo de erro pode ocorrer se uma função é chamada com todos os parâmetros corrctos, mas internamente ela realiza um cálculo incorreto produzindo um valor de retorno incorreto e, posteriormente, uma saída incorreta.

A Figura 2.5 esquematiza esses três tipos de falhas que caracterizam os erros de integração (Delamaro, 1997).

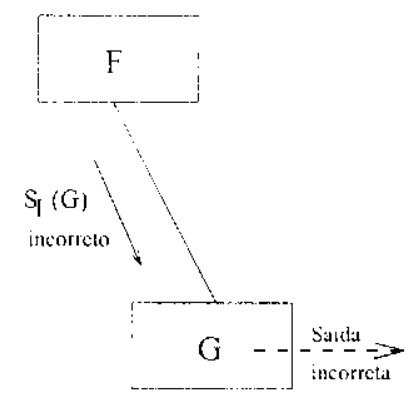

(is)

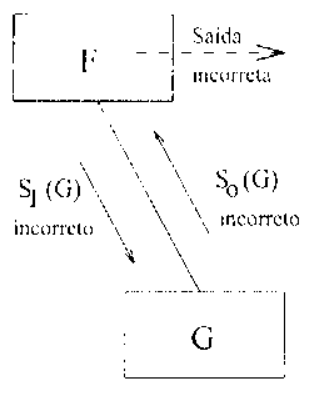

lb;

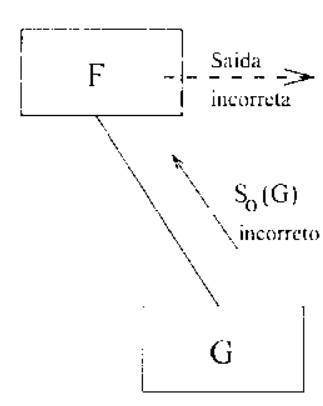

i:

Figura 2.5: Modelo de Falhas causadas por Erros de Integração: (A) Tipo 1; (B) Tipo 2;c (C) Tipo 3.

Percebe-se que esta classificação dos tipos de erro é abrangente e não especifica o local do defeito que causa a falha. Ela simplesmente considera a existencia de um valor incorreto entrando ou saindo de uma função chamada. Isso exclui, por exemplo, o caso em que $S I(C)$ tem os valores esperados, mas um erro dentro de $G$ produz uma saída incorreta antes do retorno de $G$. Neste caso, não existe nenhuma propagação de erro através da conexão $F-G$.

Mais de um erro de integração podem estar associados a (ou serem causados por) um defeito simples. Por exemplo, considere um programa com três unidades $R, S$ e $T$ tal que $R$ chama $S$ e, em scguida, $R$ chama $T$. Suponha que na unidade $S$ um valor incorreto $x$ é retornado $(S O(S))$ e esse valor é parte de $S I(T)$. Suponha que devido a $x, T$ produz uma saída incorreta. Desse modo, um defeito em $S$ produziu um erro Tipo 3 na conexão $R-S$ e um erro Tipo 1 na conexão $R-T$.

Os conjuntos $S I(G)$ e $S O(G)$ dependem, em parte, da linguagem de programação na qual o programa é escrito. Por exemplo, para programas escritos na linguagem $\mathrm{C}$, eles podem ser definidos como:

- $S I(G)$ : parâmetros formais de entrada da função $G$ e variáveis globais usadas em $G$.

- $S O(G)$ : parâmetros formais de saída da função $G$, variáveis globais definidas em $G$ c valores retornados por $G$ através de comandos return.

A seguir são apresentados alguns trabalhos com o objetivo de estender os critérios estruturais para o teste de integração com ênfase no Teste de Mutação. 


\subsubsection{Critérios para o Teste em Nível de Integração}

Alguns trabalhos foram desenvolvidos com o objetivo de estender os critérios estruturais para o teste de integração. Haley \& Zweben (1984) definiram um critério para a avaliação da adequação interprocedural baseado na cobertura de conjuntos de caminhos específicos cuja cardinalidade é determinada somente pela complexidade da interface da função, ao invés da complexidade do caminho.

Linnenkugel \& Müllerburg (1990) estenderam alguns critérios de fluxo de dados e de fluxo de controle de modo que estes pudessem ser aplicados no teste de integração. Harrold \& Soffa (1991) apresentaram uma técnica para determinar estruturas definições-usos de interface permitindo a aplicação dos critérios de adequação de fluxo de dados (Irankl \& Weyuker, 1988) em nível de integração.

Jin \& Offut (1995), baseados na classificação de acoplamento de unidades, estabeleceram um critério para o teste de integração. Conforme o tipo de acoplamento existente entre duas unidades, o critério tenta identificar alguns caminhos críticos que deveriam ser cobertos para exercitar adequadamente a conexão.

Vilela et al. (1999) apresentaram um conjunto de critérios, como uma extensão do critério Potenciais-usos (Maldonado, 1991), permitindo a aplicação destes no teste de integração. Esse critério foi denominado Critério Potenciais-usos de Integração.

Visando a estender a aplicação do Teste de Mutação para o teste de integração, Delamaro e Maldonado (Delamaro, 1997; Delamaro et al., 2001) propuseram o critério Mutação de Interface. Este critério baseia-se na idéia de mutações e procura selecionar conjuntos de casos de teste que exercitem as interações entre as unidades através da introdução de erros no programa de modo que as conexões entre as unidades sejam perturbadas. Na seção seguinte é discutido mais detalhadamente o critério Mutação de Interface.

\subsubsection{O critério Mutação de Interface}

O Teste de Mutação em nivel de unidade gera sempre o mesmo conjunto de mutantes independente de como as unidades interagem entre si para compor o programa. Em resumo, o Teste de Mutação em nível de unidade tem-se mostrado um critério efetivo para o teste da estrutura interna da unidadc, mas nâo necessariamente para excrcitar as interações entre unidades em um programa integrado (Delamaro et al., 2001).

Ao contrário do teste de unidadc, o teste de integração preocupa-se em assegurar que as interações entrc unidades sejam testadas. O objetivo do critério Mutação de Interface é inserir perturbações nas conexões entre duas unidades, de modo que, para obter um conjunto de casos de teste adequado, o testador deve criar casos de teste que exercitem essas conexões. Utilizando o mesmo raciocínio aplicado à Análise de Mutantes, casos de teste capazes de distinguir 
mutantes de interface também devem scr capazes de revelar grande parte dos erros de integração. Essa afirmação depende, evidentemente, de quais mutantes são utilizados ou, em outras palavras, quais operadores de mutação são aplicados (Delamaro \& Maldonado, 1997b).

Os operadores de mutação para o teste de unidade possuem semelhanças e diferenças cm relação aos opcradores de mutação de interface. A idéia básica de ambos é a mesma, ou seja, introduzir modificações sintáticas no programa em teste transformando-o em programas mutantes. Porém, os operadores de mutação de interface estão sempre rclacionados a uma conexão. Considere um programa que possua uma unidade $F$ que faça duas chamadas a uma unidade $G$ como mostra a Figura 2.6. Os operadores de mutação de interface irão gerar dois conjuntos de mutantes, um para cada ponto de chamada de $G$ dentro de $F$ e os mutantes de determinado conjunto só podem ser distinguidos se forem executados a partir do ponto de chamada para o qual foram criados, pois do contrário não sc estaria testando a conexão desejada (Delamaro, 1997).

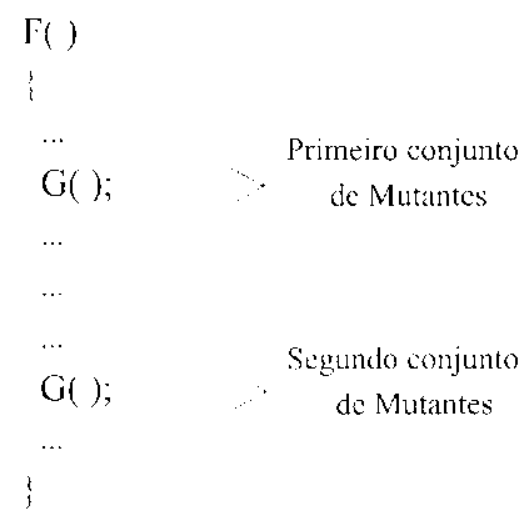

Figura 2.6: Representação do Conjunto de Mutantes Requeridos no Teste da Conexão $F-G$.

O exemplo acima aponta uma diferença sutil entre o teste de unidade, utilizando a Análise de Mutantes, e o teste de integração com a Mutação de Interface. Essa diferença pode ser formalizada através da análise das condições de necessidade c suficiência para um caso de teste distinguir um mutante de unidade. Segundo DeMillo \& Offutt (1991), para um caso de teste $t$ distinguir um mutante $M$ gerado a partir de um programa $P$, três condições são requeridas:

1. Alcançabilidade (Reachability): a execução de $M$ com o caso de teste $t$ deve fazer com que o controle do programa alcance o ponto onde a mutação foi realizada;

2. Necessidade (Necessity): o estado de $M$ difere do estado de $P$ logo após a exccução do comando modificado (mutado); c

3. Suficiência (Sufficiency): a diferença nos estados de $P$ e $M$ deve propagar-se tal que diferentes saidas sejam produzidas por $P$ e $M$. 
Na conexão $F-G$ representado pela Figura 2,6, considere que determinado operador $o p$ é aplicado a um único ponto no interior da função $G$ produzindo uma função mutante $G^{\prime}$. Com isso, visto que existem duas chamadas à função $G$ pela função $F$, dois mutantes devem ser gerados, o primeiro é aquele no qual a primeira chamada de $G$ é substituída por $G$ ' (Figura 2.7 (a)) e o segundo é aquele em que a segunda chamada é substituída (Figura 2.7 (b)).

Assim, uma mutação aplicada dentro da função chamada só deve ser efetivamente habilitada se a função foi chamada do ponto cuja conexão deseja-se testar. No exemplo da Figura 2.7, ao se exccutar o mutante (a) deve-se assegurar que a primeira chamada à função $G$ seja substituída pela função mutante $G^{\prime}$, entretanto, a segunda chamada a função $G$ deve permanecer inalterada de modo que o mutante (a) só poderá ser distinguido através da primeira chamada à $G$. Com isso pode-se exercitar de maneira mais completa a conexão que, na verdade, é composta por mais de uma chamada de função.

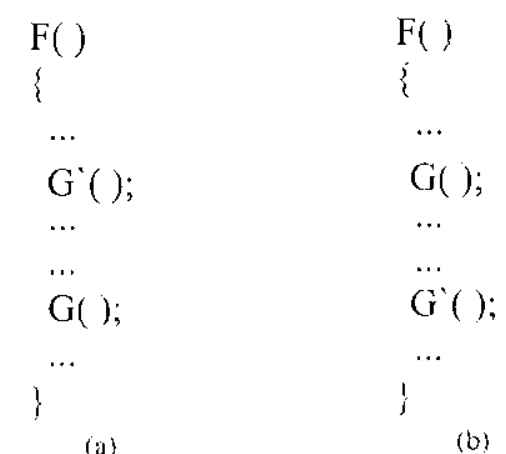

Figura 2.7: Mutantes Associados às Chamadas de $G$ e $F$.

Os operadores de mutação definidos por Delamaro (1997) para o teste de integração, são divididos em dois grupos. Considerando a conexão $F^{--} G$ da Figura 2.8, o primeiro grupo (Grupo-1) aplica mutações dentro do corpo da função $G$. Essc grupo requer a preparação da mutação no ponto onde $F$ chama $G$ tal que a mutação é aplicada somente se a função $G$ é chamada através desse ponto, caso contrário, a função $G$ sc comporta como no programa original. O segundo grupo de operadores (Grupo-II) é aplicado nos pontos onde a função $F$ faz chamadas a $G$.

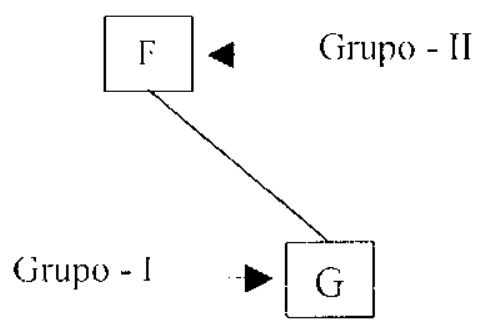

Figura 2.8: Conexão entre as unidades $F$ e $G$. 
Segundo Delamaro (1997), o conjunto de operadores proposto é experimental e foi criado com base, principalmente, na experiência no uso do Teste de Mutação. Além disso, o conjunto proposto busca ser completo, no sentido de exercitar a maioria das interações entre duas unidades mas, por outro lado, tenta também ser restrito, no sentido de que as mutações sejam restritas aos pontos essenciais ao teste de integração, mantendo baixo o custo de aplicação do critério. Entretanto, conforme ressalta o próprio autor, analisando-se a complexidade dos operadores definidos, pode-se esperar que a quantidade de mutantes gerados pelo critério Mutação de Interface scja bastante alta, mesmo para o teste de uma conexão formada por duas unidades simples. Mais detalhes sobre o critćrio Mutação de Interface c seus operadores de mutação, podem ser encontrados em (Delamaro et al., 2001).

\subsection{Ferramentas para o Teste de Mutação}

Com a crescente complexidade do software, qualquer estratégia de teste sem suporte de ferramentas tende a ser trabalhosa e propensa a erros. Para a aplicação efetiva de um critério de teste faz-se necessário o uso de ferramentas automatizadas que apóicm tal critério pois, do contrário, sua aplicação será limitada a programas muito simples (Horgan \& Mathur, 1992).

A disponibilidade de ferramentas de teste permite a transferência de tecnologia para as indústrias c contribui para uma contínua evolução de tais ambientes, fatores indispensáveis para a produção de software de alta qualidade. Além disso, tais ferramentas auxiliam pesquisadores e alunos de Engenharia de Software a adquirir os conceitos básicos c experiência na comparação, seleção e estabelecimento de estratégias de teste (Vincenzi, 1998).

As ferramentas de teste visam a reduzir a intervençâo humana durante a atividade de teste, aumentando a qualidade e a produtividade dessa atividade e influenciando de mancira direta na confiabilidade do software testado. Os casos de teste utilizados durante a atividade de teste podem ser facilmente obtidos para revalidação do software após uma modificação. Pode-se, com isso, checar se a funcionalidade do software foi alterada, reduzir o custo para gerar os testes de regressão e comparar os resultados obtidos nos testes de regressão com os resultados do teste original (Souza, 1996).

$\mathrm{Na}$ tentativa de automatizar a atividade de teste várias ferramentas de apoio aos critérios existentes têm sido desenvolvidas. Em relação ao Teste de Mutação, a primeira ferramenta construída para apoiar o critério Análise de Mutantes foi o FMS. 1 (Fortran Mutation System Versão 1) desenvolvida na Yale University em 1979. FMS.I tratava somente de um subconjunto do Fortran, ou seja, programas compostos apenas de uma única subrotina com aritmética de inteiros e sem comandos de entrada e saída. O sucesso desse projeto foi suficiente para motivar a construção de outros sistemas mais elaborados. Com o FMS.2, também desenvolvido na Yale 
University e depois no Georgia Institute of Technology, já era possivel testar programas com várias subrotinas em ANSI Fortran, exceto comandos de entrada c saída (Acree et al., 1979).

Budd (1981) desenvolveu na Yale University um sistema de mutação para programas Fortran - EXPER (Experimental Mutation System) - baseado na mesma idéia dos sistemas acima (Budd, 1981).

Novas ferramentas vêm sendo propostas e estudas a fim de suprir as deficiências encontradas nas anteriores. Entre elas destacam-se a Mothra (DcMillo ct al., 1988), a Proteum (Delamaro, 1993; Delamaro \& Maldonado, 1993) e a PRCTIM M/M (Delamaro, 1997; Delamaro \& Maldonado, 1999).

A Mothra é um ambiente de teste que apóia o critério Análise de Mutantes para programas na linguagem Fortran-77, apresentando 22 operadores de mutação. A ferramenta foi desenvolvida pela Purdue University e Georgia Institute of Technology (DeMillo et al., 1988; Choi et al., 1989) e possui interfaces baseadas em menus ou janelas, facilitando a visualização das informaçòes. Atualmente, a Mothra possui acoplada a si a ferramenta Godzilla, capaz de gerar automaticamente casos de teste muito próximos da adequação utilizando para isso um esquema chamado geração automática de casos de teste baseado em restrições (constraint-based automatic test data generation) (DeMillo \& Offutt, 1991) e a ferramenta Equalizer, capaz de determinar parte dos mutantes equivalentes (Offutt \& Craft, 1994).

As ferramentas Proteum (Program Testing Using Mutants) (Delamaro, 1993; Delamaro \& Maldonado, 1993) e PROTQM M/IM (Delamaro, 1997; Delamaro \& Maldonado, 1999) foram desenvolvidas no Instituto de Ciências Matemáticas de São Carlos - USP, e apóiam a aplicação do critério Análisc de Mutantes e Mutação de Interface, respectivamente. Atualmente cssas ferramentas estão integradas em um único ambiente denominado TROTEMMIIM 2.0 (Delamaro et al., 2000). Ambas as ferramentas são ambientes compilados e possuem interfaces baseadas em janelas e scripts. Não possuem gerador automático de casos de teste e a determinação de cquivalência entre mutantes é feita manualmente.

\subsection{Estudos Empíricos}

A realização de estudos empíricos permite comparar os diversos critérios de teste existentes, procurando fornecer uma estratégia viável para realização dos testes. Os fatores custo, eficácia e dificuldade de satisfação (strength) são os fatores básicos para avaliar um critério de teste, sendo que o custo refere-se do esforço necessário para que o critério seja usado; a eficácia refere-se à capacidade que um critério possui em detectar erros, c a dificuldade de satisfação referc-se à probabilidade de satisfazer um critério $C 2$ tendo satisfeito um critério $C 1$ (Wong et al, 1994b). Com base nesses latores comparativos, estudos empíricos e teóricos são conduzidos com o objetivo de encontrar formas cconômicas e produtivas para se desenvolver os testes. 
Embora estudos empíricos realizados demonstrem a eficácia do Teste de Mutação em revelar a presença de erros (Mathur \& Wong, 1993; Offutt et al., 1993; DeMillo et al., 1993; Offutt \& Lee, 1994; Wong et al., 1994a,b; Offutt et al., 1996b; Offutt \& Craft, 1994; Offutt et al., 1996a; Souza, 1996; Delamaro \& Maldonado, 1997b; Offutt \& Pan, 1997; Wong ct al., 1997; Barbosa, 1998; Vincenzi, 1998; Barbosa et al., 2001; Delamaro et al., 2001; Vincenzi et al., 2001), um problema relacionado a esse critério é seu alto custo. Isso ocorre devido ao grande número de mutantes gerados e o tempo e esforço gasto na determinação dos mutantes equivalentes. A seguir são descritos alguns estudos cmpíricos que visam reduzir o custo do Teste de Mutação considerando esses aspectos.

\subsubsection{Redução do Número de Mutantes Gerados}

Barbosa (1998) definiu um procedimento para a determinação de um conjunto essencial de operadores de mutação para a Linguagem C. A aplicação do procedimento Essencial fornece subsídios para que a escolha dos operadores de mutação a serem utilizados durante o teste seja feita de modo mais sistemático e critcrioso, diminuindo assim o custo de aplicação do critério.

O procedimento Essencial foi aplicado a um conjunto de programas $C$, visando a determinar um conjunto essencial de operadores de mutação para essa linguagem; para isso, foram utilizados os operadores de mutação implementados na ferramenta Proteum. De um modo geral, observou-se que o conjunto essencial obtido proporcionou uma redução de custo de $65,9 \%$, preservando alto escore de mutação em relação ao critério Análise de Mutantes. A abordagem proposta também foi comparada com outras duas, a de Offutt et al. (1996a) e a de Wong et al. (1997); os resultados obtidos mostraram que o escore de mutação proporcionado pclo conjunto essencial em relação ao critćrio Análise de Mutantes foi superior aos escores de mutação proporcionados pelas demais abordagens.

O procedimento Essencial foi também aplicado $\mathrm{cm}$ cinco programas utilitários do UNIX (Cal, Checkeq, Comm, Look, Uniq), para validar o procedimento proposto em outro domínio de aplicação. Barbosa (1998) observou que o conjunto essencial obtido a partir da aplicação do procedimento proporcionou uma redução de custo de cerca de $82 \%$ em relação ao critério Análise de Mutantes e, ainda assim, o grau de adequação manteve-se elevado (0,99761). Tais resultados fornecem indícios de que a aplicação do procedimento, mesmo em diferentes domínios, resulta em conjuntos essenciais de operadores altamente efetivos, quer seja quanto ao custo de aplicação (em termos do número de mutantes gerados), ou quanto ao grau de adequação em relação à Análise de Mutantes.

Vincenzi (1998) desenvolveu estudos empíricos envolvendo o critério Mutação de Interface, utilizando os mesmos cinco programas utilitários do UNIX (Cal, Checkeq, Comm, Look, Uniq), utilizados por Barbosa (1998), que possibilitaram analisar as relações existentes entre os 
operadores de mutação de interface e estabelecer uma estratégia incremental para a aplicação dos mesmos. Utilizando tal abordagem, foram estabelecidas duas seqüências de aplicação dos operadores de mutação de interface: uma a partir dos operadores de mutação de interface que determinavam o maior escore de mutação em relação aos demais c outra a partir dos operadores do Grupo-II ${ }^{5}$ (operadores que aplicam mulação nos pontos de chamada da função). Ambas as seqüências de operadores produziram conjuntos MI-adequados e possibilitavam redução do custo entre $21,76 \%$ e 19,25\%. Após essa análise foi aplicado o procedimento Essencial (Barbosa, 1998) utilizando operadores de mutação da ferramenta $\mathcal{P R O T E M M} / \mathcal{M}$, para determinar o conjunto essencial de operadores de Mutação de Interface. A partir desse conjunto essencial, uma nova estratégia incremental de aplicação dos operadores foi estabelecida.

Foi realizada uma comparação das três estratégias incrementais: a partir dos operadores que proporcionam os maiores scores de mutação; priorizando os operadores do Grupo-Il e a partir do conjunto de operadores essenciais. A estratégia formada a partir do conjunto de operadores essenciais apresentou-se como a que seleciona conjuntos Ml-adequados com o menor custo, cerca de $25,96 \%$ na redução de custo na geração de mutantes.

Ainda nesse trabalho, Vincenzi (1998) verificou a necessidade de aplicação de ambos os critérios, Análisc de Mutantes e Mutação de Interface. Foram avaliadas quais as relações entre os operadores de mutação utilizados cm nível de unidade e integração, ou seja, foi avaliada a adecuação de conjuntos de casos de teste AM-adequados em relação aos operadores de interface e vice-versa. Vincenzi (1998) mostrou que cmbora os critérios Análise de Mutante e Mutação de Interface sejam destinados a fases distintas da atividade de teste, esses são complementares, ou seja, devem ser utilizados em conjunto para assegurar um teste de melhor qualidade.

De um modo geral, observou-se que tanto a partir de um conjunto de casos de teste AMadequado quanto a partir de um conjunto essencial-AM-adequado, a utilização de mais 16 operadores de mutação de interface resulta $\mathrm{cm}$ um conjunto de casos de teste Ml-adequado, com uma redução no custo de aplicação dos critérios Análise de Mutantes e Mutação de Interface entre $16,27 \%$ e $42,96 \%$, dependendo se o conjunto Ml-adequado foi obtido a partir de um conjunto AM-adequado ou essencial-AM-adequado, respectivamente.

Da mesma forma, um conjunto de casos de teste Ml-adequado ou um conjunto de casos de teste essencial-MI-adequado requer que mais 13 operadores de mutação de unidade sejam utilizados até que se obtenha um conjunto de casos de teste AM-adequado. Isso representa uma redução no custo de aplicação do critério Análise de Mutantes de aproximadamente 50\% e uma redução no custo total dos critérios Análise de Mutantes e Mutação de Interface entre $23,90 \%$ e $62,10 \%$ se o conjunto AM-adequado for obtido a partir de um conjunto Ml-adequado ou essencial-MI-adequado, respectivamente.

\footnotetext{
5Mais detalhes sobre os operadores de mutação estão no Capitulo 3
} 
Além disso, demonstrou-se que somente a utilização dos conjuntos cssenciais de operadores de mutação é suficiente para se construir um conjunto de casos de teste que determine escore de mutação superiores a 0,99 com uma redução no custo total de aplicação dos critérios Análise de Mutantes e Mutação de Interface de aproximadamente $66,59 \%$.

Vincenzi et al. (2001) propuseram estratégias para a aplicação dos opcradores de mutação, procurando minimizar o custo de aplicação dos critérios Análise de Mutantes e Mutação de Interface, visando a estabeleccr um modo incremental para sua aplicação, reduzindo o custo do teste de unidade e de integração.

Para o estabelecimento dessas estratégias utilizou-se o mesmo conjunto de cinco programas (Cal, Checkeq, Comm, Look, Uniq) utilizado nos estudos anteriores. Essas estratégias foram baseadas na relação entre o escore de mutação e o custo de cada operador em relação ao número de mutantes gerados. Foram estabelecidas seis estratégias:

- SCUS-Score-Cost Incremental Unit Testing Strategy e SUS-Sufficient Incremental Unit Testing Strategy para o critério Análise de Mutantes;

- SCIS-Score-Cost Incremental Interface Testing Strategy e SIS-Sufficient Incremental Interface Testing Sirategy para o critério Mutação de Interface; e

- U-IS-Unit-Interface Incremental Testing Strategy e SU-IS-Sufficient Unit-Interface Incremental Testing Strategy para aplicação de ambos os critérios com um menor custo.

Para se estabelecer essas estratégias, Vincenzi et al. (2001) determinaram uma classificação inicial dos opcradores de mutação considerando o incremento no escore de mutação que um conjunto de casos de teste adequado para um determinado operador tem sobre o conjunto de todos os outros operadores e o número de mutantes gerados por este operador.

Aplicando-se a estratégia SCUS obteve uma redução de custo de $32,34 \%$ utilizando-se 31 dos 71 opcradores de mutação para se obter um conjunto AM-adequado. Um escore de mutação superior a 0.99 pode ser obtido com apenas 17 operadores, com uma redução de custo de $92,79 \%$. Já para o teste de integração (SCIS) foram necessários apenas 23 operadores do 33 para se obter um conjunto Ml-adequado obtendo uma redução de custo de $24,37 \%$. Usando-se somente 10 operadores, um escore de mutação superior a 0,99 é obtido com uma redução de custo de $87,16 \%$.

Utilizando-se os conjuntos essenciais de operadores de mutação, Vincenzi et al. (2001) estabeleceram as cstratégias SUS e SIS para o tcste de integração e unidade, respectivamente.

SUS obteve um conjunto de casos de teste AM-adequado com uma redução de custo de $40 \%$, o que representa uma melhora de $8 \% \mathrm{~cm}$ relação a SCUS. Alćm disso, utilizando-se a estratégia SUS um escore de mutação superior a 0,99 é obtido com apenas 5 operadores e uma 
redução de custo de $86,98 \%$ é obtida. Aplicando-se a estratégia SIS, obteve-se uma redução de custo de $25.96 \%$ e $87.54 \%$ para se chegar a um conjunto de caso de teste Ml-adequado e um escore superior a 0,99 , respectivamente.

Procurando reduzir o custo de aplicação de ambos os critérios e verificando a necessidade de aplica-los em conjunto, ou seja, tendo-se um conjunto de casos de teste AM-adequado, o quanto esse conjunto satisfaz o critério Mutação de Interface? Procurando responder cssa questão, Vincenzi et al. (2001) propuseram duas estratégias, U-IS-Unit-Interface Incremental Testing Strategy que aplica os operadores detcrminados pela aplicação da estratégia SUS mais os operadores de interface necessários para se chegar a um conjunto Ml-adequado obtendo uma redução de custo de $93,41 \%$ para um escore superior a 0.99 e $27,77 \%$ para um conjunto MI-adequado, e SU-IS-Sufficient Unit-Interface Incremental Testing Strategy que aplica os operadores essenciais para o teste de unidade e para o teste de integração e obteve-se uma redução de custo para aplicação do critério mutação de interface de $73,22 \%$ atingindo um escore de mutação de 0,998. Com isso concluiu-se que os critérios Análise de Mutantes e Mutação de Interface são complementares e devem ser aplicados em conjuntos para se obter um teste de melhor qualidade.

\subsubsection{Determinação de Mutantes equivalentes}

Um estudo realizado por Offutt \& Craft (1994), visa à redução do custo de aplicação do critério Análise de Mutantes, identificando alternativas que permitam a determinação automática de mutantes equivalentes. Nesse estudo são apresentadas 6 técnicas baseadas em estratégias de otimização de compiladores e análise de fluxo de dados para determinar mutantes equivalentes ${ }^{6}$. As técnicas são:

- Deteç̧ão de Código não Alcançável;

- Propagação de Constantes;

- Propagação de Invariantes;

- Detecção de Sub-expressões Comuns;

- Deteç̧ão de Invariantes de Repctição; e

- Hoisting e Sinking.

Essas técnicas foram implementadas em um módulo da ferramentas de teste Mothra, chamado Equalizer. O Equalizer é implementado em linguagem C' e, como a Mothra, trabalha com programas em Fortran 77.

\footnotetext{
${ }^{6}$ Detalhes dessas técnicas podem ser encontrados em (Offutt \& Craft, 1994).
} 
Para avaliar a aplicação dessas técnicas, foi realizado um experimento envolvendo a ferramenta Mothra e uma gama de 15 programas em Fortran 77. Esses programas geram de 180 a 3000 mutantes. Cada programa foi analisado manualmente por vários pesquisadores para determinar os mutantes equivalentes diminuindo assim as chances de erros com relação a determinação desses mutantes. O experimento emprega 4 passos (Offutt \& Craft, 1994):

1. Para cada programa, cada técnica de detecção do Equalizer foi executada separadamente para contar quantos mutantes equivalentes cada técnica detecta.

2. Os mutantes que foram marcados como equivalentes no passo 1 foram revivido $c$ todas as técnicas de deteção foram aplicadas juntas para obter o número total de mutantes equivalentes que o Equalizer pode detectar (alguns mutantes equivalentes foram detectados por mais de uma técnica).

3. Os mutantes que foram marcados como equivalentes no passo 2 foram novamente revividos e casos de teste foram gerados usando o gerador automático de dados de teste Godzilla, e executado novamente todos os mutantes.

4. Os mutantes que restaram vivos foram analisados manualmente para encontrar o número verdadeiro de mutantes equivalentes.

Os resultados obtidos neste experimento são mostrados na Tabela 2.1. As técnicas de Invariantes de Repetição, Hoisting e Sinking e Detecção de Sub-expressões Comuns não detectaram nenhum mutante equivalente nesses programas e por isso não estão incluidos na Tabela 2.1. $\mathrm{O}$ número de mutantes equivalentes detectado a partir de cada técnica é mostrado para cada programa. A coluna Total Detectado mostra o total de mutantes detectados aplicando-se todas as técnicas (passo 2). A coluna Total Equivalente mostra o número total de mutantes equivalentes para cada programa (determinado no passo 4). A coluna Porcentagem Detectada mostra a porcentagem do total de mutantes equivalente que o Equalizer detectou.

A porcentagem média de deteç̧ão de mutantes equivalentes foi cerca de $10 \%$, mas a divergência padrão foi bastante alta ( $25 \%$ ), ou seja, foram detectados $49 \%$ dos mutantes equivalentes para Banker, enquanto nenhum mutante equivalente foi detectado para os programas Bsearch e Cal. Lssa diferença é devido aos programas Bsearch e Cal possuirem estruturas arrays, sobre as quais o Equalizer não tem um bom controle por tratar como um elemento único, e comandos goto's, que não são controlados pela ferramenta Equalizer. Já o programa Banker possui boa estrutura de algoritmo, com loops no lugar de comandos goto's.

As técnicas de Invariantes de Repetição, Hoisting e Sinking c Deteç̧ão de Sub-expressõcs Comuns dependem de características do programa que são raras. Assim para mostrar a cficiência dessas técnicas, foram criados 3 programas nas quais a aplicação dessas técnicas obtiveram 
Tabela 2.1: Detecção de Mutantes Equivalentes - 15 Programas (Offutt \& Craft, 1994)

\begin{tabular}{|c|c|c|c|c|c|c|c|}
\hline Programas & $\begin{array}{r}\text { Tamanho } \\
\text { (LOC) }\end{array}$ & $\begin{array}{l}\text { Código não } \\
\text { Alcançável }\end{array}$ & $\begin{array}{r}\text { Propagação de } \\
\text { Constantes } \\
\end{array}$ & $\begin{array}{r}\text { Propagaçăo de } \\
\text { Invariantes }\end{array}$ & $\begin{array}{r}\text { Total } \\
\text { Detectado }\end{array}$ & $\begin{array}{r}\text { Total } \\
\text { Equivalentes }\end{array}$ & $\begin{array}{r}\text { Porcentagem } \\
\text { Detectada }\end{array}$ \\
\hline Bsearch & 20 & 0 & 0 & 0 & 0 & 27 & $0 \%$ \\
\hline Banker & 48 & 0 & $\mathrm{i}$ & 21 & 21 & 43 & $49 \%$ \\
\hline Bubble & 11 & 0 & 5 & 4 & 5 & 35 & $14 \%$ \\
\hline Cal & 29 & 0 & 0 & 0 & 0 & 263 & $0 \%$ \\
\hline Count & 8 & 0 & 1 & 4 & 5 & 19 & $26 \%$ \\
\hline Dead & 8 & 7 & 0 & 0 & 7 & 7 & $100 \%$ \\
\hline Deallook & 52 & 0 & 0 & 18 & 18 & 196 & $9 \%$ \\
\hline Euclid & 11 & 0 & 0 & 1 & 1 & 26 & $4 \%$ \\
\hline Find & 28 & 0 & 0 & 1 & 1 & 77 & $1 \%$ \\
\hline Insert & 14 & 0 & 0 & 10 & 10 & 48 & $21 \%$ \\
\hline Max & 5 & 0 & I & 0 & i & 4 & $25 \%$ \\
\hline Mid & 16 & 0 & 0 & $T$ & 1 & 13 & $8 \%$ \\
\hline Trismall & 13 & 0 & 0 & 18 & 18 & 99 & $18 \%$ \\
\hline Trityp & 28 & 0 & 3 & 12 & 12 & 111 & $11 \%$ \\
\hline Warsball & 11 & 0 & 0 & 4 & 4 & 35 & $11 \%$ \\
\hline
\end{tabular}

sucesso. Os resultados são apresentados na Tabela 2.2. O significado das colunas Total Detectado, Total de Equiv. e Porc. Detectada são os mesmos da Tabela 2.1.

Tabela 2.2: Detecção de Mutantes Equivalentes - 3 Programas (Offutt \& Craft, 1994)

\begin{tabular}{|l|r|r|r|r|r||r|r|r|}
\hline Programas & $\begin{array}{c}\text { Propag. de } \\
\text { Constantes }\end{array}$ & $\begin{array}{r}\text { Propag. de } \\
\text { Invariantes }\end{array}$ & $\begin{array}{r}\text { Sub-exp. } \\
\text { Comuns }\end{array}$ & $\begin{array}{r}\text { Invar. de } \\
\text { Repetição }\end{array}$ & $\begin{array}{r}\text { Hoisting } \\
\text { Sinking }\end{array}$ & $\begin{array}{r}\text { Total } \\
\text { Detectado }\end{array}$ & $\begin{array}{r}\text { Total } \\
\text { Equiv. }\end{array}$ & $\begin{array}{r}\text { Porc. } \\
\text { Detectada } \\
\hline \text { TESTCOM }\end{array}$ \\
\hline TESTLOOP & 0 & 0 & 2 & 0 & 0 & 2 & 2 & $100 \%$ \\
\hline TESTHOIST & 6 & 4 & 0 & 1 & 0 & 7 & 25 & $28 \%$ \\
\hline
\end{tabular}

Tabela 2.3: Mutantes Equivalentes por Operador - Mothra (Offutt \& Craft, 1994)

\begin{tabular}{|l|r|r|r|}
\hline Operadores & $\begin{array}{r}\text { Numero de } \\
\text { Equivalentes }\end{array}$ & $\begin{array}{r}\text { Numero } \\
\text { Detectado }\end{array}$ & $\begin{array}{r}\text { Porcentagem } \\
\text { Detectada }\end{array}$ \\
\hline \hline ABS & 170 & 100 & $59 \%$ \\
\hline AOR & 2 & 0 & $0 \%$ \\
\hline CRP & 4 & 2 & $50 \%$ \\
\hline CSR & 3 & 1 & $33 \%$ \\
\hline DER & 3 & 0 & $0 \%$ \\
\hline GLR & 4 & 0 & $0 \%$ \\
\hline LCR & 6 & 0 & $0 \%$ \\
\hline ROR & 14 & 0 & $0 \%$ \\
\hline RSR & 6 & 1 & $17 \%$ \\
\hline SAX & 1 & 1 & $100 \%$ \\
\hline SCR & 5 & 2 & $40 \%$ \\
\hline SDL & 4 & 1 & $25 \%$ \\
\hline SVR & 12 & 5 & $42 \%$ \\
\hline UOI & 21 & 1 & $5 \%$ \\
\hline Total & 255 & 114 & $45 \%$ \\
\hline
\end{tabular}

A Tabela 2.3 apresenta a distribuição dos mutantes equivalentes por operador de mutação referentes aos programas da Tabela 2.1. A coluna Número de Equivalentes, refere-se ao número total de mutantes equivalentes por operador; as colunas Número Detectado e Porcentagem 
Detectada, mostram respectivamente o número e a porcentagem de mutantes detectados por opcrador.

Observou-se na Tabela 2.3 , que a maioria dos mutantes equivalentes $(67 \%)$, para csses programas são mutantes gerados à partir do operador ABS (Absolute Value Insertion). A condição para matar esse tipo de mutante é que a variávcl sobre a qual cle age, possua o valor maior ou igual a zero. Por esta razão, as técnicas de Propagação de Constantes e Propagação de Invariantes detectam mais mutantes equivalentes, devido a clas se preocuparem diretamente com relação a variáveis com valor zero.

Offutt \& Craft (1994) chegaram à conclusâo que usando técnicas de análises de fluxo de dados e otimização de compiladores, pode-se detectar automaticamente uma porcentagem significativa dos mutantes equivalentes, $\mathrm{cm}$ alguns casos quase metade, reduzindo assim o custo na detccção de mutantes equivalentes.

Além do custo da determinação de equivalência manualmente ser muito alto, Offutt \& Craft (1994) afirmam que as pessoas, ao determinar os mutantes equivalentes sem uma ferramenta automatizada, julgam mutantes equivalentes corretamente em $80 \%$ dos casos. Em 12\% dos casos, pessoas marcam mutantes equivalentes como não equivalentes e em $8 \%$, mutantes não cquivalentes como equivalentes, sendo o segundo fator comprometedor para a atividade de teste. Por isto, a utilização de técnicas automatizadas para determinação de mutantes equivalentes é de extrema importância para garantir a qualidade da atividade de teste, diminuindo assim os erros cometidos pela intervenção humana.

Procurando melhorar os resultados obtidos por Offutt \& Craft (1994), no estudo realizado por Offutt \& Pan (1997), foram aplicados três estratégias baseadas em restrições matemáticas, originalmente desenvolvida para geração de dados de teste (CBT-Constraint-Based Testing), para se determinar mutantes cquivalentes e caminhos não alcançáveis. Essas cstratégias são:

- Negação;

- Divisão de Restrições; e

- Comparação de Constantes.

Essas estratćgias estão implementadas na ferramenta Equivalencer, que é integrada ao gerador de dados de teste Godzilla, dentro do conjunto de ferramentas de mutação Mothra, que hoje substitui a ferramenta desenvolvida por Offutt \& Craft (1994) para determinação de mutantes equivalentes (Equalizer).

Nesse experimento foram utilizados 11 programas Fortran 77, que geram entre 180 a 3000 mutantes, sendo 9 dos 15 utilizados no estudo realizado por Offutt \& Craft (1994), como pode ser visto na Tabela 2.4.

O experimento emprega 5 passos: 
1. Os mutantes foram analisados manualmente para encontrar o número verdadeiro de mutantes equivalentes:

2. Para cada programa, Mothra foi usada para gerar todos os mutantes, e Godzilla foi usado para gerar casos de teste (restrições de necessidade e restriçôes de alcançabilidade ${ }^{7}$ );

3. As restrições em relação a cspecificação foram criadas, por Offutt, para cada programa;

4. Equivalencer foi aplicado aos programas para obter a quantidade de mutantes detectados; c

5. Os mutantes que foram marcados como equivalentes foram comparados com os marcados manualmente.

A coluna Equivalentes mostra o número total de mutantes equivalentes por programa; a coluna Equivalentes Detectados e Porcentagem Detectada, mostram, respectivamente, o número e a porcentagem de mutantes equivalente detectados para cada programa.

Tabela 2.4: Deteç̧ão de Mutantes Equivalentes - 11 Programas (Offutt \& Pan, 1997)

\begin{tabular}{|l|r|r|r|r|r|}
\hline Programas & $\begin{array}{r}\text { Tamanho } \\
\text { (LOC) }\end{array}$ & Mutantes & $\begin{array}{r}\text { Numero de } \\
\text { Equivalentes }\end{array}$ & $\begin{array}{r}\text { Equivalentes } \\
\text { Detectados }\end{array}$ & $\begin{array}{r}\text { Porcentagem } \\
\text { Detectada }\end{array}$ \\
\hline Bsearch & 20 & 299 & 27 & 19 & $70,37 \%$ \\
\hline Bub & 11 & 3389 & 35 & 24 & $68,57 \%$ \\
\hline Cal & 29 & 3010 & 236 & 37 & $15,67 \%$ \\
\hline Euclid & 11 & 196 & 24 & 18 & $75 \%$ \\
\hline Find & 28 & 1022 & 75 & 63 & $84 \%$ \\
\hline Insert & 14 & 460 & 46 & 32 & $69,57 \%$ \\
\hline Mid & 16 & 183 & 13 & 3 & $23,08 \%$ \\
\hline Pat & 170 & 513 & 61 & 29 & $47,54 \%$ \\
\hline Qual & 10 & 359 & 31 & 4 & $12,9 \%$ \\
\hline Trityp & 28 & 951 & 109 & 80 & $73,39 \%$ \\
\hline Warshall & 11 & 305 & 35 & 22 & $62,86 \%$ \\
\hline Total & 185 & 7636 & 695 & 331 & $47,63 \%$ \\
\hline
\end{tabular}

Apesar do foco desse estudo seja a determinação de mutantes equivalentes, Offutt \& Pan (1997) obscrvaram que podiam ser aplicadas ao problema de detecção de caminhos não alcançáveis. Assim, 9 programas foram construídos artificialmente com alguns caminhos não alcançáveis, e utilizou-se a ferramenta Equivalencer para tentar detectá-los. Nos 9 programas da Tabela 2.5. existiam 14 caminhos não alcançáveis c a ferramenta conseguiu detectar 10 deles. Os resultados demonstram uma maior eficácia, das estratégias aplicadas, na detecção de caminhos não alcançáveis $(71,43 \%)$ do que na determinação de mutantes equivalentes $(47,63 \%)$.

Embora Equivalencer seja capaz de detectar aproximadamente metade dos mutantes equivalentes em média, a porcentagem encontrada para cada programa varia muito. Este fato, também

\footnotetext{
${ }^{7}$ Detalhes dessas restrições podem ser encontrados em (Offutt \& Pan, 1997).
} 
Tabela 2.5: Detecção de Pontos não Executáveis (Offutt \& Pan, 1997)

\begin{tabular}{|l|r|r||r|}
\hline Programas & $\begin{array}{r}\text { Caminhos Não } \\
\text { (Alcançáveis) }\end{array}$ & Detectados & $\begin{array}{r}\text { Porcentagem } \\
\text { Detectada }\end{array}$ \\
\hline \hline Prog 1 & 2 & 1 & $50 \%$ \\
\hline Prog 2 & 1 & 0 & $0 \%$ \\
\hline Prog 3 & 1 & 1 & $100 \%$ \\
\hline Prog 4 & 1 & 1 & $100 \%$ \\
\hline Prog 5 & 1 & 1 & $100 \%$ \\
\hline Prog 6 & 1 & 1 & $100 \%$ \\
\hline Prog 7 & 2 & 2 & $100 \%$ \\
\hline Prog 8 & 3 & 3 & $100 \%$ \\
\hline Prog 9 & 2 & 0 & $0 \%$ \\
\hline Total & 14 & 10 & $71,43 \%$ \\
\hline
\end{tabular}

encontrado no estudo de Offutt \& Craft (1994), ć devido à restrição da ferramenta no tratamento de estruturas do tipo arrays. Godzilla trata arrays como item de dado único. Por esta razão, algumas restrições que envolvem arrays não podem ser usadas para detcrminar mutantes cquivalentes, ou seja, se elementos de um array forem tratados individualmente, a técnica baseada em restrições pode ser usada para detectar mais mutantes cquivalentes. Segundo Offutt \& Pan (1997) esse problema é uma particularidade importante para o programa Cal. Se a técnica de detecção tratar os elementos de um array individualmente o Equivalencer aumenta de $15,67 \%$ para $44,92 \%$ a porcentagem de deteç̧ão dos mutantes equivalentes no programa Cal. Conclui-se ainda que usando técnicas baseadas em restrições, Equivalencer é capaz de detectar automaticamente uma porcentagem significativa para muitos programas, porém ainda não ć possível detectar todos os mutantes equivalentes. No experimento a porcentagem de detecção foi acima de $60 \%$ para 7 dos 11 programas e a média de porcentagem para todos os programas foi de $47,63 \%$ como pode ser visto na Tabela 2.4 .

Harman et al. (2000) procuraram aplicar a Análise de Dependencia para evitar a geração de mutantes equivalentes e procurar gerar dados de teste para matar os mutantes não equivalentes. Está relação entre Análise de Dependência e o Teste de Mutação é usada para definir um aumento no processo do Teste de Mutação, como mostra a Figura 2.9, adicionando duas fases de Análise de Dependência.

A primeira fase do processo proposto é a criação dos mutantes, que não é influenciada diretamente. A próxima fase consiste na detecção de mutantes equivalentes utilizando-se Análise de Dependência, visto que está técnica tem um menor custo computacional do que as técnicas baseadas em restrições. Análise de Dependência (JR-Dependência) é melhor aplicada para resolver os problemas relacionados com o Teste de Mutação do que os extensamente utilizados Diagramas de Dependência de Programa. Isto porque JR-Dependência é mais refinado, fornecendo informações não somente dos nós mas tambćm quais variáveis são importantes em um determinado nó. Com isso teremos quais variáveis são importantes para o nó de entrada do programa e quais variáveis devem ser examinadas para evitar a geração de mutantes equivalentes. 
A terceira fase scria a aplicação de técnicas baseadas em restrições, estudadas e aplicadas por Offutt \& Pan (1997), para gerar casos de teste para matar alguns mutantes e determinar outros como equivalentes.

Os mutantes que permaneceram vivos após as 3 primeiras fases são chamados de "Mutantes Difíccis". Este deverão ser analisados manualmente, porém o autor propõem à aplicação de mais 2 fases. A primeira fase seria à aplicação do Amorphous Slicing (maiores detalhes a respeito em (Hierons et al., 1999)). Esta produz um programa simplificado adequado para a questão do mutante ser equivalente ou não. Com isso pode-se aplicar a técnica JR-Dependência novamente para reduzir o domínio de entrada sobre o qual serão criados os dados de teste. Um conjunto de "Mutantes Difíceis" são finalmente apresentados para uma análise manual sendo que o testador tem uma referência para se criar os casos de teste com a aplicação da técnica JR-Dependência.

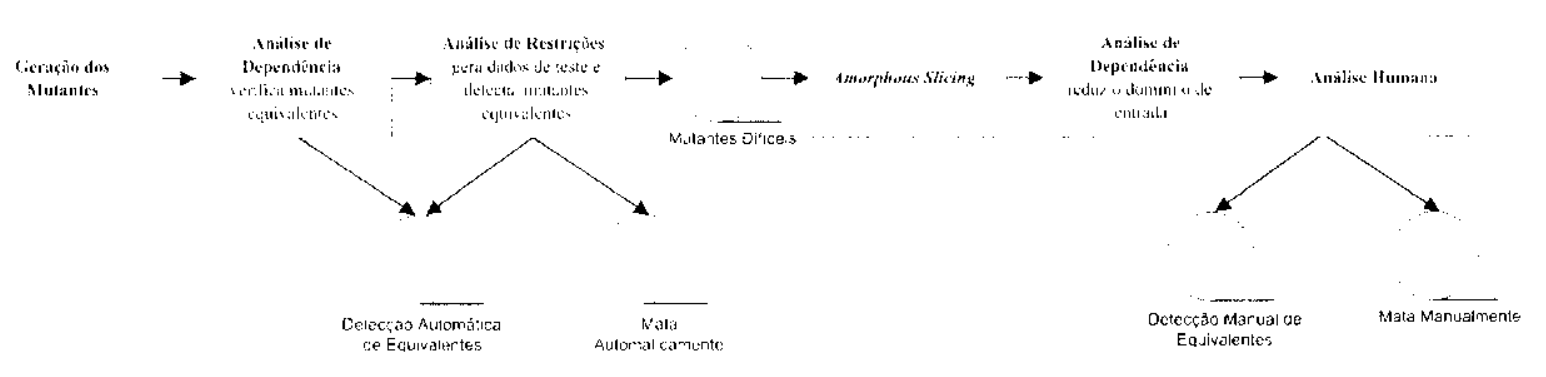

Figura 2.9: Processo do Teste de Mutação com Dependência de Associações e Análise de Restrições (Harman et al., 2000).

Os autores concluíram que Análise de Dependência funciona para o testador como uma tccnologia complementar, para ser utilizada $\mathrm{cm}$ conjunto com técnicas baseadas em restrições para reduzir o número de mutantes equivalentes e para restringir a atenção para um conjunto menor de variávcis de entrada, facilitando a geração de casos de teste.

\subsection{Considerações Finais}

Este capítulo caracterizou o Teste de Mutação, relatando uma pouco da sua história, os passos para a sua aplicação, os problemas a ele associados e algumas estratégias que procuram solucionar esses problemas de forma a torná-lo aplicável na prática.

Devido a grande eficácia do Teste de Mutação em detectar erros no teste de unidade e à necessidade de se desenvolver novos critérios para o teste de integração, foi apresentado o critério Mutação de Interface proposto por Delamaro c Maldonado (Delamaro, 1997; Delamaro \& Maldonado, 1997a, 1999), que aplica o conceito de mutação em nível de interface. Os critérios Análise de Mutantes e Mutação de Interface, assim como os demais critérios de teste, requerem a existência de ferramentas que automatizem suas aplicações. Tais ferramentas, além de 
auxiliarem a atividade de teste, são fundamentais para a realização de estudos empíricos responsáveis pela avaliação e comparação entre outros critérios de teste. Algumas dessas ferramentas de apoio ao Teste de Mutação, foram apresentadas neste capitulo. Também foram apresentados alguns estudos cmpíricos que envolvem a Análise de Mutantes e a Mutação de Interface. Esses estudos visam a reduzir o custo de aplicação dos critérios baseados em mutação diminuindo o número de mutantes gerados ou automatizando, em parte, a determinação de mutantes equivalentes.

No capítulo a seguir é apresentado um experimento com o objetivo de amenizar os problemas encontrados na aplicação do Teste de Mutação, procurando estabelecer heurísticas para determinação de mutantes equivalentes, reduzindo assim o custo relacionado à análise dos mutantes vivos. 


\section{Operadores de Mutação: Uma Avaliação Empírica}

$\mathrm{D}$ E um modo geral, os critérios Análise de Mutantes e Mutação de Interface tem se mostrado, por meio de estudos teóricos e empíricos (Budd et al., 1980; Mathur, 1991; Mathur \& Wong, 1993; Wong, 1993; Wong \& Mathur, 1995a,b; Offutt et al., 1996a,b; Barbosa, 1998; Vincenzi, 1998; Delamaro et al., 2001), serem eficazes em revelar a presença de erros. Porém, observou-se que ambos os critérios apresentam problemas com relação ao custo de aplicação, dificultando a utilização prática dos mesmos. Com isto, a utilização de alternativas, tais como determinação automática de equivalência entre mutantes e a não geração de mutantes que morrem facilmente mostra-se como uma boa alternativa para reduzir os custos de aplicação desses critérios.

A condução de estudos empíricos envolve o levantamento de uma série de requisitos que possibilitam avaliar a viabilidade e a disponibilidade de recursos para a realização dos mesmos. Com base nesses requisitos é claborado um framework que organiza a condução dos experimentos a serem realizados. Além disso, quando a quantidade de informações a ser coletada é relativamente grande. organizar a condução dos experimentos em etapas facilita o entendimento dos mesmos e contribui para a coleta e análise dos dados.

Neste capítulo são descritos alguns estudos empíricos e analíticos envolvendo o critério Análise de Mutantes e Mutação de Interface os quais possibilitam avaliar quais operadores de mutação geram grande número de mutantes equivalentes fornecendo subsídios para determina- 
ção de padrões de equivalência e guidelines para auxiliar o testador na atividade de análise dos mutantes vivos, contribuindo para a redução do custo do Teste de Mutação.

Em uma segunda etapa, descrita no Capitulo 4, os operadores de mutação são empiricamente avaliados visando a selecionar um subconjunto de operadores que atinjam um escore de mutação 1.00 para ambos os critérios com um menor custo. Para tanto, estratégias incrementais para aplicação dos operadores de mutação, baseadas nos operadores que geram mutantes dificeeis de serem mortos e poucos mutantes equivalentes, foram desenvolvidas visando a reduzir o custo de aplicação.

\subsection{Descrição dos Operadores de Mutação}

Conforme mencionado anteriormente na Seção 2.3.2.1, os operadores de mutação definem alterações sintáticas a serem realizadas num programa $P$, com base nas quais são criados seus mutantes. Ėm um nível de abstração mais alto é possível estabelecerem-se operadores de mutação de mancira genérica c que modelem tipos de defcitos comuns para qualquer linguagem de programação, ou pclo menos, para linguagens de programação com características semelhantes. Por outro lado, é necessário que os operadores levem em conta particularidades de uma determinada linguagem para a qual foram projetados. Nesse caso os operadores de mutação são dependentes da linguagem de programação para a qual são projetados.

A definição de operadores de mutação é fundamental para aplicação de critérios bascados em mutação. São esses operadores que caracterizam o critério, estabelecendo os requisitos de teste, os mutantes, a serem satisfeitos. Um ponto importante a ser investigado é qual a quantidade de operadores de mutação que deve ser definida considerando-se determinada linguagem. Se for definido um conjunto muito restrito, embora um número menor de mutantes seja gerado, um conjunto de casos de teste capaz de distinguir esses mutantes pode não ser efetivo em revelar uma série de erros não modelados pelos operadores. Por outro lado, se um conjunto abrangente de operadores é definido, o número de mutantes gerados tende a ser muito grande o que torna inviável a aplicação do critério. Em geral, o desenvolvimento do conjunto de operadores de mutação esta relacionado com um modelo de erros típicos que podem ser cometidos no contexto de dada linguagem e dada fase de teste. Assim sendo, busca-se a definição de um conjunto de operadores de mutação grande suficiente para modelar os crros típicos e, com base em estudos teóricos e empíricos, busca-se avaliar os aspectos de custo, strength ${ }^{1}$ e eficácia de cada um desses opcradores de modo que estratégias de teste de menor custo e alta cficácia possam ser definidas.

\footnotetext{
${ }^{1}$ Considerando o teste de mutação, cada operador pode ser visto como um critério de teste, o strength relativo de um operador $o p_{\perp}$ é dado pelo escore de mutação, em relação ao conjunto total de mutantes. de um conjunto de teste adequado a $o p_{1}$.
} 
Mais detalhes sobre os opcradores de mutação implementados nas ferramentas Proteum e PROTEMMIIM são apresentados a seguir.

\subsubsection{Teste de Unidade - Proteum}

Para o teste de unidade, operadores de mutação buscam modelar os defeitos simples mais comuns para uma determinada linguagem. Por excmplo, trocando-se um operador relacional por outros operadores relacionais força-se a escolha de casos de teste nos limites das condições de decisão do programa. Existem também os operadores chamados "instrumentados" (Agrawal et al., 1989), os quais não modelam defeitos comuns mas procuram assegurar aos casos de teste caractcrísticas mínimas desejadas. Um excmplo, ć o operador STRP que troca cada comando, um de cada vez, pela chamada de uma função TRAP (), cuja execução faz com que o mutante seja automaticamente distinguido. Casos de teste que distingam todos mutantes instrumentados dessa forma fazem também com que cada comando da função original seja executado pelo menos uma vez.

Ao todo, 71 operadores foram definidos e classificados em quatro grupos:

1. Mutação de Constantes ( 3 operadores);

2. Mutação de Comandos (15 operadores);

3. Mutação de Operadores (46 operadores); e

4. Mutação de Variáveis ( 7 operadores).

Cada grupo de operadores modela diferentes tipos de erros em um mesmo tipo de estrutura, e seus nomes são compostos por quatro letras; a primeira (sempre em letra maiúscula) indica qual a classe do operador: $\mathbf{S}$ (statement), $\mathbf{O}$ (operator), $\mathbf{V}$ (variable) ou $\mathbf{C}$ (constant). As outras letras fazem parte da descrição do operador como no caso do operador Cccr - C onstant for C onstant R eplacement.

\section{Mutação de Constantes}

O grupo mutação de constantes modela erros relacionados ao uso incorreto de constantes. $\mathrm{Na}$ Tabela 3.1 é descrita a função de cada um desses operadores. Esses operadores são divididos em subcategorias de acordo com os erros que eles modelam. neste sentido, são similares a operadores que substituem variáveis escalares. A Figura 3.1 mostra as subcategorias de operadores de mutação desse grupo. 
Tabela 3.1: Operadores de Mutação de Constantes

\begin{tabular}{|l|l|}
\hline Operador & Descrição \\
\hline Cecr & Troca constantes por todas constantes do programa. \\
\hline C csr & Truca referênclas escalares por constantes \\
\hline C.RC.R & Troca conslintes por: $0,1,-1$, dependendo do tipo de referência. \\
\hline
\end{tabular}

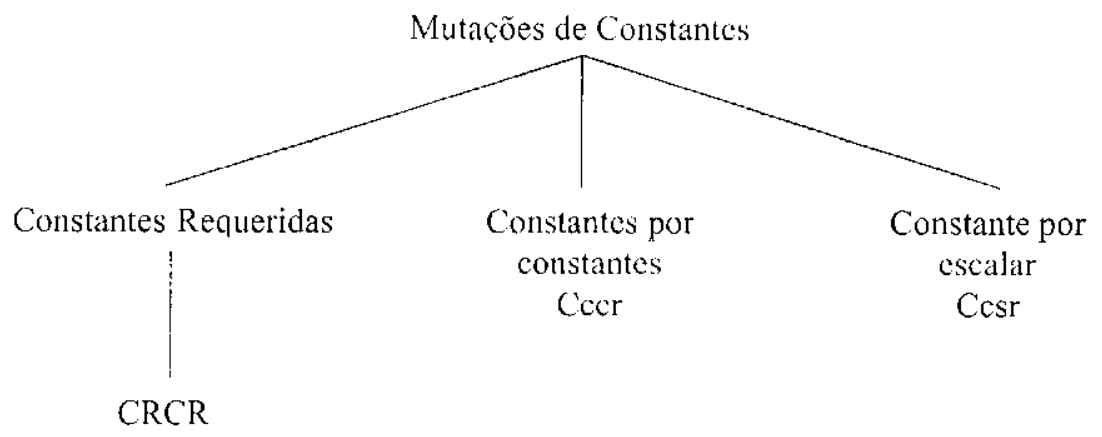

Figura 3.1: Classificação dos Operadores de Mutação de Constantes

\section{Mutação de Comandos}

Os operadores desse grupo modelam erros relacionados aos comandos do programa em teste, comandos de seleção (if, switch), repetição (while, do-while) c desvio (break, goto). A mutação também pode scr aplicar a um bloco de comandos. Cada um dos operadores pertencentes a este grupo é descrito na Tabela 3.2 e a Figura 3.2 mostra as subcategorias que eles estão classificados.

Tabela 3.2: Operadores de Mutação de Comandos

\begin{tabular}{|c|c|}
\hline Operador & Descrição \\
\hline SBRC & Substitui break por continue quando possivel. \\
\hline SBRn & $\begin{array}{l}\text { Troca o comando continue ou break por uma função break out_to_level_n(J) sendo que J varia } \\
\text { de acordo com o número de laços aninhados. Essa funça foŗ̧a a interupção dos J laços externos. }\end{array}$ \\
\hline SCRB & Troca do comando continue por break. \\
\hline SCRn & $\begin{array}{l}\text { Troca o comando continue ou break por uma função continuc_out_to_level_n(J) sendo que J varia } \\
\text { de acordo com o numero de laços aninhados. Essa função força al transferéncia do programa para o } \\
\text { fimal de J laços acima. }\end{array}$ \\
\hline $\mathrm{SDWD}$ & Troca o comando do-while por while. \\
\hline SGLR & Trocal us comandos goto l por todos os rólulos existentes na função. \\
\hline SMTC & Interrompe a execução do laço após 2 execuçòes. \\
\hline SMTT & Força a execução dos laços mais de uma vez. \\
\hline SMVB & Move "i" para cima c para baixo, quando possivel. \\
\hline SRSR & Troca cada comando por todos os relurns que existem na função en teste. \\
\hline SSDL & Retira um comando de cada vez do programa. \\
\hline SSWM & Força a execução de todos os cases do comando switch. \\
\hline STRI & Força a exccuçào para true e false sm cada if. \\
\hline STRP & Força a execução de todos os comandos do prograrma. \\
\hline SWIDI) & Troca o comando while por jo-while. \\
\hline
\end{tabular}

\section{Mutação de Operadores}

A linguagem C' provê uma variedade de operadores para uso em diferentes contextos. Para o propósito de definição de operadores de mutação, os operadores em $C$ são classificados como 


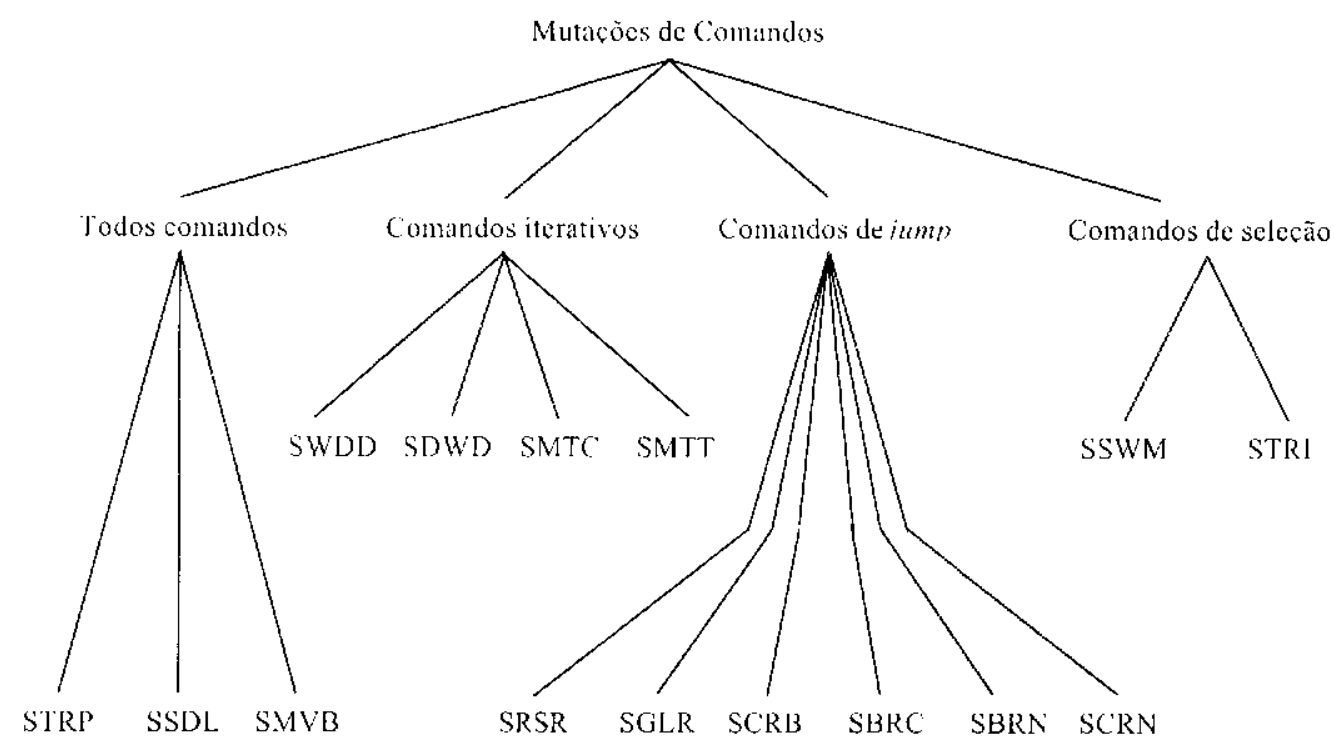

Figura 3.2: Classificação dos Operadores de Mutação de Comandos

mostra a Tabela 3.3. Esta tabela lista o conjunto de opcradores em $C$ usados posteriormente como o domínio e alcance de diferentes operadores de mutação. A coluna "Código" mostra as letras usadas para compor o nome de um operador de mutação. Os operadores desse grupo são projetados para modelar erros no uso de operadores na linguagem $C$ como são descritos na Tabela 3.4 e são subdivididos de acordo com seu objetivo como mostra a Figura 3.3.

Tabela 3.3: Classificação dos Operadores Binários em C

\begin{tabular}{|c|c|c|c|}
\hline Tipo & Categoria & Operadores & Código \\
\hline \multirow{5}{*}{ Sem Atribuiç̧o } & Aritmetica & $+\ldots * / \frac{\circ}{0}$ & $\Lambda$ \\
\hline & Bitwise & $\&$ & B \\
\hline & Lógico & 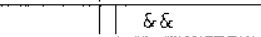 & l. \\
\hline & Deslocamento & $\langle<>>$ & $\mathrm{S}$ \\
\hline & Relacional & $\langle>\langle=\rangle===!=$ & $\bar{R}$ \\
\hline \multirow{4}{*}{ Com Atribuição } & Aritmética & $\star=/=\frac{\circ}{b}=++=-=$ & $\mathrm{A}$ \\
\hline & Bitwise & $\varepsilon={ }^{2}=:=$ & $\bar{B}$ \\
\hline & Plino & $=$ & $\mathrm{E}$ \\
\hline & Deslocamento & $\ll<=>\gg=$ & $\mathrm{S}$ \\
\hline
\end{tabular}

O projeto de mutação de operadores foi encaminhado pelos seguintes fatores (Agrawal et al., 1989):

- Em C, operadores correspondem a uma categoria que pode ser usada em uma variedade de contextos. Por exemplo, não existe entidade tal como uma expressão aritmética dentro o qual somente os operadorcs aritméticos podem ser usados. Assim, dentro de uma expressão que calcula valores aritméticos, um poderá ser usado como operadores lógicos. Por exemplo, para dois inteiros $a$ e $b$, ambos $a+b$ e $a \& \& b$ são válidos para expressões que calculam inteiros ${ }^{2}$;

\footnotetext{
${ }^{2}$ Note que isto não é verdadeiro para outras linguagens como o Pascal.
} 
Tabela 3.4: Operadores de Mutação de Operadores

\begin{tabular}{|c|c|}
\hline Operador & Descriçăo \\
\hline$O \wedge \wedge \Lambda$ & Troca atribuiçào aritmética por outra atribuç̧ăo aritmética. \\
\hline OAAN & Troca operador aritmético por outro aritmétıco. \\
\hline OABA & Troca atribuição aritmétiéa por operador de atribuição bitwise. \\
\hline OABN & Troca operador aritmético por operador bitwise. \\
\hline OAEA & Troca atribuiçăo aritmética por operador de atribuição plana. \\
\hline$O \wedge L N$ & Troca operador aritmético por operador lógico. \\
\hline OARN & Troca operador aritmético por operador relacional. \\
\hline OASA & Troca atribuição aritmética por operador atribuçǚ de deslocamento. \\
\hline OASN & Troca operador aritmético por operador de deslocamento. \\
\hline OI3AA & Troca atribuição bifwise por atribuição aritmética. \\
\hline OBAN & Troca operador bitulise por operador aritmético. \\
\hline OBBA & Troca atribuição bitwise por atribuição bitwise. \\
\hline OBBN & Troca operador bitwise por operador bitwise: \\
\hline $\mathrm{OBEA}$ & Troca atribuição bitwise por atribuiçâo plana. \\
\hline OBLN & Troca operador bitnise por operador lógico. \\
\hline OBNG & lnsere negaçāo no opcrador bitwise. \\
\hline OBRN & Troca operador bitwise por operador relacional. \\
\hline OBSA & Troca atribuiça bitwise por operador de atribuiçào de deslocamento. \\
\hline OBSN & Troca operador bitwise por operador de deslocamento. \\
\hline $\mathrm{OC} \times$ & Insere negação lógica. \\
\hline OCOR & Troca o tipo primitivo do operador cast. \\
\hline OFAA & Troca atribuiçào plana por atribuição aritmética. \\
\hline OLBA & Troca atribuição plana por atribuição bitwise. \\
\hline OFSA & Troca atribuç̧ão plana por operador de atribuiçâo de deslocamento. \\
\hline Oido & Troca operador de incremento/decremento. \\
\hline OIPM & Substitui os operadores de incremento/decremento que não possuem dirç̧ão. \\
\hline$O A N$ & Troca operador lógico por operador aritmético. \\
\hline OLBN & Troca operador lógico por operador bitwise. \\
\hline OLLN & Troca operador lógico por outro operador lógico. \\
\hline OLNG & Insere negação logica em condiçōes compostas. \\
\hline OLRX & Troca operador fógico por operador relacional. \\
\hline OI.SN & Troca operador lógico por uperador de deslocamento. \\
\hline ORAY & Troca operador relacional por operador aritmético. \\
\hline$\overline{\mathrm{OR} B N}$ & Troca operador relacional por operador bitwise. \\
\hline ORLN & Troca operador relacional por operador lógico. \\
\hline ORRN & Troca operador relacional por outro relacional. \\
\hline ORSN & Troca operador relacional por operador de deslocamento. \\
\hline OSAA & Troca atribuiçào de deslocamento por atribuição arilmética. \\
\hline OSAN & Troca operador de deslocamento por operador aritmético. \\
\hline OSBA & Troca atribuição de deslocamento por atribuição bitwist'. \\
\hline OSBN & Troca operador de deslocamento por operador bifu'se. \\
\hline OSEA & Troea atribuição de deslocamento por atribuição plana. \\
\hline OSLN & Troca operador de deslocamento por operador lógico. \\
\hline OSRN & Troca operador de deslocamento por operador relacional. \\
\hline OSSA & Troca atribuição de deslocamento por outra de deslocam. \\
\hline OSSN & Troca operador de deslocamento por outro de deslocim. \\
\hline
\end{tabular}

- Existem dois problemas para se definir um operador de mutação em relação a mutação de operadores: 1) um grande número de mutantes será gerado sempre que tal operador de mutação é habilitado e 2) o usuário não terá a flexibilidade para selecionar esses operadores. Procurando solucionar esses problemas, os operadores de mutação para $C$ são classificados de modo que o usuário tenha a máxima flexibilidade na sua seleção.

\section{Mutação de Variáveis}

$O$ uso incorreto de identificadores pode geralmente induzir erros no programa que permanecem desapercebido por muito tempo. Operadores de mutaçâo de variáveis são projetados para 


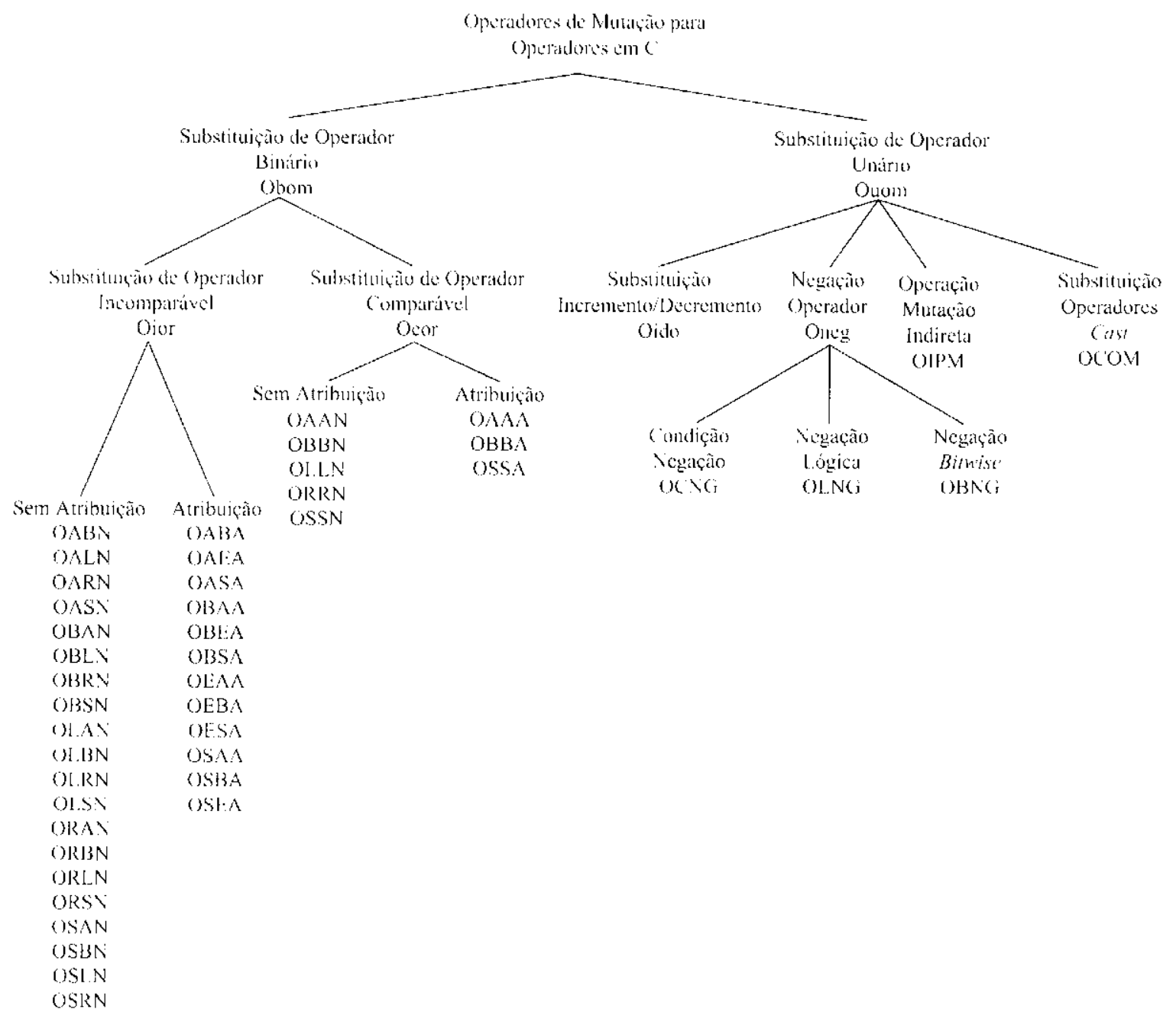

Figura 3.3: Classificação dos Operadores de Mutação de Operadores

modelar esses erros. A Tabela 3.5 descreve a função de cada operador de mutação de variável que também são classificados de acordo com suas funçôes como mostra a Figura 3.4. Essa classificaçâo assegura que mutantes sintaticamente corretos são gerados, aplicando-se mutações apenas entre variáveis de tipos compatíveis.

Tabela 3.5: Operadores de Mutação de Variáveis

\begin{tabular}{|c|c|}
\hline Operador & Descrição \\
\hline Varr & Substitui as referèncias a vetores por variáveis escalares, globais e locais do programa. \\
\hline VDTR & Força cada referência escalar possuir cada um dos valores: negativo, positivo e zero. \\
\hline Vprr & Substitui as referencias a apontadores por variaveis escalares, globais e locais do programa. \\
\hline $\mathrm{VSCK}$ & Truca is referências a componentes de uma estrutura por demais componentes da mesna estrutura. \\
\hline Visr & Substitui as referencias csealares por variaves escalares, globais e locais do programa. \\
\hline Vtrr & Substitui as referências a esiruturas e uniões por variáveis escalares, globais e locais do programa. \\
\hline VTWD & Substitui referência escalar pelo seu vilor sucessor e antecessor. \\
\hline
\end{tabular}




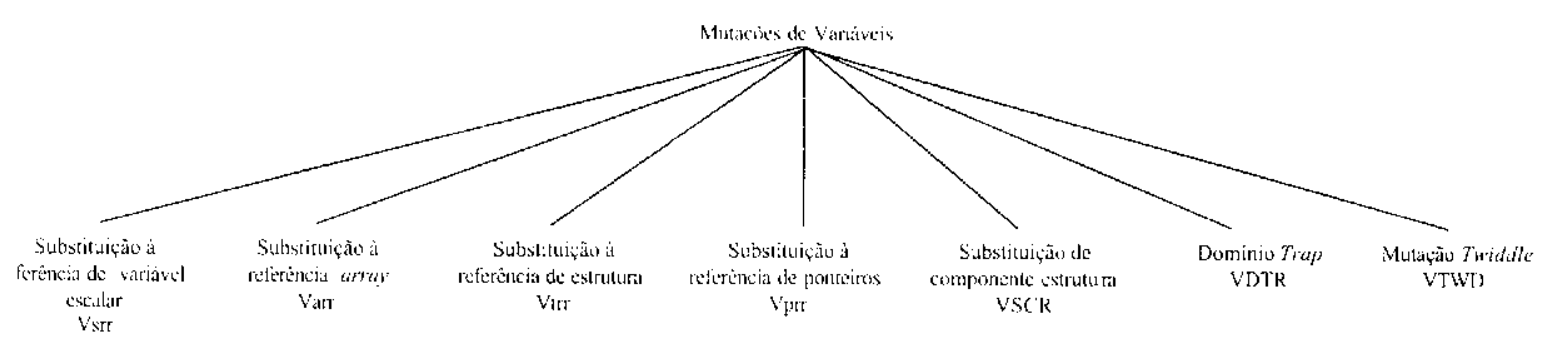

Figura 3.4: Classificação dos Operadores de Mutação de Variáveis

\subsubsection{Teste de Integração - FROTZMIIM}

Operadores de Mutação de Interface possuem semelhanças e diferenças com relação aos opcradores de unidade. A idéia por trás de ambos é a mesma, produzir pequenas alterações no programa original e o programa mutante. Por outro lado, operadores de Mutação de Interface são rclacionados a uma conexão entre duas unidades, basicamente definidas por regras de chamada de função e passagem de parâmetros, ou seja, cada mutante é relacionado com uma chamada de função como é descrito na Seção 2.3.3.3.

Um ponto essencial ao se pensar no Teste de Mutação é o custo do teste cm termos do número de mutantes a serem gerados. É preciso que o número de mutantes scja mantido baixo para que o teste possa ser executado num período de tempo razoável. Os operadores desenvolvidos por Delamaro (1997) buscam esse objetivo por meio da restrição dos pontos do programa onde são aplicados. Somente pontos relacionados com as conexões sendo testadas são sujeitos à aplicação dos operadores. Ao todo, 33 operadores foram definidos e estes estão divididos em dois grupos:

1. Grupo I - Mutações efetuadas no corpo da função chamada (24 operadores); e

2. Grupo II - Mutações efetuadas no ponto de chamada da função (9 operadores).

Os nomes dos operadores de mutação para o teste de interface também são formados por um conjunto de siglas, como os operadores de mutação para o teste de unidade, que são descritas na Tabela 3.6.

Um exemplo de operador de mutação para o teste de integração é o ArgAriNeg - Inscrts Arithmetic Negation at Arguments.

\section{Grupo I - Mutações Efetuadas na Função Chamada}

Esses operadorcs aplicam mutações dentro do corpo da função chamada. Eles "perturbam" valores que entram c/ou saem da função. Para esses operadores faz-se necessário um mecanismo 
Tabela 3.6: Siglas que Formam os Nomes dos Operadores de Mutação para o Teste de Interface

\begin{tabular}{|c|c|}
\hline Sigla & Descrição \\
\hline All & Todos os elementos da função. \\
\hline Arg (A/gtiment) & Argumento da função. \\
\hline Ari (Arithmetic) & Operador aritmélico. \\
\hline Bit & Operação bit a bit. \\
\hline $\mathrm{Cal}(\mathrm{Call})$ & Chamada de função. \\
\hline Cov (Conerage) & Procura garintir un delerminada cobertura sobre o programa. \\
\hline Dec (Decreme'nt) & Decrementa uma variável $(--)$ \\
\hline Del (Delete & Remove detcrminado comamdo, argumento, .. \\
\hline Dir $($ Direct $)$ & Alteração direta de variáveis de interface. \\
\hline Edg $\left(E d_{i g}\right)$ & Desvios existentes na funçáo. \\
\hline Ext (Externul) & Uso de variável global, nào utilizada no corpo da linção. \\
\hline Fun (Function) & Função a que se refere. \\
\hline Glo (Chlohal) & Variável global. \\
\hline Inc (Increase) & lncrementa uma variável $(++)$ \\
\hline Ind (Indirect) & Alteraçào indireta, através da mutação de variáveis não de interface. \\
\hline $\operatorname{Loc}(\operatorname{Loc} a l)$ & Variável local. \\
\hline $\log ($ Logical) & Operador lógico (á\&e ||$\overline{)}$. \\
\hline Veg (Negation) & Negaçia de variável $(!, \sim \mathrm{e}-)$ \\
\hline Vode (Nodes) & Nós existentes ma função. \\
\hline Pall (Paranders) & Paraimelro formal. \\
\hline Req (Requirt) & Constante requerida. \\
\hline Rep (Replate) & Substituiçöes de variávels e comandos. \\
\hline Ret (Retmm) & Comando de retornu. \\
\hline Sta $($ Silutencent) & Comandos em geral. \\
\hline Stc (Suitch) & Troca de argumento. \\
\hline $\operatorname{Var}$ (barable) & Variáveis em geral. \\
\hline
\end{tabular}

para que seja identificado o ponto de chamada da função, possibilitando que a mutação seja ou não habilitada.

Cada operador de mutação tem um certo escopo de aplicação. Por exemplo, alguns podem ser aplicados em referências a variáveis, outros em expressões e outros até em comandos inteiros. Assim, para cada conexão, cada operador tem um conjunto de pontos de aplicação próprio. É válido para todos operadores desse grupo, quando uma variável é um ponto de mutação, considerar-se que dereferências ou indexações àquela variável também sejam pontos de mutação. Por exemplo no programa abaixo, ao dizer que a variável $a$ é um ponto de mutação, subcntende-sc que "*u" e " $a \mid j+1]$ ]" também são pontos de mutação e devem ser alterados.

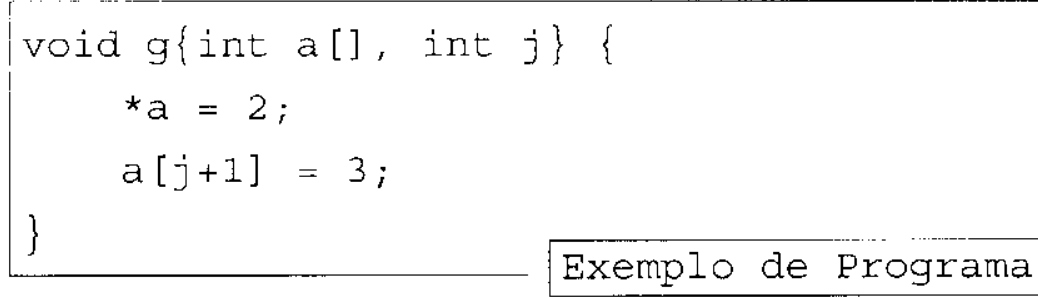

Os operadores desse grupo exigem que a mutação seja habilitada no ponto de chamada antes de ser aplicada. Por excmplo, suponha-se que o operador RetstaDel esteja sendo aplicado na conexão entre as funções $f$ e $g$, sendo que $f$ chama $g$. No ponto onde $\int$ chama $g$ existe uma "notificação" de que $y$ esta sendo chamada nesse ponto e não por outro ponto do programa. Para essa "notificação" utiliza-se a macro PREPARE_MUTA antes da chamada da função $g$, 
Além desses conjuntos, Delamaro (1997) definiu mais um conjunto denominado conjunto de constantes requeridas (conjunto $R$ ). Esse conjunto contém valores especiais, relevantes para alguns tipos primitivos de dados da linguagem $C$ e operadores associados a esses tipos. A Tabela 3.7 sumariza o conjunto dessas constantes.

Tabela 3.7: Conjunto de Constantes Requeridas - Mutação de Interface

\begin{tabular}{|c|c|}
\hline Tipo de Variavel & Constantes Requeridas \\
\hline $\begin{array}{l}\text { signed integer } \\
\text { signed char } \\
\text { signed long }\end{array}$ & $-1,1,0$, MAXINT, MININT \\
\hline $\begin{array}{l}\text { unsigned integtr } \\
\text { unsigned char } \\
\text { unsigned long } \\
\text { enum }\end{array}$ & $\because \overline{1,0, \text { MAXUNSIGINED }}$ \\
\hline $\begin{array}{c}\text { nloat } \\
\text { double }\end{array}$ & $-1.0,1.0,0.0,-0.0$ \\
\hline \multicolumn{2}{|c|}{ 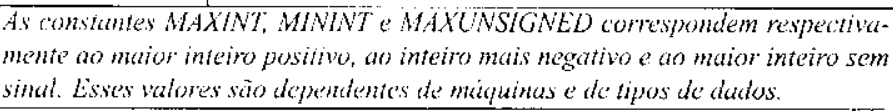 } \\
\hline
\end{tabular}

Na Tabela 3.8 é descrita a função de cada operador pertencentes a esse grupo. Já na Figura 3.5 os operadores são subdivididos de acordo com suas funções.

Tabela 3.8: Operadores de Mutação de Interface - Grupo I

\begin{tabular}{|c|c|}
\hline Operador & Descrição \\
\hline I-C'UVAIIEdg & Garante cobertuta de desvios. \\
\hline 1-CovAllNod & Garante cobertura de nós. \\
\hline 1-DirVarAriNeg & Acrescenta negaçào aritmética em variáveis de interface. \\
\hline I-J)irVarBitNeg & Acrescenta negaçao de bit em variáveis de interface. \\
\hline I-1)irVarlnelec & Acrescenta incremento $(++)$ e decremento $(--)$ em variável de interface. \\
\hline [-DirVarLogNeg & Acrescenta negação lógiea em variáveis de interface. \\
\hline I-DirVarRepCon & Troca variaveis de interface por elementos de $C$. \\
\hline i-Dir Var Repexl & Troca variaveis de interface por elenumos de E. \\
\hline [-DirVarRepGilo & Troca variáveis de interface por elementos de $\mathrm{G}$. \\
\hline I-Dirvarkeploc & Troca variáveis de interface por clementos de $\mathrm{L}$. \\
\hline 1-DirVarkepl'ur & Troca variáveis de interface por elementos de $P$. \\
\hline I-DirVarRepReq & Troca variáveis de inlerface por elementos de $R$. \\
\hline I. Ind VarariNeg & Aerescenta negação arimetica em variáveis nâo de interface. \\
\hline I-IndVarBitNeg & Acrescenta negação de bit em variáveis não de interface. \\
\hline I-IndVarlncl)ec & Acrescenta incremento $(-+)$ e decremento $(-)$ em varíivel não de interface. \\
\hline I-IndVarLogNeg & Acrescenta negação lógica em variáveis não de interface. \\
\hline l-IndVarRepCon & Troca variáveis não de interface por elementos de C. \\
\hline I-IndVarRepExi & Troca variáveis não de interface por elenentos de E. \\
\hline 1-IndVarRepGlo & Troca variáveis não de interface por elementos de $\mathrm{G}$. \\
\hline l-IndVarkeploc & Trocil variaveis nào de interface por elementos de $L$. \\
\hline l-IndVarkepPar & Troea variáveis năo de interlace por elementos de $P$. \\
\hline I-IndVarRepRey & Troca variáveis năo de interface por elementos de $R$. \\
\hline I-RetStaDel & Elimina comando return. \\
\hline l-RetStaRep & Troca comando return. \\
\hline
\end{tabular}

\section{Grupo II - Mutações Efetuadas no Ponto de Chamada}

Os operadores desse grupo são aplicados nos pontos onde a função $f$ faz chamadas a função $g$. Eles são aplicados tanto nos argumentos da chamada à função quanto à chamada da função 


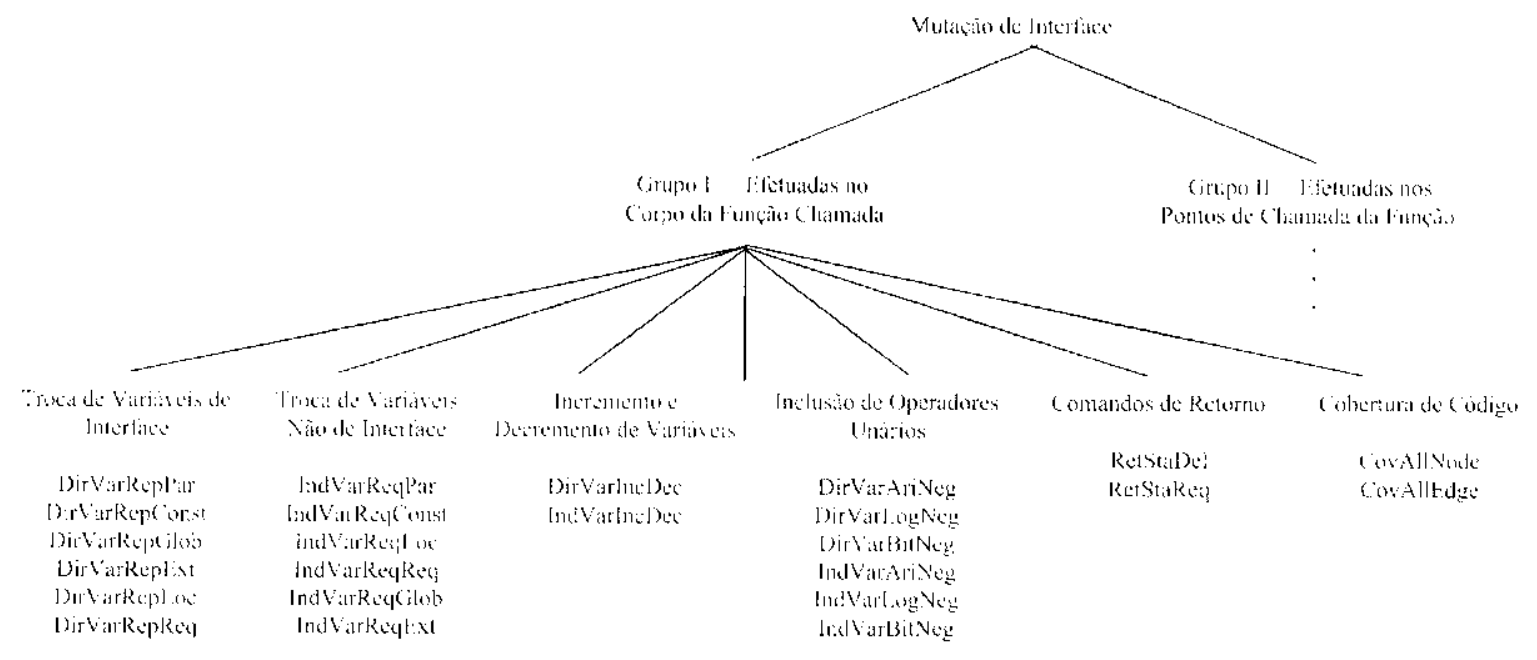

Figura 3.5: Classificação dos Opcradores de Mutação de Interface - Grupo I

como um todo. Quando um argumento ć um ponto de mutação e esse argumento é uma expressão, então o operador é aplicado à expressão como um todo e não a partes da expressão como variáveis e constantes.

Na Tabela 3.9 são apresentados todos os operadores de mutação de interface pertencentes ao Grupo II descrevendo a função que cada um tem quando aplicado o critério Mutação de Interface. A Figura 3.6 mostra as subcategorias dos operadores de mutação desse grupo.

Tabela 3.9: Operadores de Mutação de Interface - Grupo II

\begin{tabular}{|c|c|}
\hline Operador & Descrição \\
\hline II-ArgAriNeg & Acrescenta negação aritmética antes de argumento. \\
\hline II-ArgBitNeg & Acrescenlia negalçäo de bil antes de argumento. \\
\hline 11-ArgDel & Elimina argumento. \\
\hline II-ArglncDec & incrementa e decrementa argumento. \\
\hline II-ArgLog.Veg & Aerescenta negação lógico antes de argumento. \\
\hline Il-ArgRepReq & Troed argumentos por elementos de $\mathrm{R}$. \\
\hline II $-\Lambda \mathrm{rgStc} A \mathrm{li}_{\mathrm{i}}$ & Troca posição de argumentos de tipos compativeis. \\
\hline $\mathrm{II}-\Lambda \mathrm{rgStcDif}$ & Troca posição de argumentos de tipos diferentes. \\
\hline II-funCalDel & Elimina chamada de funç̌̃o. \\
\hline
\end{tabular}

A seguir é apresentado um experimento no qual os operadores de mutação descritos nesse capítulo, tanto para o teste de unidade quanto para o teste de integração, são analisados buscando-se reduzir o custo de aplicação dos critérios baseados em mutação por meio de heurísticas para determinação de mutantes equivalentes.

\subsection{Descrição do Experimento}

Este experimento tem como objetivo analisar teórica e empiricamente os operadores de mutação implementados nas ferramentas Proteum e $\mathcal{P R O T E M M / L M}$. A análise teórica é realizada 


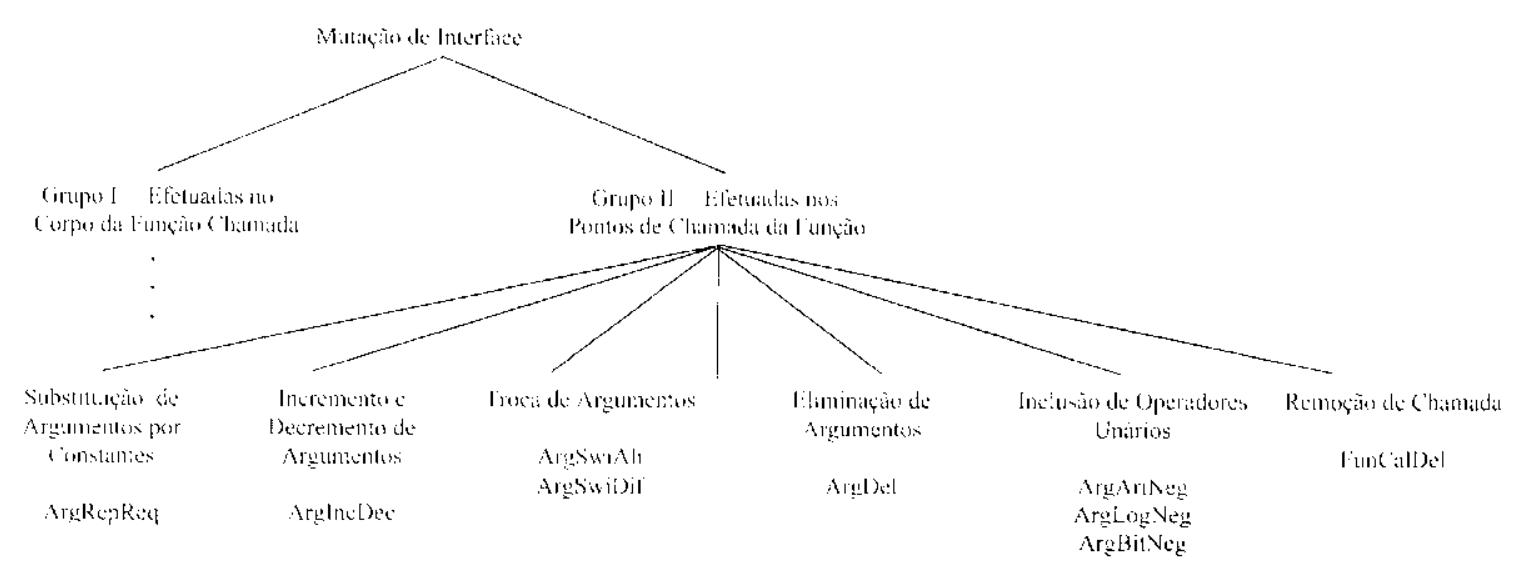

Figura 3.6: Classificação dos Operadores de Mutação de Interface - Grupo II

por meio da avaliação das regras estabelecida para a aplicação dos opcradores, enquanto que a análise empírica utiliza dados colctados sobre o comportamento desses operadores como a probabilidade de gerar mutantes cquivalentes ou mutantes que são facilmente distinguidos. Sua aplicação é composta das seguintes atividades:

1. Seleção de Programas;

2. Geração de Conjuntos de Casos de Teste;

3. Seleção de Ferramentas de Teste; c

4. Colcta c Análise dos Resultados.

A seguir, cada uma dessas atividades é detalhada considerando as informações sobre o experimentos referente a este trabalho.

\subsubsection{Seleção dos Programas}

Este experimento foi conduzido a partir de um grupo formado por seis programas utilitários do UNIX cscritos na linguagem $C$. Tais programas além de terem sido utilizados $\mathrm{cm}$ estudos anteriores (Wong, 1993; Delamaro, 1997; Wong et al., 1997; Barbosa, 1998; Vincenzi, 1998), devido ao seu uso intenso, possuem uma baixa probabilidade de apresentarem erros naturais em seu código. Além disso, procuro-se selecionar programas que possuam em sua implementação construções sintáticas para que os operadores de mutação possam ser aplicados pois aplicando um determinado operador $o p$, pode ocorrer que, em um programa $P$ este não gere mutantes. Isto ocorre quando $P$ não contem nenhuma estrutura do domínio das mudanças sintáticas impostas pelo operador op. Por exemplo, considere o operador SDWD para a linguagem $C$ que 
troca comandos do-while por comandos while. Se $P$ não possuir nenhum comando do-while, a aplicação do operador SDWD não gerará mutantes.

A Tabela 3.10 apresenta a descrição, o número de funções $\mathrm{c}$ o total de linhas de código (LOC) dos programas utilizados.

Tabela 3.10: Conjunto de Programas Utilizados no Experimento

\begin{tabular}{|c|c|c|c|}
\hline Programas & Descriçũo & Funções Chamadas & LOC \\
\hline Cal & Apresconta um calendário para o ano ou mês especiticado. & 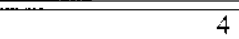 & 119 \\
\hline Checkey & Informa us delimiladores ausentes ou desbalanceados e pares . EQ/,EN. & 1 & 76 \\
\hline Comm & Seleciona ou rejeita linhas comuns entre dois arquivos. & 7 & 119 \\
\hline Look & Procura palavras em um dicionário ou linhas em uma lista ordenada. & 3 & 111 \\
\hline Sort & Classifica e realiza merge em arquivos. & 19 & 628 \\
\hline Uniq & Informa ou remove finhas adjacentes duplicadas. & 5 & 103 \\
\hline
\end{tabular}

Observa-se que, 5 dos 6 programas utilizados no experimento possuem aproximadamente 100 LOC's, ao contrário do programa sort que possui uma complexidade maior, 628 LOC's. Nas Tabelas 3.11 e 3.12 são apresentados o total de mutantes gerados, equivalentes e q-equivalentes utilizando as ferramentas Proteum e $\mathcal{P R O T E M} / \mathcal{I M}$, respectivamente.

Tabela 3.11: Complexidade dos Programas: Ferramenta Proteum

\begin{tabular}{|l|r|r|r|r|r|}
\hline Programas & $\begin{array}{r}\text { Mutantes } \\
\text { Gerados }\end{array}$ & $\begin{array}{r}\text { Mutantes } \\
\text { Equivalentes }\end{array}$ & $\begin{array}{r}\text { Mutantes } \\
\text { Q-Equivalentes }\end{array}$ & $\begin{array}{r}\text { Porcentagem de } \\
\text { Equivalentes }\end{array}$ & $\begin{array}{r}\text { Porcentagem de } \\
\text { Q-Equivalentes }\end{array}$ \\
\hline \hline Cal & 4332 & 221 & 9,5 & $5,10 \%$ & $2,19 \%$ \\
\hline Checkeq & 3099 & 206 & 17 & $6,65 \%$ & $0,55 \%$ \\
\hline Comm & 1728 & 166 & 29 & $9,61 \%$ & $1.68 \%$ \\
\hline Look & 2056 & 143 & 114 & $6,96 \%$ & $5,55 \%$ \\
\hline Sort & 22419 & 1074 & 1676 & $4,79 \%$ & $7,48 \%$ \\
\hline Uniq & 1619 & 94 & 77 & $5,81 \%$ & $4,76 \%$ \\
\hline \hline Total & 35253 & 1904 & 2008 & $5,4 \%$ & $5,7 \%$ \\
\hline
\end{tabular}

Tabela 3.12: Complexidade dos Programas: Ferramenta $\mathcal{F R O T Z M M} / \mathrm{MM}$

\begin{tabular}{|l|r|r|r|r|r|}
\hline Programas & $\begin{array}{c}\text { Mutantes } \\
\text { Gerados }\end{array}$ & $\begin{array}{c}\text { Mutantes } \\
\text { Equivalentes }\end{array}$ & $\begin{array}{r}\text { Mutantes } \\
\text { Q-Equivalentes }\end{array}$ & $\begin{array}{r}\text { Porcentagem de } \\
\text { Equivalentes }\end{array}$ & $\begin{array}{r}\text { Purcentagem de } \\
\text { Q-Equivalentes }\end{array}$ \\
\hline \hline Cal & 4350 & 488 & 80 & $11,22 \%$ & $1,84 \%$ \\
\hline Checkeq & 2974 & 12 & 6 & $0,40 \%$ & $0.20 \%$ \\
\hline Comm & 2952 & 481 & 30 & $16,29 \%$ & $1,02 \%$ \\
\hline Look & 1825 & 181 & 172 & $9,92 \%$ & $9,43 \%$ \\
\hline Sort & 20554 & 5640 & 1017 & $27,44 \%$ & $4,95 \%$ \\
\hline Uniq & 194.3 & 185 & 35 & $9,52 \%$ & $1,80 \%$ \\
\hline \hline Total & 34598 & 6987 & 1340 & $20,2 \%$ & $3,87 \%$ \\
\hline
\end{tabular}

Como pode ser observado, é gerado um grande número de mutantes para os programas $\mathrm{cm}$ teste (35253 referentes o testc de unidade e 34598 referentes o teste de integração), sendo o programa sort o responsável por gerar grande parte desses mutantes, para ambos os critćrios, devido a sua complexidade em termos de linhas de código. Já o programa Uniq gera um pequeno número de mutantes quando aplicados os operadores de mutação referentes ao teste de unidade e o Comm gera o menor número de mutantes para o teste de integração, devido ao fato 
de possuir apenas uma chamada de função. Vale ressaltar que, para o conjunto de programas utilizados, alguns operadores de mutação não geraram mutantes, por isso não foi possível fazer uma análise empírica dos mesmos. Dos 71 operadores de mutação para o teste de unidade, 10 não geraram mutantes, porém, para o teste de integração todos os 33 operadores geraram mutantes.

Como dito anteriormente, pela atividade de determinação de mutantes equivalentes ser uma questão indecidível, a mesma foi feita manualmente c as informações coletadas são de fundamental importância para o desenvolvimento de heurísticas que permitam sua automatizaçào, reduzindo o custo e o esforço de aplicação dos critérios.

\subsubsection{Seleção de Ferramentas de Teste}

A sclcção das ferramentas de teste deve levar em consideração quais critérios scrão analisados, a linguagem nas quais os programas estão escritos c, principalmente, o suporte oferecido para a realização de experimentos, ou seja, deve-se observar se a funcionalidade e o conjunto de informações disponibilizados pela ferramenta são suficientes para atingir os objetivos propostos.

Em ferramentas tipicas para a aplicação dos critérios baseados em mutação, essas atividades se traduzem em um conjunto essencial de tarefas que devem ser executadas:

- Delinição de casos de teste;

- Execução do programa em teste;

- Geração de mutantes;

- Lixecução dos mutantes;

- Análise dos mutantes vivos;

- Cálculo do escore de mutação; e

- Geração de relatórios.

Para o experimento em questão, foram utilizadas as ferramentas Proteum e $\mathcal{T R O T E M} / \mathrm{IM}$ por possuírem uma série de características que as tornam adequadas para a realização deste trabalho. Como dito anteriormente, hoje essas ferramentas estão intcgradas em um único ambientes denominado FROTEM/IM 2.0 (Delamaro et al., 2000). Porém, para essa integração, os operadores de mutação para o teste de unidade sofreram algumas alterações $\mathrm{cm}$ suas implementações. Essas alterações justificam a escolha das ferramentas Proteum e $\mathcal{P R O T E M M} / \mathcal{M}$ para aplicação do experimento uma vez que a seqüencia dos mutantes gerada pela ferramenta 
TROTEUM/LM 2.0 não é a mesma das versões anteriores, ficando inviável, por questão de tempo, a geração de 11 sessões de teste para cada programa e critério como descrito na Seção 3.2.3. Mais informações sobre essas alterações podem scr cncontradas em (Jorge et al., 2002b).

O teste utilizando-se essas ferramentas é dirigido por sessões de teste. O estado de uma sessão de teste ć caracterizado por uma base de dados identificada por um nome e composta, basicamente, por dados sobre os casos de teste, mutantes utilizados e alguns arquivos intermediários que descrevem o programa sendo testado. Uma sessão de teste é constituída de uma seqüência de operações realizadas sobre essa base de dados através de chamadas aos programas que compõem as ferramentas (Delamaro, 1997).

A vantagem de se utilizar as sessões de teste é que o testador pode, por meio das operações disponiveis nas ferramentas, obter diferentes resultados a partir de uma única sessão de teste, realizando operações sobre a mesma. Por exemplo, as ferramentas Proteum e PROTEMM/TM oferecem as seguintes funcionalidades:

- Habilitar e desabilitar diferentes grupos de mutantes;

- Habilitar e desabilitar diferentes operadores de mutação; e

- Habilitar e desabilitar diferentes conjuntos de casos de teste.

Desse modo, diferentes combinações de conjuntos de casos de teste podem ser avaliadas com diferentes conjuntos de mutantes em uma mesma sessão de teste. Pode-se, por exemplo, avaliar qual a capacidade de um conjunto de casos de teste adequado a um único operador em distinguir os mutantes gerados pelos demais, características essa fundamental para a condução dos experimentos realizados neste trabalho.

\subsubsection{Geração dos Conjuntos de Casos de Teste}

Como já foi dito, o teste exaustivo é desejável para se testar um programa, porém sabe-se que é inviável por razões de custo e tempo. A maioria das técnicas e critérios apresentados anteriormente auxiliam a atividade de teste dividindo o domínio de entrada do programa em subdomínios e fazzendo com que pelo menos um ponto de cada subdomínio seja executado.

A tarefa de geração de dados de teste visa a selecionar pontos de cada subdomínio a fim de satisfazer um determinado critério, revelando um maior número de erros possível. Embora a automatização dessa tarefa seja desejável, não cxiste um algoritmo de propósito geral para determinar um conjunto de casos de teste que satisfaça um dado critério. Não é possível nem mesmo determinar se csse conjunto existe, o que torna o problema de geração de casos de teste indecidivel. 
Visto que os melhores pontos do domínio para a seleção de dados de teste são aqueles com maior probabilidade de revelar erros, a estratégia cmpregada para selecionar esses pontos é de fundamental importância, pois dela depende a efetividade do critério.

Uma das principais estratégias para geração de dados é a geração aleatória que tem sido a mais utilizada para a condução de estudos empíricos, na qual pontos do domínio são sclecionados alcatoriamente. Esta estratégia não garante a seleção dos melhorcs pontos, nem mesmo a satisfação do critério, entretanto, é de fácil automatização e capaz de gerar grandes conjuntos de dados de teste a baixo custo. Além disso, a técnica aleatória elimina qualquer possível influência do testador em conduzir a geração dos dados de teste conforme o conhecimento prévio dos programas utilizados.

Para a realização deste experimento, para cada programa e cada critério (Análise de Mutantes c Mutação de Interface) foi criado um pool de casos de teste adequado o qual possui a seguinte composição:

- casos de teste funcionais ad hoc $\left(D T_{f u n c}\right)$ : gerados a partir da especificação funcional de cada programa;

- casos de teste aleatórios ( $\left.D T_{\text {aleat }}\right)$ : obtidos dos experimentos desenvolvidos por Wong (1993) que comparava os critérios Análise de Mutantes e Todos-Usos; e

- casos de teste manuais ( $\left.D T_{\text {manut }}\right)$ : gerados a partir dos mutantes que permaneceram vivos após a aplicação dos casos de teste funcionais e aleatórios. Os mutantes foram analisados c criados casos de teste específicos para distingui-los.

A Tabela 3.13 apresenta e o Gráfico da Figura 3.7 ilustra uma síntese desses dados.

Tabela 3.13: Número de Casos de Teste Utilizados por Programa

\begin{tabular}{|l|r|r|r|r|r|r|} 
& \multicolumn{3}{|c|}{ Análise de Mutantes } & \multicolumn{3}{c|}{ Mutaça de Interface } \\
\hline Programas & $D T_{\text {func }}$ & $D T_{\text {aleat }}$ & $\bar{D} T_{\text {manu }}$ & $D T_{\text {func }}$ & DT $T_{\text {aleat }}$ & $D T_{\text {manu }}$ \\
\hline Cal & 1 & 162 & 21 & 1 & 162 & 2 \\
\hline Checke4 & 12 & 166 & 35 & 12 & 166 & 18 \\
\hline Comm & 39 & 754 & 8 & 39 & 754 & 46 \\
\hline Look & 52 & 193 & 7 & 52 & 193 & 12 \\
\hline Sort & 107 & 997 & 172 & 107 & 997 & 128 \\
\hline Uniq & 42 & 431 & 17 & 42 & 431 & 36 \\
\hline
\end{tabular}

Ressalta-se que para os programas Cal, Checkeq, Comm, Look e Uniq, que possuem um tamanho aproximadamente de 100 LOC's, a partir desse pool, mais 10 sequiências diferentes de casos de teste foram geradas totalizando 11 conjuntos de casos de teste para cada programa e critério. Já para o programa sort (628 L.OC's) uma única sessão de teste foi gerada devido ao alto custo computacional de se gerarem mais 10 sessões de teste para esse programa. Assim sendo, para avaliar o número equivalentes e q-equivalentes, os 6 programas foram utilizados, 


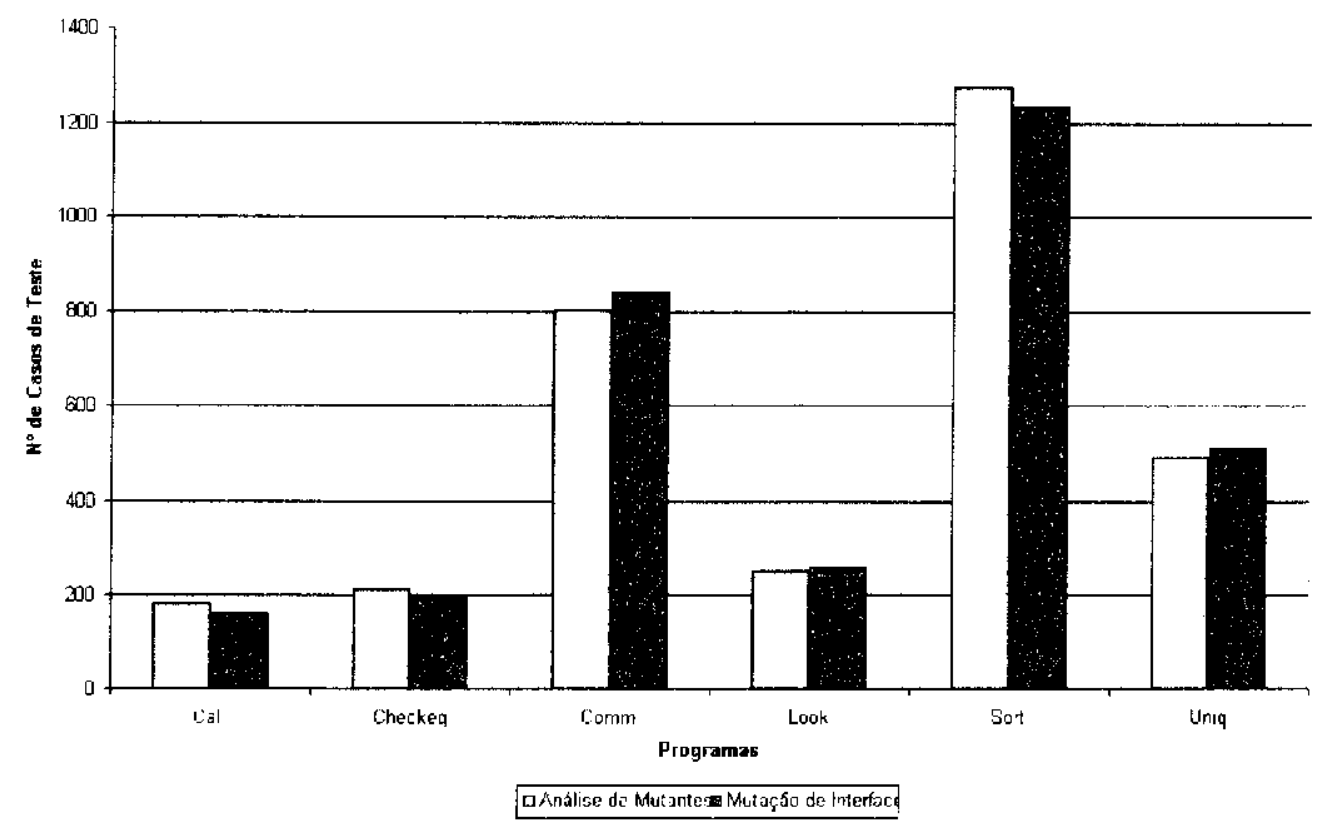

Figura 3.7: Cardinalidade dos Conjuntos de Casos de Teste $\Lambda \mathrm{M}$-adequado e MI-adequado

tendo em vista que essa informação pode ser obtida a partir de uma única sessão de teste, pois a única dilerença entre as sessões de teste de um mesmo programa é o conjunto de casos de teste necessário para matar os mutantes não equivalentes e não a quantidade desses mutantes. Entretanto, nos casos em que é necessário a coleta de informações estatísticas a respeito dos operadores, por exemplo o número de mutantes que são mortos por uma determinada quantidade de casos de teste, os 5 programas que possuem 11 conjuntos de casos de teste foram utilizados.

É importante que dilerentes conjuntos de casos de teste sejam avaliados pois, para um dado critério, pode existir um número infinito de conjuntos de casos de teste que o satisfaça c, selecionar apenas um desses conjuntos pode levar a falsas conclusões (Wong et al., 1997).

\subsubsection{Coleta e Análise dos Dados}

Terminada a fase anterior, as informações relevantes para se atingir o objetivo proposto são coletadas a partir da base de dados construída durante a geração das sessões de teste.

Foram coletadas diferentes informações de modo a permitir a determinação de:

- Quais operadores geram o maior número de mutantes;

- Quais operadores geram o maior número de mutantes equivalentes;

- Quais operadores geram o maior número de mutantes q-equivalentes; e

- Quais operadores geram mutantes que morrem facilmente, ou seja, mutantes que morre com um grande número de casos de teste. 


\subsection{Avaliação dos Operadores de Mutação}

Para avaliar os operadores de mutação, é feita uma análise teórica procurando descrevê-los detalhadamente com o objetivo de estabelecer heurísticas para a determinação de mutantes equivalentes. Em seguida, é feita uma análise empírica dos operadores de mutação buscando determinar quais operadores geram mais mutantes equivalentes, proporcionando guidelines ao testador para facilitar na atividade de identificação desses mutantes e fornecer subsídios para a estabelecimento de estratégias de teste baseadas no Teste de Mutação que sejam incrementais, de baixo custo e eficazes, c apóiem todo o ciclo de desenvolvimento de software.

O padrão utilizado para análise dos operadores é apresentado a seguir.

\section{SIGLA - Nome do Operador}

Para cada operador é apresentado seu nome e a sigla que o identifica.

\section{Descrição:}

Também é elaborada uma descrição para o operador em questão, exemplos contendo um trecho de código com a estrutura sintática necessária para a aplicação do operador e trechos de código mutante.

\section{Exemplos:}

Trecho de Código Original

Programa Original

Trecho de Código Mutante 1

Mutante 1

Trecho de Código Mutante n

Mutante $\mathrm{n}$

Informações Estatísticas:

\begin{tabular}{|c|c|c|c|c|c|c|c|}
\hline $\begin{array}{c}\text { Mutantes } \\
\text { Gerados }\end{array}$ & $\begin{array}{c}\text { Mutantes } \\
\text { Equiv. }\end{array}$ & $\begin{array}{c}\text { Mutantes } \\
\text { Q-Equiv. }\end{array}$ & $\begin{array}{c}\text { Mutantes } \\
\text { Mortos }\end{array}$ & Stdout & Retcode & Timeout & Trap \\
\hline \hline $1,322 \%$ & $7,002 \%$ & $6,346 \%$ & $86,652 \%$ & $83,586 \%$ & $15,404 \%$ & $1,01 \%$ & $0 \%$ \\
\hline
\end{tabular}

\begin{tabular}{|c|c|c|c|c|c|c|c|c|c|}
\hline \multicolumn{10}{|c|}{ Casos de Teste Habilitados } \\
\hline $10 \%$ & $20 \%$ & $30 \%$ & $40 \%$ & $50 \%$ & $60 \%$ & $70 \%$ & $80 \%$ & $90 \%$ & $100 \%$ \\
\hline \hline $77,24 \%$ & $6,04 \%$ & $3,02 \%$ & $3,02 \%$ & $3,93 \%$ & $0,91 \%$ & $4,03 \%$ & $0,4 \%$ & $0,81 \%$ & $0,6 \%$ \\
\hline
\end{tabular}




\begin{tabular}{|c|c|c|c|c|c|c|c|c|c|}
\hline \multicolumn{7}{|c|}{ Porcentagem de Casos de Teste (Índice de Mortalidade dos Mutantes) } \\
\hline$[0-10]$ & $(10-20]$ & $(20-30]$ & $(30-40]$ & $(40-50]$ & $(50-60]$ & $(60-70]$ & $(70-80]$ & $(80-90]$ & $(90-100]$ \\
\hline \hline $12,99 \%$ & $10,07 \%$ & $14,5 \%$ & $7,65 \%$ & $12,69 \%$ & $8,36 \%$ & $11,78 \%$ & $4,63 \%$ & $0,00 \%$ & $17.33 \%$ \\
\hline
\end{tabular}

Para cada operador também são coletadas informações estatísticas, como mostram as tabelas acima. Por cxcmplo, a primeira tabela fornece a porcentagem de mutantes gerados em relação ao total de mutantes para cada sessão de teste, porcentagem de mutantes equivalentes, q-equivalentes e mortos em relação ao número de mutantes gerados pelo operador e porcentagem de mutantes mortos por tipo de morte?

Como dito anteriormente, para construção da primeira e segunda tabelas, foram utilizadas as 11 sessões de teste pelo fato do conjunto de casos de teste de cada sessão ser diferente.A segunda tabela mostra o incremento de porcentagem de mutantes mortos a medida que mais casos de teste são adicionados. Primeiramente, do conjunto adequado de casos de teste, foram aplicados apenas os primeiros $10 \%$ dos casos, na média para 11 sessões, 77,24\% dos mutantes mortos gerados por aquele operador morrem. Habilitando mais $10 \%$ dos casos de teste (agora com $20 \%$ dos casos de teste habilitados), mais $6,04 \%$ dos mutantes são mortos.

As ferramentas utilizadas na aplicação do experimento (Proteum e PROTGM/TM), permitem que todos os mutantes, independentemente de já estar morto ou não, sejam executados com todos os casos de teste. Com isso, a terceira tabela foi construída e apresenta a porcentagem de mutantes mortos por um determinado número de casos de teste que chamamos de Índice de Mortalidade dos Mutantes. Tomando essa tabcla como exemplo, 12,99\% dos mutantes não equivalentes gerados pelo operador, são mortos por apenas $[0 \%-10 \%]$ do total de casos de teste. Esses são os mutantes considerados mais dificeis de serem mortos, por serem mortos por uma "baixa" quantidade de casos de teste. Por outro lado, 17,33\% dos mutantes morrem com quase todos os casos de teste (no intervalo [90\%-100\%]), caracterizando esses mutantes como mutantes mais fáceis de serem mortos. Essa informação é utilizada posteriormente no Capítulo 4 para o estabelecimento de estratégias de teste incrementais que definem uma seqüência de aplicação dos operadores de mutação visando a um menor custo.

\section{Informações Sobre Equivalência:}

Quando pertinente, são feitas considerações que auxiliem na determinação de mutantes equivalentes e observações sobre os resultados estatísticos sobre equivalência obtidos para dado operador.

Neste trabalho considerou a existência de dois tipos de equivalência:

1. A partir da semântica do operador; e

2. Para um determinado domínio de aplicação.

\footnotetext{
'Os tipos de morte implementados nas ferramentas Proleun e FROTEZM/DM são detalhados na Seção 2.3.2.3.
} 
A definição de um padrão de equivalência a partir da semântica dos opcradores leva em consideração mutações que sempre são equivalentes ao programa original. Alguns cxemplos desses mutantes são mostrados na Tabela 3.14. Observa-se que os exemplos das linhas 2 e 3 da tabela não são válidos para todas as situações:

- Só valem se as sub-expressões forem booleanas, no caso da linguagem $C, 0$ ou 1. A regra valc, por exemplo, para $(a<b) \|(c>d)$, cujo resultado, se utilizado apenas como predicado de um desvio, é o mesmo que o da cxpressão $(a<b)+(c>d)$. No entanto nào vale por exemplo, se a expressão original for $(-1) \mid i(1)$ cujo resultado difere de $(-1)+(1)$ ; e

- Dependem de onde estão sendo aplicadas. Em predicados de desvios como em comando if ou de laço a equivalência pode ser identificada, porém sua utilização dentro de uma expressão, o quc ć possível na linguagem $C$, em geral, não caracteriza a equivalência. Por exemplo:

$a=b-(0 \wedge 1): / /$ resulta $\mathrm{a}=\mathrm{b}-1$

$a-b-(0-1) ; / /$ resulta $\mathrm{a}=\mathrm{b}+1$

Tabela 3.14: Construções Típicas de Mutantes Equivalentes

\begin{tabular}{|c|c|}
\hline Programa Original & Programa Mutante \\
\hline $\mathrm{x}=0$ & $\mathrm{x}^{*}=0$ \\
\hline$(\mathrm{e} 1) !(\mathrm{e})$ & $(\mathrm{e})+(\mathrm{e})$ \\
\hline$(\mathrm{e}) \wedge(\mathrm{e})$ & $(\mathrm{e}) \mathrm{e}) \cdot(\mathrm{e})$ \\
\hline
\end{tabular}

Para estabelecer um padrão de equivalência para um determinado domínio de aplicação, foram analisados dados coletados a respeito dos operadores de mutação quando aplicados no conjunto de programas descritos na Tabela 3.10, definindo quais operadores geram mais mutantes equivalentes. Analisando-se um programa cspccífico, o testador terá que decidir, utilizando seu conhecimento sobre o programa em questão, sc determinado mutante vivo é ou não equivalente. Uma vez que ele decide que determinado mutante é equivalentc, a "inferência" utilizada para a sua deteç̧ão pode ser utilizada na detecção de outros mutantes equivalentes, caracterizando um padrão de equivalência para aqucle determinado programa. Por exemplo, considere um programa em que a partir de determinado ponto, duas variáveis $a$ e $b$ assumem sempre os mesmos valores. Qualquer mutante que tenha a variável $a$ trocada pela variável $b$, a partir do ponto no qual as duas têm o mesmo valor, será um mutante equivalente.

Quando não forem possível definir um padrão de equivalência mais genérico que possa ser aplicado para outros programas e outros domínios, é possível, com base nas informações estatísticas coletadas, fornecer guidelines ao testador para auxiliá-lo na atividade de análise dos 
mutantes vivos. Suponha-se que para um detcrminado operador op, tem-se uma indicação de que $94,5 \%$ dos mutantes vivos gerados pelo operador são equivalentes contra $5,5 \%$ de mutantes que ainda podem ser mortos. Estes ccrtamente seriam os primeiros candidatos à identificação como équivalentes, ou mesmo à não geração.

Uma outra maneira de identificar um padrão de equivalência a partir da semântica dos operadores, é verificar se um operador não possui características sintáticas para sua aplicação que "inclua" as características de um outro operador, ou seja, sc aplicarmos um determinado operador, o conjunto de casos de teste adequado para matar todos seus mutantes com certeza será adequado para matar os mutantes de um outro operador. Vale ressaltar que, em alguns casos pode ocorrer de operadores, mesmo que não se incluam teoricamente, se incluam para o domínio de aplicação espccificado, caracterizando um padrão de equivalência para esse domínio de aplicação.

A seguir, a título de ilustração, é apresentada a descrição de um operador de mulação de cada grupo de mutação para o teste de unidade (constantes, operadores, comandos e variáveis) e integração (grupo I e grupo II) com os resultados obtidos após a aplicação das análises estabelecidas. Informações detalhadas a respeito de cada operador podem ser encontradas em (Jorge et al., 2002b).

\subsubsection{Operadores de Mutação para o Teste Unidade}

\section{CRCR - Required Constant Replacement (Mutação de Constantes)}

\section{Descrição:}

Estc operador troca cada referência escalar por constantes requeridas dependendo do tipo da referência. Esse conjunto de constantes é apresentado na Tabela 3.15.

Tabela 3.15: Conjunto de Constantes Requeridas - Mutação de Unidade

\begin{tabular}{|c|c|}
\hline Tipo de Variável & Constantes Requeridas \\
\hline integer & $-1,1,0$ \\
\hline float & $1,0,-1.0,0.0,-0.1,0.1$ \\
\hline char & $\backslash \backslash \backslash 0,, \backslash \backslash 177, \backslash \backslash \backslash 200,, \backslash \backslash 377$ \\
\hline
\end{tabular}

Suponha que o conjunto na primcira linha da Tabela 3.15 seja o conjunto $C 1$, o segundo o conjunto $C 2$ e o terceiro o conjunto $C 3$. Quando aplicado o operador CRCR, cada referencia escalar é substituida por um elemento de $C 1, C 2$ ou $C 3$. Se a referencia escalar é inteira, $C 1$ é usado. Caso as referencias sejam pontos flutuantes ou caracteres, $C 2$ e $C 3$ são usados, respectivamente. 


\section{Exemplos:}

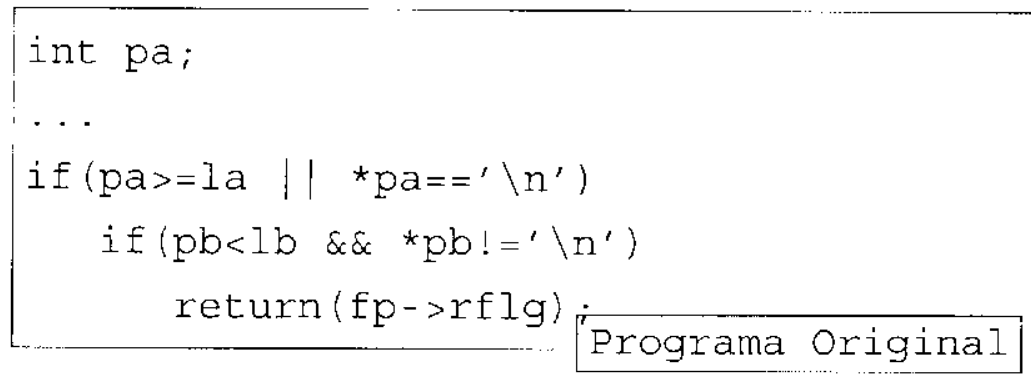

int pa;

if $\left(0>=1 \mathrm{a}|| * \mathrm{pa}==^{\prime} \backslash \mathrm{n}^{\prime}\right)$

if $\left(\mathrm{pb}<1 \mathrm{~b} \& \& * \mathrm{pb} !=^{\prime} \backslash \mathrm{n}^{\prime}\right)$

return ( $f p->r f l g)$;

Mutante 1

int pa;

‥

if $\left(1>=\mathrm{la}|| * \mathrm{pa}==^{\prime} \backslash \mathrm{n}^{\prime}\right)$

if $\left(\mathrm{pb}<\mathrm{Ib} \& \& * \mathrm{pb} !==^{\prime} \backslash \mathrm{n}^{\prime}\right)$

return (fp->rflg);

Mutante 2

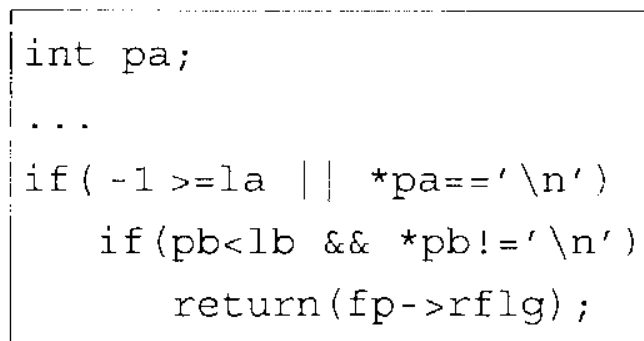

Mutante 3

\section{Informações Estatísticas:}

\begin{tabular}{|c|c|c|c|c|c|c|c|}
\hline $\begin{array}{c}\text { Mutantes } \\
\text { Gerados }\end{array}$ & Mutantes & Mutantes & Mutantes & \multicolumn{4}{|c|}{ Mortos } \\
\hline \hline $5,12 \%$ & $3,39 \%$ & Q-Equiv & Mortos & Stdout & Retcode & Timeout & Trap \\
\hline \hline
\end{tabular}

\begin{tabular}{|c|c|c|c|c|c|c|c|c|c|}
\hline \multicolumn{10}{|c|}{ Casos de Teste Habilitados } \\
\hline $10 \%$ & $20 \%$ & $30 \%$ & $40 \%$ & $50 \%$ & $60 \%$ & $70 \%$ & $80 \%$ & $90 \%$ & $100 \%$ \\
\hline \hline $51,15 \%$ & $13,30 \%$ & $5,53 \%$ & $5,89 \%$ & $10,15 \%$ & $1,82 \%$ & $6,50 \%$ & $2,10 \%$ & $2,00 \%$ & $1,46 \%$ \\
\hline
\end{tabular}

\begin{tabular}{|c|c|c|c|c|c|c|c|c|c|}
\hline \multicolumn{1}{|c|}{ Porcentagem de Casos de Teste (Indice de Mortalidade dos Mutantes) } \\
\hline$[0-10]$ & $(10-20)$ & $(20-30)$ & $(30-40]$ & $(40-50]$ & $(50-60]$ & $(60-70]$ & $(70-80]$ & $(80-90]$ & $(90-100]$ \\
\hline \hline $33,78 \%$ & $14,16 \%$ & $15,92 \%$ & $11,36 \%$ & $6,80 \%$ & $6,50 \%$ & $6,14 \%$ & $2,55 \%$ & $0,67 \%$ & $2,13 \%$ \\
\hline
\end{tabular}




\section{Informações Sobre Equivalência:}

Dependendo do programa, csse operador gera mutantes equivalentes caso existam referências escalares com valores iguais as constantes requeridas. Por exemplo, suponhamos que seja atribuída a variável pa o valor 0 antes do ponto de mutação, ou seja, a variável passará a possuir um valor constante e que é igual ao valor da constante requerida, com isso esse mutante é equivalente como mostra o trecho de código mutante abaixo.

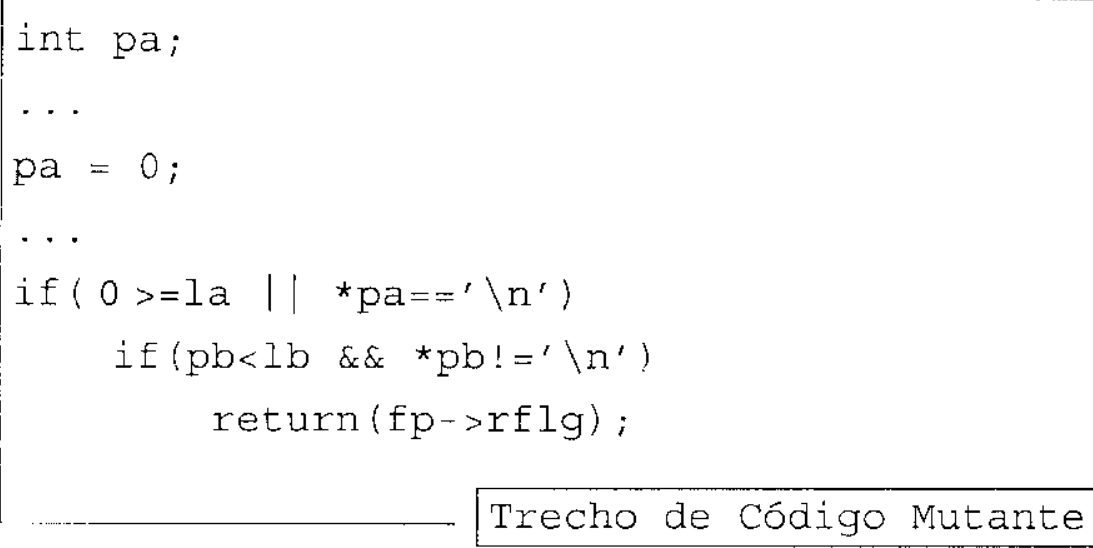

\section{OLBN - Logical by Bitwise Operator Replacement (Mutação de Operadores)}

O opcrador OLBN tem como objetivo substituir operadores lógicos por operadores do tipo bitwi$s e^{4}$ sem atribuição.

\section{Exemplos:}

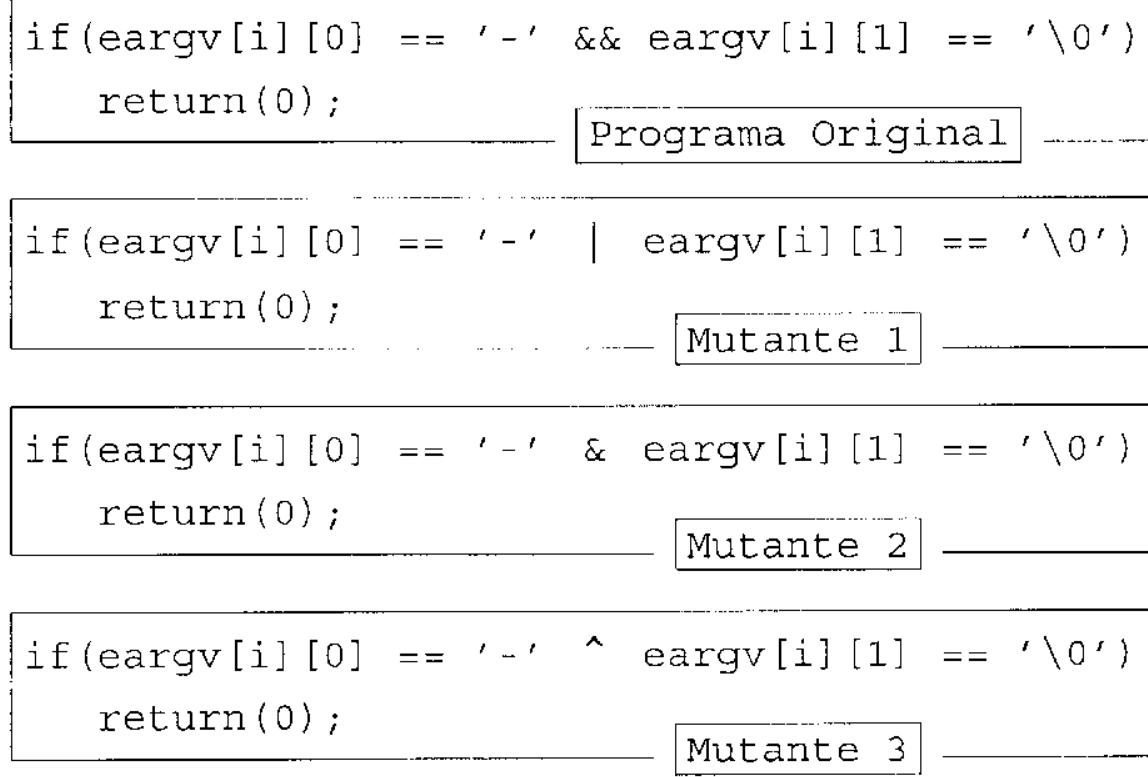

${ }^{4}$ Un operador bitwise aplica operações entre os bits dos opcrandos (operação bit a bit). 


\section{Informações Estatísticas:}

\begin{tabular}{|c|c|c|c|c|c|c|c|}
\hline $\begin{array}{c}\text { Mutantes } \\
\text { Gerados }\end{array}$ & Mutantes & Mutantes & Mutantes & \multicolumn{4}{|c|}{ Mortos } \\
\hline Equiv & Q-Equiv. & Mortos & Stdout & Retcode & Timeout & Trap \\
\hline $0.56 \%$ & $28,13 \%$ & $3.13 \%$ & $68,75 \%$ & $89.68 \%$ & $7,94 \%$ & $2,38 \%$ & $0,00 \%$ \\
\hline
\end{tabular}

\begin{tabular}{|c|c|c|c|c|c|c|c|c|c|}
\hline \multicolumn{10}{|c|}{ Casos de Teste Habilitados } \\
\hline $10 \%$ & $20 \%$ & $30 \%$ & $40 \%$ & $50 \%$ & $60 \%$ & $70 \%$ & $80 \%$ & $90 \%$ & $100 \%$ \\
\hline $53,17 \%$ & $23,02 \%$ & $5.56 \%$ & $2,38 \%$ & $2,38 \%$ & $0.79 \%$ & $7,94 \%$ & $0,00 \%$ & $4,76 \%$ & $0,00 \%$ \\
\hline
\end{tabular}

\begin{tabular}{|c|c|c|c|c|c|c|c|c|c|}
\hline \multicolumn{8}{|c|}{ Porcentagem de Casos de Teste (Indice de Mortalidade dos Mutantes) } \\
\hline$[0-10]$ & $(10-20]$ & $(20-30]$ & $(30-40]$ & $(40-50]$ & $(50-60)$ & $(60-70]$ & $(70-80]$ & $180-90]$ & $(90-100]$ \\
\hline $38,10 \%$ & $18,25 \%$ & $13,49 \%$ & $3,18 \%$ & $4,76 \%$ & $7,94 \%$ & $5,56 \%$ & $5,56 \%$ & $0,79 \%$ & $2,38 \%$ \\
\hline
\end{tabular}

\section{Informações Sobre Equivalência:}

Este operador de mutação, quando aplicado em uma operação lógica (operadores booleanos), terá todos os mutantes que substituam o operador lógico $\& \&$ pelo operador Bitwise $(\&)$ como equivalentes como mostra a Tabela 3.16, caracterizando um padrão de equivalência a partir da scmântica do operador ${ }^{5}$.

Tabela 3.16: Tabela Lógica - Operadores $\& \&$ e $\&$.

\begin{tabular}{|c|c|}
\hline$\& \&$ & $\&$ \\
\hline $00=0$ & $00=0$ \\
\hline $10-0$ & $10=0$ \\
\hline $01=0$ & $01=0$ \\
\hline $11=$ & 1 \\
\hline
\end{tabular}

Isto também é válido para o operador lógico (|||), quando os mutantes forem gerados com a substituição pelo operador Bitwise (|), como mostra a Tabela 3.17.

Tabela 3.17: Tabcla Lógica - Operadores || $\mathrm{e} \mid$.

\begin{tabular}{|c|c|}
\hline & \\
\hline $00=0$ & $00=0$ \\
\hline $10=1$ & $10=1$ \\
\hline $01=1$ & $01=1$ \\
\hline $11=1$ & $11=1$ \\
\hline
\end{tabular}

Como pode ser observado nos dados estatístico desse operador, grande parte dos seus mutantes são equivalentes (aproximadamente $28 \%$ ) c, levando-se em consideração que parte desses mutantes foram gerados a partir de modificações semclhantes as das Tabelas 3.16 e 3.17, esses mutantes não precisariam ser gerados e teríamos uma redução de custo significativa na aplicação do critério Análise de Mutantes.

\footnotetext{
${ }^{5}$ Todo valor diferente de 0, na linguagem $C$, é verdadeiro.
} 


\section{Informações Sobre Equivalência:}

Os mutantes gerados com a aplicação desse operador de mutação só serão cquivalentes quando a função TRAP_ON_CASE () estiver em um bloco de comandos não executável ${ }^{6}$ pois, caso contrário, as funções serão cxecutadas e os mutantes scrão mortos como acontece como o operador STRP ${ }^{7}$.

Pode-se dizer que o operador STRP é mais "genérico" pois aplica a função TRAP_ON_STAT () em bloco de comandos, incluindo os case's. Como o operador SSWM inclui a função TRAP_ON_CASE () somente nos case's do comando switch (e), podese dizer que um conjunto de casos de teste STRP-adequado vai ser SSWM-adequado. Porém, caso algum dos case's não possua um comando de desvio, o teste do restante dos case's será comprometido tornando a afirmação acima incorreta. Caso contrário, se todos os case's possuírem um comando de desvio um conjunto de casos de teste STRP-adequado será também SSWM-adequado. Esta relação é apresentada na Tabela 3.18 obtida por meio da aplicação do experimento no qual verificou-se a cobertura que um conjunto de casos de teste STRP-adequado tem sobre os mutantes gerados pelo operador SSWM e vice-versa.

Como pode ser observado com os dados apresentados, para os scis programas utilizados no experimento, o operador STRP sempre inclui, em termos de cobertura, o operador SSWM não sendo verdadeiro o inverso. Assim sendo, sempre que o operador STRP tiver sido aplicado cm programas que possuam comandos de desvio em seus case' $s$, não se faz necessário gerar os mutantes do operador SSWM diminuindo o custo de aplicação do critério Análise de Mutantes.

Tabela 3.18: Análise de Inclusão Entre os operadores STRP e SSWM

\begin{tabular}{|l|c|c|}
\hline & \multicolumn{2}{|c|}{ Operadores } \\
\hline Programas & STRP->SSWM & SSWM->STRP \\
\hline Cal & 1.0000 & 0.9268 \\
\hline Checkeq & 1.0000 & 1.0000 \\
\hline Comm & 1.0000 & 0.8350 \\
\hline Look & 1.0000 & 0.8750 \\
\hline Sort & 1.0000 & 1.0000 \\
\hline Uniq & 1.0000 & 0.8111 \\
\hline Média & 1.0000 & 0.9080 \\
\hline
\end{tabular}

\section{VDTR - Domain Traps (Mutação de Variáveis)}

\section{Descrição:}

\footnotetext{
Isso é válido para a aplicação de todos os operadores de mutaçióo. Todos os mutantes, quando gerados a partir de um bloco de comandos não executável, sempre serão equivalentes.

${ }^{7}$ Este operador é projetado para revelar códigos não executáveis do programa a ser testado. (ada bloco do grafo de programa é substituído sistematicamente pela função TRAP_ON_STAT (). Quando TRAP_ON_STAT() é executada o mutante é morto.
} 


\begin{tabular}{|c|c|c|c|c|c|c|c|c|c|}
\hline \multicolumn{10}{|c|}{ Casos de Teste Habilitados } \\
\hline $10 \%$ & $20 \%$ & $30 \%$ & $40 \%$ & $50 \%$ & $60 \%$ & $70 \%$ & $80 \%$ & $90 \%$ & $100 \%$ \\
\hline $62,96 \%$ & $7,46 \%$ & $2,44 \%$ & $4,77 \%$ & $6,97 \%$ & $2,44 \%$ & $6,72 \%$ & $2,93 \%$ & $2,81 \%$ & $0,49 \%$ \\
\hline
\end{tabular}

\begin{tabular}{|c|c|c|c|c|c|c|c|c|c|}
\hline \multicolumn{7}{|c|}{ Porcentugem de Casos de Teste (Indice de Mortalidade dos Mutantes) } \\
\hline$[0-10]$ & $(10-20]$ & $(20-30]$ & $(30-40]$ & $(40-50]$ & $(50-60]$ & $(60-70]$ & $(70-80]$ & $(80-90]$ & $(90-100]$ \\
\hline $27,75 \%$ & $12,35 \%$ & $17.73 \%$ & $8,44 \%$ & $7,21 \%$ & $6,72 \%$ & $6,60 \%$ & $3,67 \%$ & $2,08 \%$ & $7,46 \%$ \\
\hline
\end{tabular}

\section{Informações Sobre Equivalência:}

Quando aplicado esse operador de mutação cm variáveis do tipo char e unsigned int, os mutantes gerados com a função TRAP_.ON_NEGATIVE() sempre serão equivalentes, visto que variáveis desses tipos não assumem valores negativos.

Vale destacar que, mesmo para variáveis cscalares de outros tipos (int, long, short), que podem assumir valores negativos, positivos e zero, esse operador pode gerar mutantes equivalentes caso, para o programa em questão, o domínio de valores que determinadas variáveis possa assumir seja restrito, ou seja, se a variável que está sofrendo a mutação em nenhum ponto do programa assumir os valores:

- zero - todos os mutantes com TRAP_ON_ZERO() serão equivalentes;

- positivo - todos os mutantes com TRAP_ON_POSITIVE() serão equivalentes;e

- negativo - todos os mutantes com TRAP_ON_NEGATIVE() serão equivalentes.

Além desse operador de mutação gerar grande parte do total dos mutantes (4,27\%). 40,65\% deles são equivalentes, ou seja, caso csses mutantes não sejam gerados, haverá uma redução significativa em termos do número de mutantes equivalentes na aplicação da Análise de Mutantes.

A coleta desse tipo de informação foi realizada para todos os operadores de mutação para o teste de unidade e a Tabela 3.20 sintetiza os dados coletados. Mais informaçõos podem scr encontradas em (Jorge et al., 2002b).

Na segunda coluna da Tabela 3.20 é apresentado o número de mutantes gerados pelo operador quando aplicado nos seis programas utilizados no experimento $\mathrm{c}$ a terceira coluna representa a porcentagem de mutantes do operador cm relação ao total de mutantes gerados com a aplicação de todos os operadores de mutação. O número de mutantes equivalentes e q-equivalente também são dados pela quarta e quinta coluna, respectivamente. A sexta coluna representa a porcentagem de mutantes equivalentes $\mathrm{e}$ a sétima coluna a porcentagem de mutantes qequivalentes em relação ao número de mutantes gerados pelo operador. Referente ao total de mutantes equivalentes e q-equivalentes, na oitava e nona coluna são apresentadas as porcentagem de mutantes equivalente e q-equivalentes, respectivamente. Vale ressaltar que, para o 
teste de unidade 61 opcradores de mutação geraram pelo menos um mutante quando aplicados aos 6 programas utilizados no experimento, assim sendo, por falta de dados estatísticos, 11 operadores não foram avaliados empiricamente, como é o caso do operador OSAA.

Utilizando a mesma terminologia da Tabela 3.20, procurou-se selecionar os 10 operadores de mutação referentes ao teste de unidade que se destacam no número de mutantes gerados, mutantes cquivalentes e mutantes q-equivalentes. As Tabela 3.21 (a), Tabela 3.21 (b) e Tabela 3.21 (c) apresentam esse operadores, respectivamente.

Como pode ser observado nas Tabelas 3.21 (a), (b) c (c), seis operadores se destacam tanto no número de mutantes gerados como na geração de mutantes equivalentes e q-equivalentes como é o caso dos opcradores CCCr, CCSr, ORAN, ORRN, VDTR, e Vsrr. Considerando que, tanto os mutantes equivalentes como os q-equivalentes não devem ser gerados, devc-sc analisar o quanto desses mulantes, somados, os operadores de mutação geram por se tratar dos mutantes mais custosos de serem determinados. Observa-se que, o operador VDTR gera o maior número de mutantes equivalentes e q-cquivalentes somados $(34,50 \%)$ c ainda é responsável por gerar $4,27 \%$ do total de mutantes. Por este fator, os mutantes gerados por esse operador de mutação são fortes candidatos a serem identificados como equivalentes ou q-equivalentes. Outro operador que se destaca na geração de mutantes equivalentes e q-equivalentes é o operador Cccr que tem $34.45 \%$ de seus mutantes como equivalentes ou q-equivalentes e ainda é responsável por gerar $8,35 \%$ dos total de mutantes. O contrário ocorre com o operador Vprr, no qual é responsável por gerar $10,64 \%$ do total de mutantes, porém não gera uma quantidade significativa de mutantes equivalentes nem q-equivalentes, $0,163 \%$ e $0,82 \%$, respectivamente. 


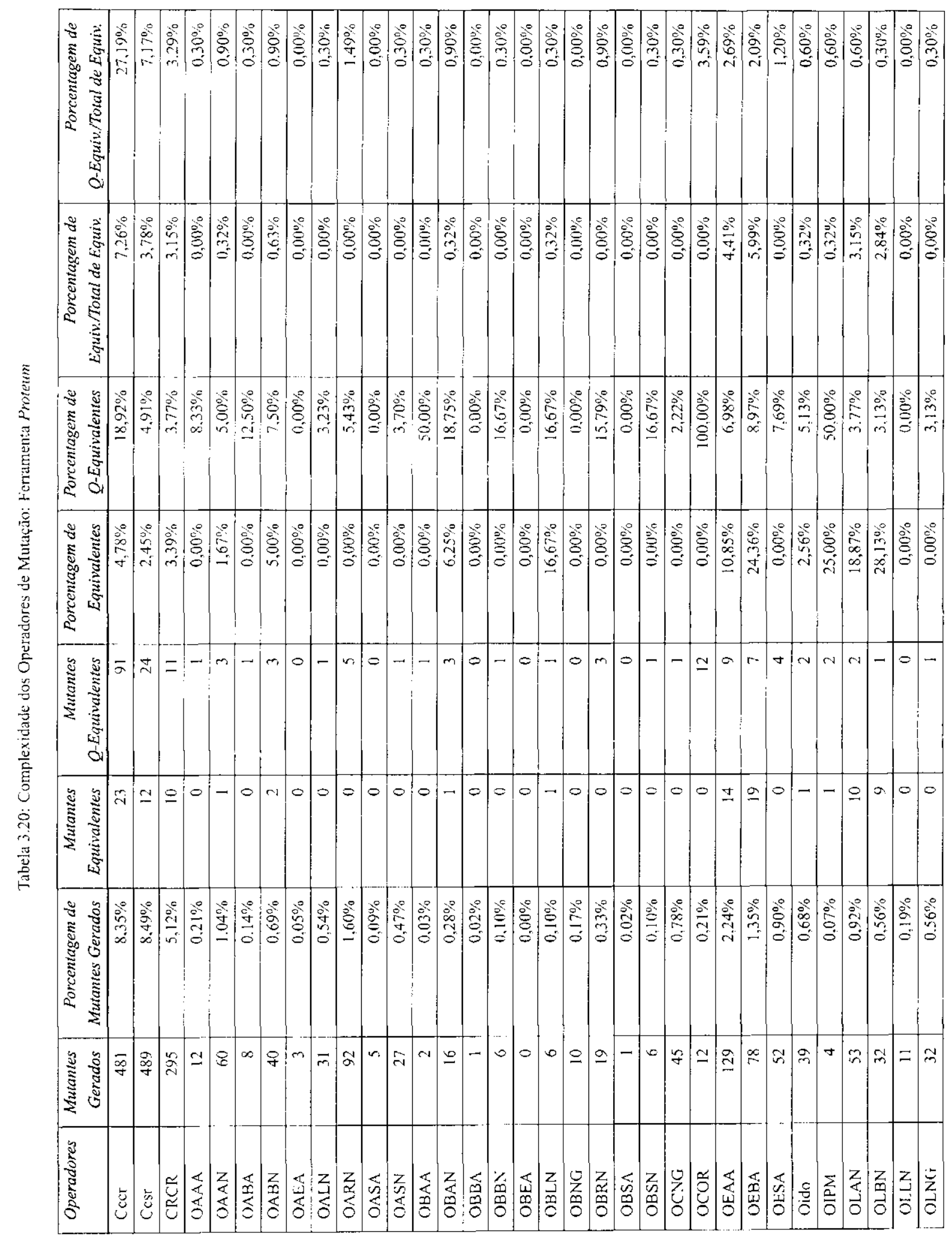




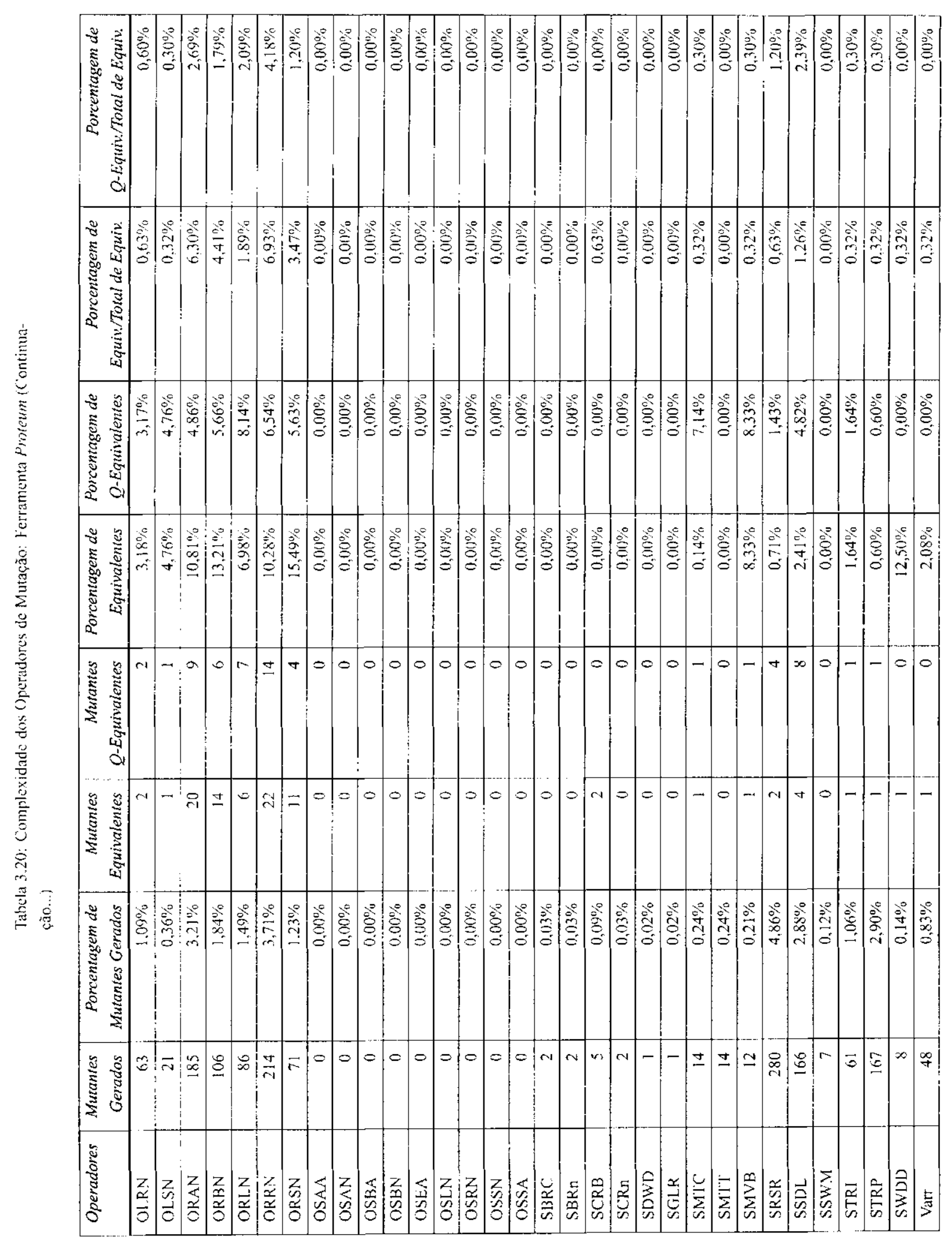




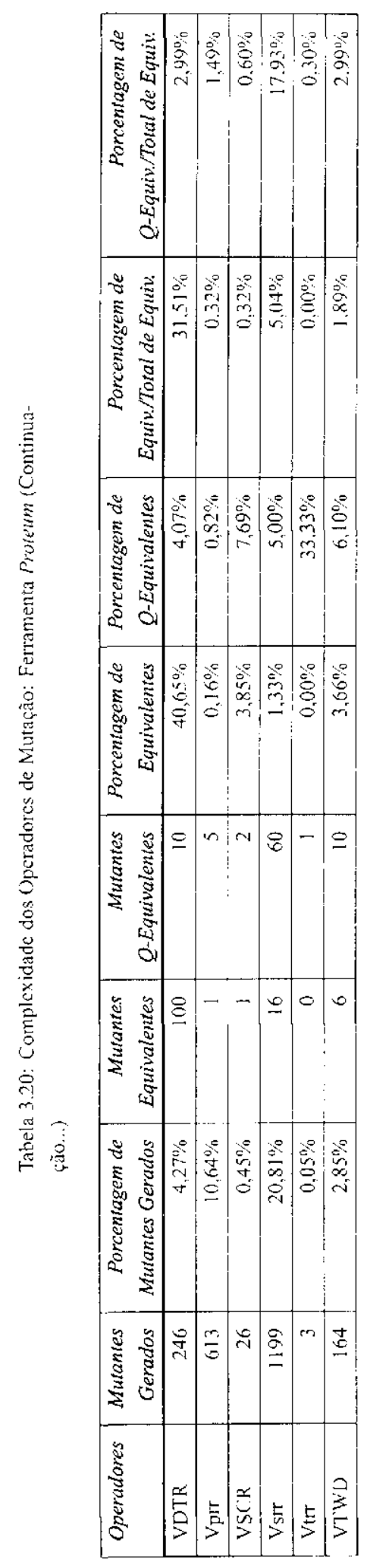


Tabela 3.21: Operadores de Mutação de Unidade mais Custosos: (a) Mutantes Gerados, (b) Mutantes Equivalentes e (c) Mutantes Q-Equivalentes

\begin{tabular}{|l|r|r|r|}
\hline Operadores & $\begin{array}{r}\text { Porcentagen de } \\
\text { Mutantes Gerados }\end{array}$ & $\begin{array}{r}\text { Porcentagem de } \\
\text { Equiv/Total de Equiv }\end{array}$ & $\begin{array}{r}\text { Porcentagem de } \\
\text { Q-Equiv/Total de Equiv }\end{array}$ \\
\hline V Vir & $20,81 \%$ & $5,04 \%$ & $17,93 \%$ \\
\hline Vprr & $10,64 \%$ & $0,32 \%$ & $1,49 \%$ \\
\hline Cesr & $8,40 \%$ & $3,78 \%$ & $7,17 \%$ \\
\hline Cecr & $8,35 \%$ & $7,25 \%$ & $27,19 \%$ \\
\hline CRCR & $5,12 \%$ & $3,15 \%$ & $3,29 \%$ \\
SRSR & $4,86 \%$ & $0,63 \%$ & $1,20 \%$ \\
\hline VDTR & $4,27 \%$ & $31,51 \%$ & $2,99 \%$ \\
\hline ORRN & $3,71 \%$ & $6,93 \%$ & $4,18 \%$ \\
\hline ORAN & $3,21 \%$ & $6,30 \%$ & $2,69 \%$ \\
\hline STRP & $2,90 \%$ & $0,32 \%$ & $0,30 \%$ \\
\hline
\end{tabular}

(a)

\begin{tabular}{|l|r|r|r|}
\hline Operadores & $\begin{array}{r}\text { Porcentagem de } \\
\text { Mutantes Gerados }\end{array}$ & $\begin{array}{r}\text { Porcentagem de } \\
\text { Equiv./Total de Equiv. }\end{array}$ & $\begin{array}{r}\text { Porcentagem de } \\
\text { Q-Equiv/Total de Equiv. }\end{array}$ \\
\hline VDTR & $4,27 \%$ & $31,51 \%$ & $2,99 \%$ \\
\hline Cicr & $8,35 \%$ & $7,25 \%$ & $27,19 \%$ \\
\hline ORRN & $3,71 \%$ & $6,93 \%$ & $4,18 \% \%$ \\
\hline ORAN & $3,21 \%$ & $6,30 \%$ & $2,60 \%$ \\
\hline OFBA & $1,35 \%$ & $5,99 \%$ & $2,09 \%$ \\
\hline VSTr & $20,81 \%$ & $5,04 \%$ & $17,93 \%$ \\
\hline OEAA & $2,24 \%$ & $4,41 \%$ & $2,6 \% \%$ \\
\hline ORBN & $1,84 \%$ & $4,41 \%$ & $1,79 \%$ \\
\hline Cos & $8,49 \%$ & $3,78 \%$ & $7,17 \%$ \\
\hline ORSN & $1,23 \%$ & $3,47 \%$ & $1,20 \%$ \\
\hline
\end{tabular}

(b)

\begin{tabular}{|l|r|r|r|}
\hline Operadores & $\begin{array}{r}\text { Porcentagem de } \\
\text { Mutantes Gerados }\end{array}$ & $\begin{array}{r}\text { Porcentagem de } \\
\text { Equiv.Total de Equiv. }\end{array}$ & $\begin{array}{r}\text { Porcentagem de } \\
\text { Q-Equiv./Total de Equiv. }\end{array}$ \\
\hline \hline Cccr & $8,35 \%$ & $7,26 \%$ & $27,19 \%$ \\
\hline V Srr & $20.81 \%$ & $5,04 \%$ & $17,93 \%$ \\
\hline Ccsr & $8,49 \%$ & $3,78 \%$ & $7,17 \%$ \\
\hline ORRN & $3,71 \%$ & $6,93 \%$ & $4,18 \%$ \\
\hline OCOR & $0,21 \%$ & $0,00 \%$ & $3,59 \%$ \\
\hline CRCR & $5,12 \%$ & $3,15 \%$ & $3,29 \%$ \\
\hline VDTR & $4,27 \%$ & $31,51 \%$ & $2,99 \%$ \\
\hline VTWD & $2,85 \%$ & $1,89 \%$ & $2,99 \%$ \\
\hline OEAA & $2,24 \%$ & $4,41 \%$ & $2,69 \%$ \\
\hline ORAN & $3,21 \%$ & $6,30 \%$ & $2,69 \%$ \\
\hline
\end{tabular}

(c)

A seguir a mesma análise teórica e empírica que é aplicada nos operadores de mutação de unidade é aplicada sobre os operadores de mutação para o teste de integração.

\subsubsection{Operadores de Mutação para o Teste de Integração}

\section{DirVarAriNeg - Inserts Arithmetic Negation at Interface Variable (Grupo I)}

\section{Descrição:}

Este operador inclui o operador de negação aritmética (-) em cada referência a variáveis de interface. 


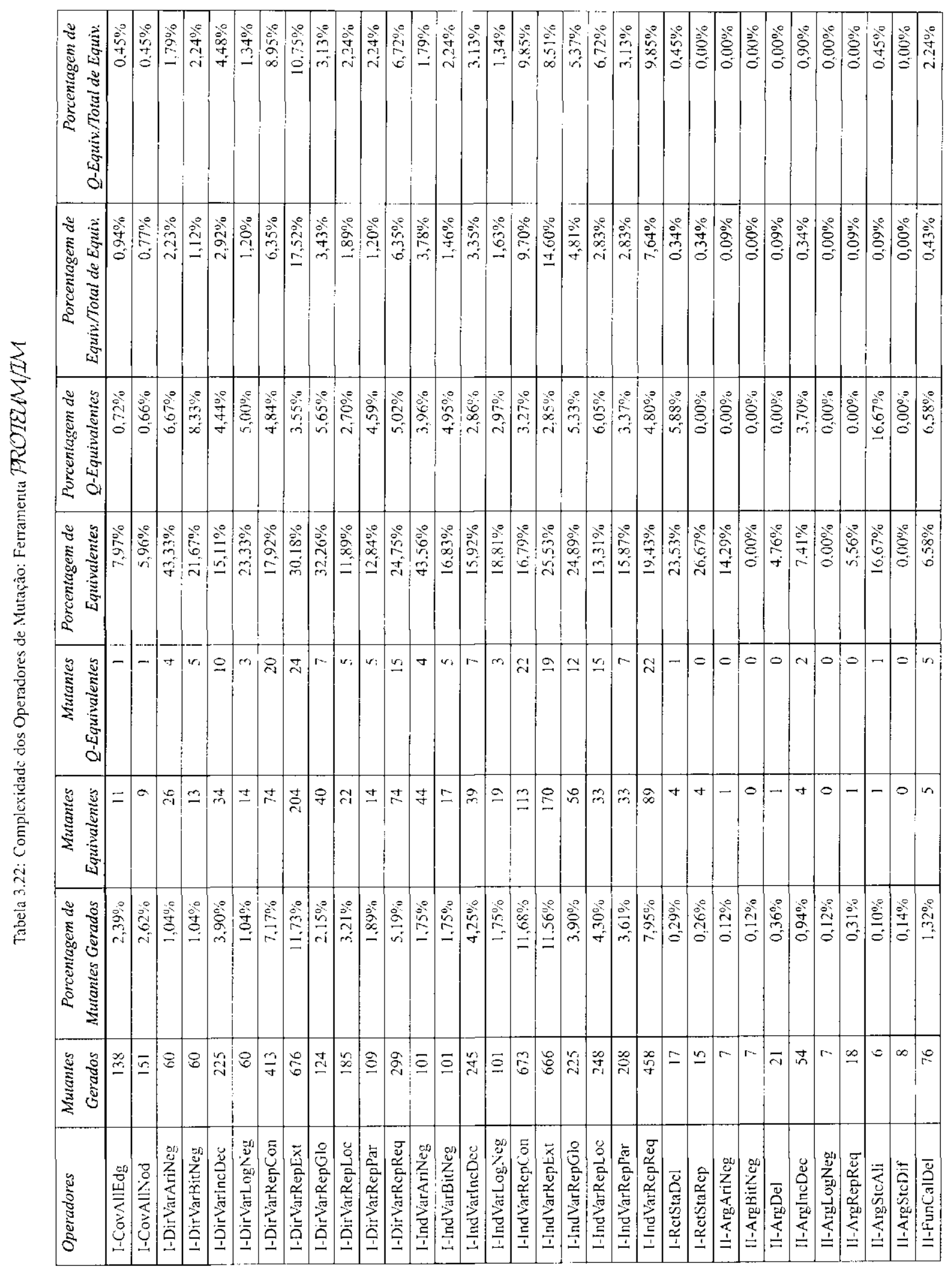


A partir da Tabela 3.22 foram determinados quais os 10 operadores de mutação, referentes ao teste de integração, que se destacam na quantidade de mutantes gerados, mutantes equivalentes c mutantes q-equivalentes. As Tabela 3.23 (a), Tabela 3.23 (b) e Tabcla 3.23 (c) apresentam esse operadores, respectivamente.

Tabcla 3.23: Operadores de Mutação de Interface mais Custosos: (a) Mutantes Gerados, (b) Mutantes Equivalentes e (c) Mutantes Q-Equivalentes

\begin{tabular}{|l|r|r|r|}
\hline Operadores & $\begin{array}{r}\text { Porcentagem de } \\
\text { Mutantes Gerados }\end{array}$ & $\begin{array}{r}\text { Porcentagem de } \\
\text { Equiv./Total de Equiv. }\end{array}$ & $\begin{array}{r}\text { Porcentagem de } \\
\text { Q-Equiv/Total de Equiv }\end{array}$ \\
\hline \hline I-DirVarRepExt & $11,73 \%$ & $17,52 \%$ & $10,75 \%$ \\
\hline I-IndVarRepcon & $11,68 \%$ & $9,70 \%$ & $9,85 \%$ \\
\hline I-IndVarReptxt & $11,56 \%$ & $14,60 \%$ & $8,51 \%$ \\
\hline I-IndVarRepReq & $7,95 \%$ & $7,64 \%$ & $0,85 \%$ \\
\hline I-DirVarRepCon & $7,17 \%$ & $6,35 \%$ & $8,95 \%$ \\
\hline I-DirVarRepReq & $5,19 \%$ & $6,35 \%$ & $6,72 \%$ \\
\hline I-IndVarRepLoc & $4,30 \%$ & $2,83 \%$ & $6,72 \%$ \\
\hline I-IndVarIncDec & $4,25 \%$ & $3,35 \%$ & $3,13 \%$ \\
\hline I-IndVarRepCilo & $3,90 \%$ & $4,81 \%$ & $5,37 \%$ \\
\hline I-DirVarIncDec & $3,90 \%$ & $2,92 \%$ & $4,48 \%$ \\
\hline
\end{tabular}

(a)

\begin{tabular}{|l|r|r|r|}
\hline Operadores & $\begin{array}{r}\text { Porcentagem de } \\
\text { Mutantes Gerados }\end{array}$ & $\begin{array}{r}\text { Porcentagem de } \\
\text { Equiv/Total de Equiv }\end{array}$ & $\begin{array}{r}\text { Porcentagem de } \\
\text { Q-Equiv/Total de Equiv. }\end{array}$ \\
\hline I-DirVarRepEx & $11,73 \%$ & $17,52 \%$ & $10,75 \%$ \\
\hline I-IndVarReptxt & $11,56 \%$ & $14,60 \%$ & $8,51 \%$ \\
\hline I-IndVarRepCon & $11,68 \%$ & $9,70 \%$ & $9,85 \%$ \\
\hline I-IndVarRepReq & $7,95 \%$ & $7,64 \%$ & $9,85 \%$ \\
\hline I-DirVarRepCon & $7,17 \%$ & $6,35 \%$ & $8,95 \%$ \\
\hline I-DirVarRepReq & $5,19 \%$ & $6,35 \%$ & $6,72 \%$ \\
\hline I-IndVarRepGlo & $3,90 \%$ & $4,81 \%$ & $5,37 \%$ \\
\hline I-IndVarAriNeg & $1,75 \%$ & $3,78 \%$ & $1,79 \%$ \\
\hline I-DirVarRep(jlo & $2,15 \%$ & $3,43 \%$ & $3,13 \%$ \\
\hline I-IndVarIncDec & $4,25 \%$ & $3,35 \%$ & $3,13 \%$ \\
\hline
\end{tabular}

(b)

\begin{tabular}{|l|r|r|r|}
\hline Operadores & $\begin{array}{r}\text { Porcentagem de } \\
\text { Mutantes Gerados }\end{array}$ & $\begin{array}{r}\text { Porcentagem de } \\
\text { Equiv./Total de Equiv. }\end{array}$ & $\begin{array}{r}\text { Porcentagem de } \\
\text { Q-Equiv./Total de Equiv }\end{array}$ \\
\hline \hline I-DirVarRepExt & $11,73 \%$ & $17,52 \%$ & $10,75 \%$ \\
\hline I-IndVarRepCon & $11,68 \%$ & $9,70 \%$ & $9,85 \%$ \\
\hline I-IndVarRepReq & $7,95 \%$ & $7,64 \%$ & $9,85 \%$ \\
\hline I-DirVarRepCon & $7,17 \%$ & $6,35 \%$ & $8,95 \%$ \\
\hline I-IndVarRepExi & $11,56 \%$ & $14,60 \%$ & $8,51 \%$ \\
\hline I-DirVarRepReq & $5,19 \%$ & $6,35 \%$ & $6,72 \%$ \\
\hline I-IndVarRepLoc & $4,30 \%$ & $2,83 \%$ & $6,72 \%$ \\
\hline I-IndVarRepClo & $3,90 \%$ & $4,81 \%$ & $5,37 \%$ \\
\hline I-DirVarIncDec & $3,90 \%$ & $2,92 \%$ & $4,48 \%$ \\
\hline I-DirVarRepCilo & $2,15 \%$ & $3,43 \%$ & $3,13 \%$ \\
\hline
\end{tabular}

(ci

Observa-se na Tabela 3.23 que, sete operadores se destacam tanto no número de mutantes gerados como na geração de mutantes equivalentes e q-equivalentes como é o caso dos operadores DirVarRepCon, DirVarRepExt, DirVarRepReq, IndVarRepCon, IndVarRepExt, IndVarRepGlo e IndVarRepReq. Um desses operadores é o operador DirVarRepExt que gera o maior número de mutantes $(11,73 \%)$, mutantes equivalentes $(17,52 \%)$ 
e mutantes q-equivalentes (10,75\%). O mesmo destaque é dado ao operador IndVarRepcon pois, apesar de ser o terceiro opcrador que mais gera mutantes equivalentes $(9,70 \%)$ é o segundo que gera o maior número de mutantes ( $11,68 \%)$ c mutantes q-equivalentes $(9,85 \%)$.

Conclui-se que, a maioria dos operadores que geram grande número de mutantes também são responsáveis por gerarem grande número de mutantes equivalentes c q-equivalentes, porém, isso não é uma regra, como é o caso do operador STRP que apesar de estar entre os 10 operadores que geram o maior número de mutantes $(2,90 \%)$, a quantidade de mutantes equivalentes e q-equivalentes gerados com sua aplicação é relativamente baixa, $0,32 \%$ e $0,30 \%$ respectivamente.

\subsection{Considerações Finais}

Neste capítulo mostraram-se os resultados da aplicação dos critérios Análise de Mutantes e Mutação de Interface em seis programas selecionados para a aplicação do experimento. Deste experimento foram analisados todos os operadores de mutação definidos e implementados nas ferramentas Proteum e PROTaM M/IM com o objetivo de fornecer subsídios para reduzir o custo de aplicação dos critérios baseados em mutação por meio da identificação dos operadores de mutação geram o maior número de mutantes equivalentes, q-equivalentes e mutantes que morrem facilmente. Os resultados se mostraram promissores pois, a partir deles foram identificadas heurísticas para determinação de mutantes equivalentes que facilitará a vida do testador na fase de análise dos mutantes vivos, uma vez que essa atividade é feita manualmente, sendo a mais custosa quando aplicado o Teste de Mutação.

Com base nos dados estatisticos obtidos com a aplicação do experimento, pode-se criar alternativas para a aplicação dos operadores de mutação por meio da seleção de subconjuntos desses operadores, reduzindo o custo de aplicação dos critérios, sem comprometer a qualidade da atividade de teste. A seguir é apresentado uma dessas alternativas para aplicação dos operadores de mutação, utilizando os dados estatísticos obtidos nesse capitulo. 


\section{4}

\section{Estabelecimento de Estratégias de Teste para Aplicação dos Operadores de} Mutação

OMO pode ser visto Capítulo 3, o número de mutantes gcrados tanto para o critério Análise de Mutantes como para o critério Mutação de Interface é grande, mesmo para programa simples (vide Tabelas 3.11 e 3.12), fortalecendo o interesse de investigar mecanismos para redução do custo de aplicação dos critérios.

Para o estabelecimento de estratégias de teste para aplicação dos operadores de mutação, os critérios Análise de Mutantes e Mutação de Interface são analisados separadamente. A idéia é minimizar o custo de aplicação desses critérios, visando a estabelecer um modo incremental para aplicação dos operadores de mutação reduzindo o custo do teste de unidade e de integração.

Tendo um conjunto de operadores de mutação, a questão que se coloca é: "Como selecionar um subconjunto de operadores que conduzam a conjuntos de teste adequados ou próximos da adequação em relação ao conjunto total de mutantes, reduzindo o custo tanto em termos do número de mutantes gerados quanto do númcro de mutantes equivalentes ?". Procurando responder a essa questão. alguns estudos teóricos (Barbosa, 1998; Vincenzi, 1998) e empíricos (Vincenzi et al., 2001) foram aplicados. Porém, os mesmos não consideravam o número de mutantes equivalentes gerado pelos operadores. Neste capítulo é descrito um experimento que visa a avaliar os critérios Análise de Mutantes e Mutação de Interface com o objetivo de scle- 
cionar um subconjunto de operadorcs de mutação levando em consideração informações sobre equivalência.

\subsection{Descrição do Experimento}

A metodologia usada na condução deste experimento foi a mesma utilizada no experimento apresentado no Capítulo 3 e compreende quatro passos: seleção dos Programas, seleção das ferramentas, geração dos casos de teste, coleta e Análise dos dados.

Este experimento foi conduzido a partir dos mesmo cinco programas utilizados no experimento do Capítulo 3, (Cal, Checkeq, Comm, Look e Uniq), por possuírem 11 sessões de teste para cada programa tanto para o critério Análise de Mutantes como para o critério Mutação de Interface. Neste capítulo, para referenciarmos esse conjunto de 5 programas, utilizaremos a nomenclatura 5-UNIX. As ferramentas utilizadas para aplicação do experimento foram as mesmas utilizadas no cxperimento anterior, a Proteum e a $\mathcal{F R O T E Z M} / \mathcal{I M}$. Os conjuntos de casos de teste utilizados também foram os mesmos utilizados no experimento anterior (Seção 3.2.3).

Os dados colctados e a análise sobre eles aplicada são descritos a seguir.

\subsubsection{Coleta e Análise dos Dados}

Para se estabelecer uma estratćgia incremental de aplicação dos operadores de mutação, é preciso definir como classificá-los, por exemplo: por custo (númcro de mutantes gerados), por strength relativo, por eficácia, por número de mutantes equivalentes, por dificuldade de se matar os mutantes ou por uma combinação desses aspectos. No trabalho desenvolvido por Vincenzi et al. (2001) foi utilizada uma classificação baseada no cscore de mutação e no custo em termos do númcro de mutantes gerados. Este trabalho utiliza outra abordagem na qual o custo em termos do número de mutantes equivalentes e a dificuldade em distinguir os mutantes também é considerado. As estratégias aqui apresentadas classificam os operadores de mutação de acordo com o strength relativo, o número de mutantes equivalentes, custo de cada operador em relação ao número de mutantes gerados e a dificuldade de se distinguir mutantes de um determinado operador.

Sabe-se que, em geral, independentemente da qualidade dos conjuntos de casos de teste utilizados, 80\% dos mutantes gerados morrem na primeira execução (Budd et al., 1980). Assim sendo, cm torno de $20 \%$ dos mutantes gerados são os que contribuem efetivamente para a cficácia do critério. Procurou-se estabelecer uma ordenação parcial entre os operadores de mutação de modo que os operadores que geram mutantes dificeis de matar fossem aplicados primeiro.

Para isso, uma informação fundamental é a quantidade de mutantes que são mortos por uma determinada quantidade de casos de teste, identificando os opcradores que produzem mutantes 
dificeis de serem mortos. Considera-se que, um mutante é difícil de ser morto quando apenas uma pequena porcentagem dos casos de teste é capaz de distinguir seu comportamento do programa original. Para isso avaliou-se qual a relação entre o número de casos de teste executados e a porcentagem de mutantes mortos. A Tabela 4.1 apresenta parte desta informação coletada para um dos conjuntos de casos de teste AM-adequados do programa Cal. Por exemplo, considerando o operador Cccr, $14,83 \%$ dos mutantes mortos podem ser considerados difíceis de screm distinguidos pois, do conjunto de teste utilizado, no máximo $10 \%$ dos casos de teste são capazes de distinguir tais mutantes. Observa-se ainda que, no caso desse mesmo operador, $0,11 \%$ de seus mutantes morrem facilmente quando executados com qualquer caso de teste $((90 \%$ à $100 \%$ ] dos casos de teste). Já para o operador VSCR (última linha), 100\% de seus mutantes são considerados dificeis de serem mortos caracterizando esse operador como um operador que gera mutantes mais dificeis de serem distinguidos do que os mutantes gerados pelo operador cecr.

Tabela 4.1: Porcentagem de Casos de Teste Necessárias para Matar os Mutantes de cada Operador para um conjunto AM-adequado: Programa $\mathrm{Cal}$

\begin{tabular}{|c|c|c|c|c|c|c|c|c|c|c|}
\hline & \multicolumn{10}{|c|}{ Porcentagem de Casos de Teste (Indice de Mortalidade dos Mutantes) } \\
\hline Opt'r & {$[0-10]$} & $(10-20)$ & $(20-30)$ & $(30-40]$ & $(40-50]$ & $(50-60)$ & $(60-70)$ & $(70-80]$ & $(80-90)$ & $(90-100)$ \\
\hline Cecr & $14,83 \%$ & $11,38 \%$ & $33,91 \%$ & $14,37 \%$ & $8,51 \%$ & $5,17 \%$ & $11,72 \%$ & $0,00 \%$ & $0,00 \%$ & $0,11 \%$ \\
\hline $\operatorname{ccs} r$ & $20,37 \%$ & $1,56 \%$ & $32,50 \%$ & $11,35 \%$ & $11,20 \%$ & $5,75 \%$ & $17,26 \%$ & $0,00 \%$ & $0,00 \%$ & $0,00 \%$ \\
\hline CRCR & $15,90 \%$ & $0,00 \%$ & $30,26 \%$ & $9,74 \%$ & $10.26 \%$ & $7,18 \%$ & $26,67 \%$ & $0,00 \%$ & $0,00 \%$ & $0,00 \%$ \\
\hline . & & & $\ldots$ & .. & $\ldots$ & $\ldots$ & $\cdots$ & $\ldots$ & $\ldots$ & $\ldots$ \\
\hline $\mathrm{OABA}$ & $20,00 \%$ & $10.00 \%$ & $40,00 \%$ & $10.00 \%$ & $3.33 \%$ & $10,00^{\mathrm{1} \%} \%$ & $6,67 \%$ & $0,00 \%$ & $0,00 \%$ & $0,00 \%$ \\
\hline OAFA & $20,00 \%$ & $0.60 \%$ & $50,00 \%$ & $10,00 \%$ & $0,00 \%$ & $10.00 \%$ & $10,00 \%$ & $0,00 \%$ & $0,00 \%$ & $0,00 \%$ \\
\hline OBBN & $0,00 \%$ & $0,00 \%$ & $0,00 \%$ & $0,00 \%$ & $0,00 \%$ & $0,00 \%$ & $0,00 \%$ & $0,00 \%$ & $0,00 \%$ & $0,00 \%$ \\
\hline$\ldots$ & $\cdots$ & $\ldots$ & $\ldots$ & $\ldots$ & $\ldots$ & $\ldots$ & $\ldots$ & $\ldots$ & $\cdots$ & \\
\hline SCRn & $0,00 \%$ & $0,00 \%$ & $0.00 \%$ & $0,00 \%$ & $0,00 \%$ & $0,00 \%$ & $0,00 \%$ & $0,00 \%$ & $0,00 \%$ & $0.00 \%$ \\
\hline SMTC & $0,00 \%$ & $0,00^{6}, 6$ & $37,50 \%$ & $12,50 \%$ & $0,00^{0 \%}$ & $12,50 \%$ & $37,50 \%$ & $0,00^{\mathrm{w}} \mathrm{\sigma}$ & $0,00 \%$ & $0,00 \%$ \\
\hline SRSR & $9.47 \%$ & $8,42 \%$ & $21,05 \%$ & $5,26 \%$ & $10,53 \%$ & $5,26 \%$ & $37,89 \%$ & $0,00 \%$ & $0.00 \%$ & $2,11 \%$ \\
\hline$\cdots$ & $\cdots$ & . & & $\cdots$ & & & & & 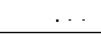 & \\
\hline Varr & $14,81 \%$ & $7.41 \%$ & $40,74 \%$ & $18,52 \%$ & $5,56 \%$ & $3,70 \%$ & $9,26 \%$ & $0,00 \%$ & $0,00 \%$ & $0,00 \%$ \\
\hline VDTR & $9.30 \%$ & $1,16 \%$ & $32,56 \%$ & $15,12 \%$ & $2,33 \%$ & $5,81 \%$ & $32,56 \%$ & $0.00 \%$ & $0,00 \%$ & $1,16 \%$ \\
\hline VSCR & $100.00 \%$ & $0,00 \%$ & $0,00 \%$ & $0,00 \%$ & $0,00 \%$ & $0,00 \%$ & $0,00 \%$ & $0,00 \%$ & $0,00 \%$ & $0,00 \%$ \\
\hline
\end{tabular}

A Tabela 4.1 foi gerada 11 vezes para cada programa c critério, correspondendo aos 11 conjuntos de casos de teste AM-adequados e Ml-adequados. Em seguida foi gerada a Tabela 4.2 contendo a média obtida para os 11 conjuntos de casos de teste existentes para cada programa.

Desse modo, considerando-se que para o estabelecimento das estratégias foram utilizados cinco programas, cinco tabelas sintetizando os resultados de cada programa foram geradas e a Tabela 4.3 apresenta a média obtida para os cinco programas.

Desse modo, utilizando tal informação, é possível classificar os operadores de mutação priorizando a aplicação daqueles que geram os mutantes mais dificeis de serem mortos pois, os casos de teste capazes de distinguir tais mutantes provavelmente serão capazes de distinguir mutantes gerados por outros operadores. Porćm, existem casos nos quais a distribuição de porcentagem de mutantes mortos não é trivial. Por exemplo, caso um operador tenha $50 \%$ dos 
Tabcla 4.2: Média para os 11 conjuntos AM-adequados: Programa Cal

\begin{tabular}{|c|c|c|c|c|c|c|c|c|c|c|}
\hline Oper & {$[0-1 \overline{0}]$} & $(10-20)$ & $\{20-30]$ & $(30-40)$ & & & & & & \\
\hline $\mathrm{cer}$ & $15,31 \%$ & $12,61 \%$ & $=\frac{1}{2068 \%}$ & $\frac{(30-40]}{24,450}$ & $(40-50\}$ & $(50-60)$ & $(60-70)$ & $(70-80]$ & $(80-90]$ & $(90-100]$ \\
\hline $\operatorname{Cost}$ & $20,37 \%$ & $2,77 \%$ & $20,54 \%$ & $-\frac{24,45 \%}{21.65 \%}-$ & $9,09 \%$ & $5,14 \%$ & $12,46 \%$ & $0,15 \%$ & $0,00 \%$ & $0,11 \%$ \\
\hline$C R C$ & $\overline{15.9} 0 \%$ & $1.18 \%$ & $19,79^{\circ}$ & $\frac{2,03 \%}{19,03 \%}$ & $\begin{array}{l}10.26 \% \\
470 \%\end{array}$ & $7.57 \%$ & 16. & $0,05 \%$ & 0,0 &, $00 \%$ \\
\hline & & & & $19,0.3 \%$ & 9,7 & $8,26 \%$ & $25,95 \%$ & $0,15 \%$ & $0,00 \%$ & $0,00 \%$ \\
\hline$O A B A$ & $0,67 \%$ & $10,67 \%$ & $26,67 \%$ & $20,00^{\circ}$ & & & & & & \\
\hline OAEA & $20,00 \%$ & $6,00 \%$ & $3 \overline{0,0}$ & 22,0 & $\frac{3,6 / \%}{6,00 \%}-$ & $\frac{9,35 \%}{6,000 \%}$ & $\frac{1000 \%}{1000 \%}$ & $0,00 \%$ & 0,0 & $0,00 \%$ \\
\hline$O B \overline{B N}$ & $0,00 \%$ & $0,00 \%$ & $0,00 \%$ & $0,00 \%$ & $0,00 \%$ & $0,00 \%$ & $\frac{10,00}{0,0]}$ & 0.0 & 0.0 & $0,00 \%$ \\
\hline & & & & & & & 0,0 & $0,00 \%$ & $0.00 \%$ & $0,00 \%$ \\
\hline $\mathrm{SCR}$ & $0 \%$ & 0.00 & $0,00^{\circ}$ & $0, \overline{00}$ & $0, \overline{00 \%}$ & $0,00 \%$ & & & & \\
\hline SMTC & $0,00 \%$ & $0,00 \%$ & $2 \overline{1,25 \%}$ & $26,25 \%$ & $10,00 \%$ & 5,0 & 0,06 & & 0,0 & $0,00 \%$ \\
\hline SRSR & $10,21 \%$ & $7.68 \%$ & $13,16 \%$ & 16,21 & & $\frac{3,50 \%}{4.53 \%}$ & 37,5 & 0,0 & 0,0 & $0.00 \%$ \\
\hline & & & & & $7,20 \%$ & $4,53 \%$ & $-38,42$ & 0.42 & $0,00 \%$ & $2,11 \%$ \\
\hline Varr & $15,93 \%$ & $+8 \%$ & 5.7 & 31,4 & 9 & 3, & $9,26^{\circ}$ & & & \\
\hline VDT & $9,77^{\circ}$ & $.70 \%$ & 20.23 & & 4,4 & 4,8 & 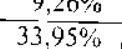 & 0,00 & 0,0 &, $00 \%$ \\
\hline VSCR & $9,33 \%$ & $0,00 \%$ & $0.00 \%$ & $0,00 \%$ & $0,0, \overline{0}$ & $0, \overline{O 0 \%}$ & $\frac{33,95 \%}{0,00 \%}$ & $0,00 \%$ & $\frac{0,00 \%}{0,00 \%}$ & $1.16 \%$ \\
\hline
\end{tabular}

Tabela 4.3: Média da Porcentagem de Casos de Teste Necessárias para Matar os Mutantes de cada Operador: 5 Programas

\begin{tabular}{|c|c|c|c|c|c|c|c|c|c|c|}
\hline & \multicolumn{10}{|c|}{ Porcentagem de Casos de Teste (Indice de Mortalidade dos Mutantes) } \\
\hline Oper & {$[0-10]$} & $(10-20)$ & $(20-30]$ & $(30.40]$ & $(40-50)$ & $(50-60]$ & $(60-70)$ & $(70-80)$ & $(80-90)$ & $(90.100)$ \\
\hline $\mathrm{Cecr}$ & $15,76 \%$ & $11,03 \%$ & $26.59 \%$ & $14.97 \%$ & $12,34 \%$ & $4,40 \%$ & $8,73 \%$ & $4.20 \%$ & $0,66 \%$ & $1,31 \%$ \\
\hline Cesr & $17,71 \%$ & $8,14 \%$ & $2 \overline{8,80} \%$ & $14,90 \%$ & $10, \overline{01 \%}$ & $5,11 \%$ & $8,78 \%$ & $4, \overline{68 \%}$ & $0,58 \%$ & $1,30 \%$ \\
\hline $\mathrm{CRCR}$ & $13,69 \%$ & $8,32 \%$ & $25, \overline{50 \%}$ & $15,44 \%$ & $9,26 \%$ & $8, \overline{59 \%}$ & $10,87 \%$ & $5,50 \%$ & $1,48 \%$ & $1,34 \%$ \\
\hline$\ldots$ & - & & & & - & & $\therefore$ & & $\ldots$ & \\
\hline ()ABA & $17,14 \%$ & $8,57 \%$ & $37,14 \%$ & $1,43 \%$ & $2,86 \%$ & $11,43 \%$ & $5, \overline{71} \%$ & $0,00 \%$ & $2,86 \%$ & $2,86 \%$ \\
\hline$\overline{\mathrm{OAFA}}$ & $16,67 \%$ & $0.00 \%$ & $41.67 \%$ & $16.67 \%$ & $8,33 \%$ & $8,33 \%$ & $8,33 \%$ & $0,00 \%$ & $0,00 \%$ & $0.00 \%$ \\
\hline $\mathrm{OBBN}$ & $42,86 \%$ & $0,00 \%$ & $0,00 \%$ & $0,00 \%$ & $0,00 \%$ & $57.14 \%$ & $0,00 \%$ & $0,00 \%$ & $0, \overline{00 \%}$ & $0,00 \%$ \\
\hline$\cdots$ & $\ldots$ & $=$ & $\cdots$ & & & & $\overline{-1}$ & & & \\
\hline$S C R n$ & $0,00^{1 \%} \%$ & $0,00 \%$ & $0,00 \%$ & $0,00 \%$ & $100,00 \%$ & $0,00 \%$ & $0, \overline{00 \%}$ & $0,00 \%$ & $0,00 \%$ & $0,00 \%$ \\
\hline SMTC & $18,75 \%$ & $12,50 \%$ & $25,00 \%$ & $6, \overline{25 \%}$ & $6,25 \%$ & $12,50 \%$ & $18, \overline{75} \%$ & $0,00 \%$ & $0,00 \%$ & $0,00 \%$ \\
\hline SRSR & $9,76 \%$ & $7,16 \%$ & $16.49 \%$ & $18,00 \%$ & $12,15 \%$ & $12,58 \%$ & $14,75 \%$ & $6,72 \%$ & $0.43 \%$ & $1,95 \%$ \\
\hline$\ldots$ & & $\ldots$ & $\ldots$ & $\ldots$ & & & & & & $\cdots$ \\
\hline Varr & $12,65 \%$ & $7,83 \%$ & $27,71 \%$ & $20, \overline{48 \%}$ & $1,3,25 \%$ & $8, \overline{43} \%$ & $4,22 \%$ & $5, \overline{42 \%}$ & $0,00 \%$ & $0,00 \%$ \\
\hline VLTTR & $14,60 \%$ & $6,21 \%$ & $20,81 \%$ & $14,291 / 1$ & $4,97 \%$ & $6,83 \%$ & $13,66 \%$ & $7,76 \%$ & $4, \overline{35 \%}$ & $6,52 \%$ \\
\hline VSCR & $43,90 \%$ & $2,44 \%$ & $4,88 \%$ & $7,32 \%$ & $2,44 \%$ & $17,07 \%$ & $7,32 \%$ & $9,76 \%$ & $0,00 \%$ & $4,8 \%$ \\
\hline
\end{tabular}

seus mutantes mortos classificados na primeira coluna ((0-10]) e os outros $50 \%$ na última coluna ((90-100]), e um outro operador tenha $40 \%$ dos seus mutantes na primeira coluna e o restante $(60 \%)$ na segunda coluna ((10-20]), qual desses operadores de mutação geram mutantes mais dificeis de sercm mortos? Uma alternativa para responder essa pergunta é utilizar um modelo estatístico, no caso, o modclo adotado foi o modelo de ordem estocástica descrito a seguir.

\subsubsection{Modelo de Ordem Estocástica}

Ncsta seção é apresentado o modelo estatístico utilizado para ordenar os operadores de mutação com relação a geração de mutantes mais dificeis de serem mortos. Na Tabela 4.4 é apresentada a nomenclatura utilizada para definição desse modelo cstatístico que está descrito em (McCullagh \& Nelder, 1990), onde: 
- $y_{i j}$ : representa a quantidade de mutantes do operador $i$ que estão na categoria Al, A2,...,An (Tabela 4.4); c

$$
i=1, \ldots, n \text { e } j=1, \ldots, k
$$

- $m_{i}$ : representa a quantidade de mutantes gerados pelo operador $i$.

Tabela 4.4: Definições para Aplicação do Algoritmo

\begin{tabular}{|c|c|c|c|c|c|c|c|}
\hline & \multicolumn{7}{|c|}{ Categorias } \\
\hline Operadores & Al & $A 2$ & $A \overline{3}$ & $A 4$ & $\ldots$ & $A n$ & Mutantes \\
\hline$\frac{1}{3}$ & $y / 11$ & $y_{12}$ & $y_{13}$ & $-y_{1 \cdot 1}$ & .. & $y_{1 k}$ & $m_{1}$ \\
\hline 2 & $y_{21}$ & 322 & $y_{23}$ & $y \cdot 1$ & $\cdots$ & $y_{2 k}$ & $m_{2}$ \\
\hline$\cdots$ & $\cdots$ & $\cdots$ & $\cdots$ & $\because$ & $\ldots$ & $\ldots$ & $\ldots$ \\
\hline $\mathrm{n}$ & $\underline{y_{n 1}}$ & $t_{r_{1} \cdot 2}$ & $y_{n: 3}$ & $y_{n \leq 1}$ & $\ldots$ & $y_{n k}$ & $m_{k:}$ \\
\hline
\end{tabular}

Considere:

$\pi_{i j}$ : probabilidade de um mutante do operador $i$ estar na categoria $j$.

$$
\gamma_{i j}=\pi_{i 1}+\pi_{i 2}+\ldots+\pi_{i j}
$$

$\gamma_{i j}$ : é a probabilidade do mutante ser detectado até a categoria $j$, ou seja, será o somatório da probabilidade desse mutante estar na primeira categoria $\left(\pi_{i 1}\right)$ até a categoria $j\left(\pi_{i j}\right)$.

Ncste caso, temos o seguinte modelo logístico linear:

$$
\log \frac{\gamma_{i j}}{1-\gamma_{i j}}=\Theta_{j}+\beta_{i}
$$

O modelo logístico 4.1 nos dá a relação entre a probabilidade acumulada e os parâmetros $\Theta_{j}$ e $\beta_{i}$ onde $\Theta_{j}$ está relacionado com o categoria e $\beta_{i}$ está relacionado como operador de mutação.

Os parâmetros $\Theta_{j}$ tem pouco interesse e são conhecidos como "cut points" no modelo logístico. O parâmetro da regressão $\beta_{i}$ descreve como o log "odds" está rclacionado com os operadores (covariáveis). Se tomarmos, como excmplo, dois operadores $i_{1}$ e $i_{2}$, obtemos que:

$$
\log \frac{\gamma_{i_{1} j}}{1-\gamma_{i_{1 j} j}}-\log \frac{\gamma_{i_{2 j}}}{1-\gamma_{i_{2 j} j}}=\beta_{i_{1}}-\beta_{i_{2}}=\Delta
$$

Desde que, a função logística é monótona crescente, obtemos que:

$$
\begin{aligned}
& \gamma_{i_{1 j}}>\gamma_{i_{2 j} j} \text { para } \Delta>0 \quad\left(\beta_{i_{1}}>\beta_{i_{2}}\right) \\
& \gamma_{i_{1} j}<\gamma_{i_{2} j} \quad \text { para } \quad \Delta<0 \quad\left(\beta_{i_{1}}<\beta_{i_{2}}\right)
\end{aligned}
$$


Desta forma, quanto maior o $\beta_{i}$ mais mutantes do operador $i$ estão nas categorias iniciais, tornando os mutantes desse operador mais dificeis de serem mortos.

\section{Estimador da Máxima Verossimilhança}

O método da máxima verossimilhança é um procedimento geral para obtermos cstimativas (aproximações) de parâmetros desconhecidos no nosso modelo.

Ao propormos o modelo logístico (Equação 4.I) temos como parâmetros as constantes $\theta_{j} \mathrm{e}$ $\beta_{i}(j=1, \ldots, k$ e $i=1, \ldots, n)$. Diferentes métodos podem ser utilizados para estimar (aproximar) os valores destes parâmetros, sendo que cada método utiliza uma avaliação apropriada. No método da máxima verossimilhança a funçâo de avaliação é definida pela probabilidade do operador $i$ apresentar $y_{i 1}$ mutantes na categoria $A_{1}, y_{i 2}$ mutantes na categoria $A_{2}$ e assim por diante. Essta função de avaliação é denominada verossimilhança. Aqui, queremos encontrar os estimadores (função dos dados) que maximizam a verossimilhança.

A seguir, vamos descrever a verossimilhança via a distribuição multinomial. Esta distribuição descreve a probabilidade do operador $i(i=1, \ldots, n)$ apresentar $y_{i j}$ mutantes na categoria $j$ para $(j=1, \ldots, k)$. Para maximizar a verossimilhança, vamos derivá-la e igualá-la a zero. A fim de determinarmos o zero da derivada da verossimilhança, utilizamos o mćtodo de Newton-Raphson (McCullagh \& Nelder, 1990) modificado apresentado na Seção 4.1.2.1.

Distribuição Multinomial

$$
\begin{gathered}
y_{i}=\left(y_{i 1}, \ldots, y_{i_{k}}\right) \mathrm{e} \\
P\left[Y_{i 1}=y_{i 1} ; \ldots ; Y_{i k}=y_{i k}\right]=\frac{m_{i} !}{y_{i 1} ! \ldots y_{i k} !}\left(\pi_{i 1}\right)^{y_{i 1}} \ldots\left(\pi_{i k}\right)^{y_{i k}} \quad \text { onde } i=1, \ldots, n
\end{gathered}
$$

A contribuição da distribuição multinomial $Y_{i}$ para a função da verossimilhança é dada por:

$$
\left(\pi_{i 1}\right)^{3 / 1} \ldots\left(\pi_{i k}\right)^{y_{i k}}
$$

Como estamos lidando com as probabilidades acumuladas, tomamos:

$$
\begin{gathered}
r_{i 1}=y_{i 1} \quad z_{i 1}=\frac{r_{i 1}}{m_{i}} \\
r_{i 2}=y_{i 1}+y_{i 2} \quad z_{i 2}-\frac{r_{i 2}}{m_{i}}
\end{gathered}
$$




$$
r_{i k}=-y_{i 1}+y_{i 2}+\ldots+y_{i k} \quad z_{i k}=-\frac{r_{i k}}{m_{i}}
$$

Assim a função de verossimilhança pode ser escrita, na forma:

$$
\begin{gathered}
\left\{\left(\frac{\gamma_{i 1}}{\gamma_{i 1}}\right)^{r_{i 1}}\left(\frac{\gamma_{i 2}-\gamma_{i 1}}{\gamma_{i 2}}\right)^{r_{i 2}-r_{i 1}}\right\} *\left\{\left(\frac{\gamma_{i 2}}{\gamma_{i 2}}\right)^{r_{i 2}}\left(\frac{\gamma_{i 3}-\gamma_{i 2}}{\gamma_{i 3}}\right)^{r_{i 3}-r_{i 2}}\right\} * \ldots \\
\ldots *\left\{\left(\frac{\gamma_{i(k-1)}}{\gamma_{i k}}\right)^{r_{i(k-1)}}\left(\frac{\gamma_{i k}-\gamma_{i(k-1)}}{\gamma_{i k}}\right)^{\left.r_{2 k}-r_{i(k-1)}\right\}}\right.
\end{gathered}
$$

Se tomarmos,

$$
\begin{gathered}
\Phi_{i j}=\log \frac{\gamma_{i j}}{\gamma_{i(j+1)}-\gamma_{i j}} ; \\
g\left[\Phi_{i j}\right]=\log \left\{1+\exp \left(\Phi_{i j}\right\}=\log \frac{\gamma_{i(j+1)}}{\gamma_{i(j,-1)}-\gamma_{j}}\right.
\end{gathered}
$$

Então, o log-verossimilhança é dado por:

$$
\rho_{i}=n\left[\left(z_{i 1} * \Phi_{i 1}-z_{i 2} * g\left(\Phi_{i 1}\right)\right)+\left(z_{i 2} \Phi_{i 2}-z_{i 3} g\left(\Phi_{i 2}\right)\right)+\ldots+\left(z_{i(k-1)} \Phi_{i(k-1)}-g\left(\Phi_{i(k-1)}\right)\right)\right]
$$

\subsubsection{Algoritmo Matemático de Newton Raphson}

Para maximizar a verossimilhança foi aplicado o algoritmo de Newton Raphson (McCullagh, 1989) modificado, utilizando o software estatístico S-Plus ${ }^{1}$. As Tabelas 4.5 c 4.6 apresentam a classificação dos operadores após a aplicação do algoritmo proposto onde os operadores foram ordenados de forma decrescentc pelo coeficiente $\beta$ quc, como dito anteriormente, quanto maior, mais difícil os mutantes gerados por aquele operador de serem distinguidos. O coeficiente $P$ refere-se ao comportamento do operador em relação ao opcrador utilizado como ponto de relerencia, que no caso dos operadores de unidade foi o opcrador Cccr e para integração foi o operador I - CovAl 1Edg. Ao estimarmos os parâmetros $\beta_{i}$ utilizando um operador $i *$ como referência, fazemos testes de hipótcse entre $\beta_{i} \mathrm{c} \beta_{i *}$, ou seja, testamos:

$$
H_{0}: \beta_{i *}=\beta_{i}
$$

\footnotetext{
'S-PLUS é um ambiente integrado (software) para manipulação, cálculo e exibição de dados (Krause \& Olson,
} 


$$
H_{j}: \beta_{i *} \neq \beta_{i}
$$

Se o coeficiente $P$ for "pequeno", digamos abaixo de $0,05(5 \%)$, rejeitamos a hipótese $H_{0}$, ou seja, cxiste uma diferença significativa entre estes operadores. Por outro lado, se o coeficiente $P$ for "alto", digamos acima de $0,05(5 \%)$, não rejeitamos a hipótese $H_{(1)}$, ou scja, não existe uma diferença significativa entre estes operadores de mutação.

Quanto mais o coeficiente $P$ for próximo de zero, mais parecido o comportamento do operador com o ponto de referência, ou seja, quando maior $P$ maior é a diferença de comportamento do opcrador em relação ao ponto de referência.

Tabela 4.5: Aplicação do Algoritmo de Newton Raphson: Operadores de Unidade

\begin{tabular}{|c|c|c|c|c|c|}
\hline Operadores & $\begin{array}{r}\text { Numero de } \\
\text { Mutantes }\end{array}$ & Coeficiente $(\beta)$ & Coeficiente P & $\begin{array}{r}\text { Mutantes } \\
\text { Equivalentes } \\
\end{array}$ & $\begin{array}{r}\text { Mutantes } \\
\text { Q-Equivalentes } \\
\end{array}$ \\
\hline $\mathrm{OLSN}$ & 54 & $0,80 \overline{38 \overline{8}}$ & 0,001 & 1 & 0 \\
\hline$O B N G$ & 15 & 0,70462 & 0.140 & 1 & 0 \\
\hline$O B A N$ & 25 & $0,5 1 7 \longdiv { 1 2 }$ & 0,194 & 0 & 5 \\
\hline VSCR & 43 & $0,271 \overline{12}$ & $0,33 !$ & $i$ & 1 \\
\hline $\mathrm{OA} \overline{\mathrm{BA}}$ & 36 & 0,14162 & 0,638 & 1 & 0 \\
\hline VIWD & 422 & $0, \sqrt{0536}$ & 0,286 & 19 & 4 \\
\hline $\mathrm{OAEA}$ & 12 & $0,07 \overline{435}$ & $0, \overline{884}$ & 0 & 0 \\
\hline ORIN & 206 & $0,04 \overline{245}$ & 0,753 & 18 & 3 \\
\hline OBBN & 10 & 0.04026 & $0, \overline{952}$ & 0 & $\overline{3}$ \\
\hline OASA & 24 & 0,02625 & 0,942 & 0 & 0 \\
\hline $\operatorname{cosr}$ & $13 \overline{93}$ & $0,0 2 \longdiv { 1 0 7 }$ & $0, \overline{746}$ & 3 & 1 \\
\hline SMTS & 33 & 0,02105 & 0,946 & 1 & 0 \\
\hline Cecr & 1676 & 0.00000 & 0,000 & 55 & 98 \\
\hline ORSN & 196 & -0.02368 & $\overline{0.872}$ & 35 & 3 \\
\hline OILN & 27 & $-0,03102$ & 0.927 & 0 & 0 \\
\hline$\overline{O A A A}$ & 50 & $-0,05848$ & 0,817 & 0 & 0 \\
\hline$O A B N$ & 123 & $-0,06369$ & 0,707 & 6 & 2 \\
\hline Viart & 169 & $-0,09962$ & $0, \overline{487}$ & 3 & 0 \\
\hline$\cdots$ & $\cdots$ & $\because$ & $\ldots$ & $\cdots$ & $\cdots$ \\
\hline V1rr & 0 & $-3,00000$ & 0,00 & 0 & $\overline{0}$ \\
\hline
\end{tabular}

Com o objetivo de estabelecer uma estratégia de aplicação dos operadores de mutação que se aproxime do resultado ideal, para cada programa deve ser gerada uma tabela contendo as seguintes informações:

- Operadores: nome do operador de mutaçâo $o p_{i} ;$ I indica a linha do operador na tabela.

- Escore de mutação atual (EM): Em $k$ é o escore de mutação, em relação ao conjunto total de mutantes, obtido pelo conjunto de casos de teste $\left(T=T o p_{1} \cup T o p_{2} \cup \ldots \cup T o p_{k-1}\right.$ $\left.\cup T o p_{k}\right)$. Top ${ }_{i}$ denota o conjunto de casos de teste que é adequado ao operador $i$;

- Incremento (Inc): diferença entre o escore de mutação atual e o anterior $\left(I n c_{i}=E M_{i}\right.$. $\left.E M_{i-1}\right)$; 
Tabela 4.6: Aplicação do Algoritmo de Newton Raphson: Opcradores de Interface

\begin{tabular}{|c|c|c|c|c|c|}
\hline Operadores & $\begin{array}{r}\text { Nimero de } \\
\text { Mutanies }\end{array}$ & Coeficiente (B) & Coeficiente $P$ & $\begin{array}{r}\text { Mutantes } \\
\text { Equivalentes } \\
\end{array}$ & $\begin{array}{r}\text { Mutantes } \\
\text { Q-Equivalentes }\end{array}$ \\
\hline Ii-AigStcDif & 43 & $0.98 \overline{383}$ & 0,001 & 0 & $=\overline{0}$ \\
\hline T-DirVarkepCon & 1380 & 0,53901 & 0,000 & 76 & 11 \\
\hline I-IndVarRepCon & 2555 & $0.4892 \mathrm{~S}$ & 0,000 & 283 & 62 \\
\hline II-ArgSicAIi & 21 & $0,4707 \overline{0}$ & 0.308 & 3 & 3 \\
\hline 1-DirVir RepLoc & 488 & 0.38730 & 0,002 & 29 & 5 \\
\hline I-DirVarRepPar & 385 & 0,37858 & 0,004 & 44 & $\overline{4}$ \\
\hline Il-ArgAriNeg & 26 & 0.57096 & 0,297 & 0 & 0 \\
\hline II-ArgBitNeg & 26 & $0 . \overline{37096}$ & 0,297 & 0 & 0 \\
\hline II-ArgLogNeg & 26 & 0,37096 & 0,297 & 0 & 0 \\
\hline 1-DirVar AriNeg & 154 & 0,36545 & $0,05 \overline{6}$ & 41 & 4 \\
\hline I-DirVarBitNeg & 154 & $0, \overline{27528}$ & 0,117 & 14 & 3 \\
\hline J-DirVarRepRea & 770 & $0, \overline{25742}$ & $\overline{0,023}$ & $7 !$ & 8 \\
\hline 1-DirVarLogNeg & $15 \overline{4}$ & $0,25 \overline{17}$ & 0,139 & 13 & 0 \\
\hline [-IndVarkepLoc & 618 & 0,21029 & 0.077 & 61 & 16 \\
\hline I-Dirvarinclece & 536 & 0,15278 & 0,207 & 31 & $\overline{10}$ \\
\hline I-IndVarAriite & 306 & 0,14298 & $0.36 !$ & 108 & 8 \\
\hline $11-\wedge \mathrm{rg} \overline{\mathrm{DCl}}$ & 92 & 0,13367 & $0, \overline{513}$ & 0 & 0 \\
\hline [-Cov $\Lambda \mathrm{IINod}$ & 438 & 0,12103 & 0,335 & 20 & 0 \\
\hline II-AgglncDec & 200 & 0,07677 & 0,627 & 2 & $1 \overline{3}$ \\
\hline !-DirVarRepGlo & 170 & 0,06369 & 0,711 & 25 & 0 \\
\hline I-IndVarIncDec & 684 & 0,04481 & 0,764 & 64 & 21 \\
\hline 1-IndVarRepl & 672 & $0,0 \overline{0333}$ & $0, \overline{977}$ & 73 & 15 \\
\hline I-COVAllEdg & 390 & 0,00000 & 0.000 & 30 & 0 \\
\hline [-DirVarRepExt & 494 & $-0,00885$ & $0,9 \overline{43}$ & 32 & 2 \\
\hline I-ind VarkepRey & $139 !$ & $-0,01200$ & 0,909 & 162 & 46 \\
\hline$\ldots$ & $\cdots$ & $\ldots$ & $\ldots$ & $\cdots$ & $\ldots$ \\
\hline 1-RetStaRep & 42 & -0.46987 & $0,0 \overline{99}$ & 0 & 0 \\
\hline
\end{tabular}

- Custo Cumulativo (CC): número de mutantes gcrados pela aplicação dos $k$ primeiros operadores, ou seja, a soma do número de mutantes gerados $C_{i}$ de cada operador $i$ até a aplicação do operador $h_{i}\left(C C_{k}=\sum_{i=1}^{k} C_{i}^{\gamma}\right)$;

- Redução de Custo (RC): porcentagem da redução do número de mutantes ( $R C_{i}=1-$ $\left.\left(\frac{C C_{k}}{\sum_{k-1}^{n} C_{k}}\right) * 100,1 \leq n \leq|O P|\right)$;

- Custo Cumulativo de Equivalentes(CCE): número de mutantes equivalentes gerados pela aplicação dos $k$ primeiros operadores, ou seja, soma-se o númcro de mutantes equivalentes $\left(C E_{i}\right)$ de cada operador $i$ até a aplicação do operador $k\left(C C E_{k}=: \sum_{i=1}^{k} C L_{i}\right)$;

- Redução de Custo de Equivalentes(RCE): porcentagem da redução do número de mutantes equivalentes $\left(R C E_{i}=1-\left(\frac{C C E_{i}}{\sum_{i=1}^{n} C F_{k}}\right) * 100,1 \leq n \leq|O P|\right)$.

Por exemplo, na Tabela 4.7 são apresentadas as informações acima coletadas para um conjunto de casos de teste AM-adequado do programa Cal. Essa tabela foi gerada 11 vezes para se obter a média referente a um único programa.

Observe que o incremento proporcionado com a seleção dos casos de teste de cada operador varia. Incremento zero indica que o operador em questão não está agregando nenhum caso de teste novo ao conjunto $T$, ou seja, o operador está sendo incluido pelos operadores aplicados anteriormente. Desse modo, ordenar a Tabela 4.7 pelo incremento faz com que somente 
Tabela 4.7: Dados Coletados para um Conjunto de Casos de Teste AM-adequado: Programa Cal.

\begin{tabular}{|c|c|c|c|c|c|c|}
\hline Operadores & $E M$ & $\operatorname{Inc}$ & $\mathrm{CC}^{\prime} \mathrm{C}$ & $R C$ & $C \overline{C E}$ & $R C E$ \\
\hline OLSN & $0, \overline{5428204}$ & 0,5428204 & $\overline{8}$ & $99.82 \%$ & $\overline{0}$ & $100,00 \%$ \\
\hline $\mathrm{OA} \overline{\mathrm{B} \wedge}$ & $0,9 \overline{238920}$ & $0,3 \times 107 \overline{16}$ & 38 & $90,12 \%$ & 0 & $100,00 \%$ \\
\hline SMTC & $0,92,38920$ & 0,0000000 & 46 & $98,94 \%$ & 0 & $100,00 \%$ \\
\hline ()BNG & 0.9238920 & 0,0000000 & 46 & $98 . \overline{94 \%}$ & 0 & $100,00 \%$ \\
\hline STR! & $0,9718 \overline{389}$ & 0.0479469 & 70 & $98,38 \%$ & 0 & $100,00 \%$ \\
\hline SSWM & 0,9771362 & 0,0052973 & 73 & $98,31 \%$ & 0 & $100,00 \%$ \\
\hline SWDD & $0 . 9 7 7 \longdiv { 1 3 6 2 }$ & 0.0000000 & 75 & $98,27 \%$ & 0 & $100,00 \%$ \\
\hline OASN & $0,9 \overline{783812}$ & $0,0 0 1 \longdiv { 2 4 5 0 }$ & 135 & $96.88 \%$ & 0 & $100,00 \%$ \\
\hline Varr & 0,9784038 & 0,0000226 & 191 & $95.59 \%$ & 2 & $99,37 \%$ \\
\hline$O \mathrm{OKN}$ & 0,9903335 & $0,0 1 \longdiv { 9 2 9 7 }$ & 215 & $95.04 \%$ & 5 & $98,42 \%$ \\
\hline$\overline{\text { SMVB }}$ & 0,9903335 & 0.0000000 & 218 & $94,97 \%$ & 5 & $98,42 \%$ \\
\hline$O A \triangle A$ & 0,9903335 & 0,0000000 & 259 & $94,02 \%$ & $\overline{5}$ & $98,42 \%$ \\
\hline VTWD & 0,9974192 & 0.0070857 & 383 & $91,16 \%$ & 15 & $95,25 \%$ \\
\hline Oido & 0,9974192 & 0,0000000 & 398 & $90,81 \%$ & 15 & $15,25 \%$ \\
\hline ORLY & $0,99 \overline{74192}$ & 0,0000000 & $4 \overline{2}$ & $89.80 \%$ & 15 & $95,25 \%$ \\
\hline Vsir & 0.9095698 & 0.0021506 & 833 & $80,77 \%$ & 25 & $92,09 \%$ \\
\hline $\mathrm{SSDL}$ & 0,9995698 & $0,0 \overline{000000}$ & 934 & $78,44 \%$ & 32 & $89,87 \%$ \\
\hline $\mathrm{OEBA}$ & 0,9995698 & 0.0000000 & 1015 & $76,57 \%$ & 60 & $81,01 \%$ \\
\hline$\overline{O R R N}$ & 0,9995698 & 0,0000000 & 1125 & $74,03 \%$ & 73 & $76,90 \%$ \\
\hline Cesr & 0,9995925 & 0,0000227 & 1770 & $59,14 \%$ & 75 & $76,27 \%$ \\
\hline SRSR & 0.9995925 & 0.0000000 & $1 \times 70$ & $56,83 \%$ & 80 & $74,68 \%$ \\
\hline ORAN & 0,9995925 & 0,0000000 & 1980 & $54,29 \%$ & 91 & $71,20 \%$ \\
\hline VDTR & 0,9998415 & 0,0002490 & 2166 & $50,00 \%$ & 191 & $39,56 \%$ \\
\hline ORBN & 0.9498415 & 0,0000000 & 2232 & $48,48 \%$ & 197 & $37,66 \%$ \\
\hline $\mathrm{Cecr}$ & 1,0000000 & 0,0001585 & 3171 & $26,80 \%$ & 266 & $15,82 \%$ \\
\hline VSCR & 1,0000000 & 0,0000000 & 3187 & $26,43 \%$ & 267 & $15.51 \%$ \\
\hline$\cdots$ & & $\ldots$ & $\ldots$ & $\cdots$ & $\ldots$ & \\
\hline Vtrr & 1,0000000 & 0,0000000 & 4332 & $0.00 \%$ & 316 & $0,00 \%$ \\
\hline
\end{tabular}

operadores que realmente contribuem para a melhoria no escore de mutação sejam considerados. Sempre que os operadores de mutação são reordenados, essa avaliação deve ser repetida. $\mathrm{O}$ processo termina quando todos os operadores de mutação estiverem ordenados de forma decrescente a partir de seu incremento. Porém, se simplesmente ordenarmos os opcradores pelo seu incremento, deixaríamos de analisar a questão do número de mutantes gerados e equivalentes de cada operador. Para isso foram definidas duas estratégias que são apresentadas a seguir.

\subsection{Estratégias para Aplicação dos Operadores de Mu- tação Considerando o Número de Mutantes Equi- valentes}

Visto que os opcradores que não produzem incremento foram incluídos pelos demais, estes podem ser descartados, reduzindo o custo de aplicação da estratégia. Alćm disso, foi definida una relação denominada SEC (Score-Equivalent-Cost) quc procura priorizar a aplicação dos operadores que proporcionam o maior incremento c possui o menor custo em termos do número de mutantes gerados e do número de mutantes equivalentes como representado abaixo: 


$$
S E C_{i}=\left(\frac{\frac{I H C_{i}}{\left(C C_{i}-C C_{i-1}\right)}}{\left(C C_{i}-C C_{i-1}\right)}\right)
$$

A idéia das estratégias é reordenar os operadores até que se obtenha uma ordem decrescente segundo a relação $S E C$ (última coluna da Tabela 4.8). As estratćgias para o teste de unidade e para o teste de integração são denominadas Estochastical-Score-Equivalent-Cost Incremental Unit Testing Strategy (ESECUS) e Estochastical-Score-Equivalent-Cost Incremental Interface Testing Strategy (ESECIS), respectivamente. A definição e aplicação dessas estratégias são apresentadas a seguir.

\subsubsection{Estratégia ESECUS: Teste de Unidade}

A estratégia ESECUS estabelece uma classificação para aplicação dos operadores de mutação para o teste de unidade. Fstabelecida a classificação primária, apresentada na Seção 4.1.2, a Tabela 4.8 ilustra o primeiro passo da aplicação incremental desses operadores, onde pode-se observar na terceira linha, que o conjunto de caso de teste OBAN-adequado determina um escore de mutação (coluna $E M$ ) de 0,7908126 que representa um incremento em relação ao escore anterior (coluna Inc) de 0,0005356. O custo cumulativo em termos do númcro de mutantes gerados (coluna $C C$ ) é de 94 mutantes. Como o custo do critério Análise de Mutantes aplicando-se todos os 71 operadores é de 12834 mutantes, a utilização de apenas 3 operadores (OLSN, OBNG e OBAN) gcrou 94 mutantes, o que representa um redução de custo (coluna $R C$ ) de 99,27\%. Considerando o número de mutantes equivalentes, o custo cumulativo (coluna $C C E$ ) é de 7 mutantes e a redução de custo no númcro de equivalentes (coluna $R C E$ ) é de 99,40\%. Dessa forma, os demais operadores de mutação foram aplicados um a um até que um conjunto de caso de teste adequado à Análise de Mutantes (AM-adequado) fosse obtido.

De acordo com a primeiro passo da estratégia ESECUS, 45 operadores de unidade são necessários para se obter um conjunto de teste AM-adequado, o que representa uma redução de custo de 6,94\% em termos de número de mutantes gerados e $9,12 \%$ em termos de mutantes equivalentes. Porém, vale destacar que alguns desses operadores não produzem incremento no escore de mutação. Por exemplo, o operador OAEA (sétima linha) foi incluído pelos operadores aplicados anteriormente (OLSN, OBNG, OBAN, VSCR, OABA E VTWD).

Para o conjunto de operadores apresentado na Tabela 4.8 foram necessárias mais sete reordenações até que a estratégia final fosse obtida (Tabela 4.9). Analisando-se a Tabela 4.9, observa-se que todos os operadores estão ordenados de forma decrescente pela coluna $S E C$. Desejando-se obter um conjunto de teste AM-adequado, 25 operadores são necessários, 20 operadores a menos do que cram necessários no primeiro passo (Tabela 4.8), e a redução de 
Tabela 4.8: Aplicação da Estratégia ESECUS: Primciro Passo

\begin{tabular}{|c|c|c|c|c|c|c|c|}
\hline Operadores & $E M$ & $\operatorname{Inc}$ & $C C$ & $R C$ & $C C E$ & $R C E$ & $S E C$ \\
\hline OLSN & 0.77048806 & 0,7704806 & 54 & $99,58 \%$ & 1 & $99,91 \%$ & 142,6815926 \\
\hline OBNG & 0,7902770 & 0,0197964 & 69 & $99,46 \%$ & 2 & $99,83 \%$ & 13,1976000 \\
\hline$O B A N$ & 0.7908126 & 0,0005356 & 94 & $99.27^{1 \%}$ & 7 & $99,40 \%$ & 0,0428480 \\
\hline VSCR & 0,8102240 & $0,0194 ! 14$ & 137 & $98,93 \%$ & 9 & $99,23 \%$ & 2,2571395 \\
\hline OABA & 0,8808572 & 0.0706332 & 173 & $98,65 \%$ & 10 & $99.14 \%$ & 19,6203333 \\
\hline VTWD & $0.9638950^{\circ}$ & 0,0830378 & 595 & $95,36 \%$ & 33 & $97,16 \%$ & 0,0855531 \\
\hline OAEA & 0,9638950 & 0,0000000 & 607 & $95,27 \%$ & 33 & $97,16 \%$ & 0,0000000 \\
\hline ORLN & 0,9793578 & 0,0154628 & 813 & $93,67 \%$ & 54 & $95,35 \%$ & 0,0357439 \\
\hline$O B B N$ & 0,9793578 & 0,0000000 & 823 & $93,59 \%$ & 57 & $95,09 \%$ & 0,0000000 \\
\hline OASA & 0.9793578 & 0,0000000 & 847 & $93,40 \%$ & 57 & $95,09 \%$ & 0,0000000 \\
\hline Cesr & 0.9824258 & 0,0030680 & 2240 & $82,55 \%$ & 61 & $94,75 \%$ & 0,0055061 \\
\hline SMTC & 0,9839276 & 0,0015018 & 2273 & $82,29 \%$ & 62 & $94,66 \%$ & 0,4550909 \\
\hline $\mathrm{Cecr}$ & 0,9010342 & 0,0071066 & 3949 & $69,23 \%$ & 215 & $81,50 \%$ & 0,0002771 \\
\hline ORSN & $0,99 \overline{10342}$ & 0,0000000 & 4145 & $67.70 \%$ & 253 & $78,23 \%$ & 0,0000000 \\
\hline OLLN & 0,9910342 & 0,0000000 & 4172 & $67.49 \%$ & 253 & $78,23 \%$ & 0,0000000 \\
\hline$O A \wedge A$ & 0,9910948 & 0,0000606 & 4222 & $67,10 \%$ & 253 & $78,23 \%$ & 0,0121200 \\
\hline $\mathrm{OAB} \mathrm{X}$ & $0,99 \overline{10948}$ & $0,0000000^{-}$ & 4345 & $66,14 \%$ & 261 & $77.54 \%$ & 0,0000000 \\
\hline Varr & 0,9915596 & 0,0004648 & 4514 & $64.83 \%$ & 264 & $77,28 \%$ & 0,0091677 \\
\hline SSWM & 0,9915714 & 0,0000118 & 4537 & $64.65 \%$ & 265 & $77.19 \%$ & 0,0051304 \\
\hline OASN & 0.9916598 & 0,0000884 & 4619 & $64,01 \%$ & 266 & $77.11 \%$ & 0.0107805 \\
\hline Vsrr & 0,9961092 & 0,0044494 & 6240 & $51,38 \%$ & 300 & $74,18 \%$ & 0,0008073 \\
\hline ORBN & 0,9961784 & 0,0000692 & 6534 & $49,09 \%$ & 355 & $69,45 \%$ & 0,0000428 \\
\hline SMVB & 0,9962788 & 0,0001004 & 6563 & $48,86 \%$ & 358 & $69,19 \%$ & 0,0115402 \\
\hline()$\wedge \wedge N$ & 0,9962788 & 0,0000000 & 6745 & $47,44 \%$ & 359 & $69.10 \%$ & 0.0000000 \\
\hline OALN & 0,9902788 & 0,0000000 & 6835 & $46,74 \%$ & 360 & $69,02 \%$ & 0,0000000 \\
\hline CRCR & 0,9963166 & 0,0000378 & 7586 & $40,89 \%$ & 366 & $68,50 \%$ & 0.0000839 \\
\hline SSDL & 0.9968792 & 0,0005626 & 8032 & $37,42 \%$ & 384 & $66.95 \%$ & 0.0007008 \\
\hline OEBA & 0.9973250 & 0,0004458 & 8287 & $35,43 \%$ & 465 & $59.98 \%$ & $0.000215 \overline{8}$ \\
\hline OESA & 0.9973250 & 0,0000000 & 8457 & $34,10 \%$ & $47 !$ & $59.47 \%$ & 0,0000000 \\
\hline OBSN & 0,9973250 & 0,0000000 & 8467 & $34,03 \%$ & 472 & $59,38 \%$ & 0,0000000 \\
\hline OARN & 0.9973250 & 0,0000000 & 8737 & $31,92 \%$ & 475 & $59.12 \%$ & 0,0000000 \\
\hline ORRN & 0.9977312 & 0,0004062 & 9252 & $27,91 \%$ & $54 !$ & $53,44 \%$ & 0,0001195 \\
\hline ()RAN & 0,9979434 & 0,0002122 & 9742 & $24,09 \%$ & 602 & $48,19 \%$ & 0,0000710 \\
\hline OBRN & 0.9979434 & 0,0000000 & 9772 & $23,86 \%$ & 603 & $48,11 \%$ & 0,0000000 \\
\hline OBLL & 0,9979434 & 0,0000000 & 9782 & $23,78 \%$ & 605 & $47,93 \%$ & 0,0000000 \\
\hline SDWD & 0.9979434 & 0,00000000 & 9784 & $23,76 \%$ & 605 & $47.93 \%$ & 0.00000000 \\
\hline OLRI & 0,9985446 & 0,0006012 & 9946 & $22,50 \%$ & 615 & $47,07 \%$ & 0.0037111 \\
\hline Oido & 0.9986158 & 0,0000712 & 10037 & $21,79 \%$ & 618 & $46.82 \%$ & 0,0026081 \\
\hline VDTR & $0, \overline{9998134}$ & 0,0011976 & 10670 & $16,86 \%$ & 929 & $20,05 \%$ & 0.0000608 \\
\hline SRSR & 0,9999044 & 0,0000910 & 11154 & $13.09 \%$ & 952 & $18,07 \%$ & 0.0000817 \\
\hline Vpre & 0,9999044 & 0,0000000 & 11259 & $12.27 \%$ & 953 & $17,99 \%$ & 0,0000000 \\
\hline SWDD & 0,9999798 & 0,0000754 & 11277 & $12,13 \%$ & 955 & $17,81 \%$ & 0,0209444 \\
\hline$O \overline{O E A}$ & 0,9999798 & 0,0000000 & 11702 & $8.82 \%$ & 1.025 & $11.79 \%$ & 0,0000000 \\
\hline OLBN & 0,9999798 & 0,0000000 & 11783 & $8,19 \%$ & 1.055 & $9,21 \%$ & 0,0000000 \\
\hline STRI & 1,0000000 & 0,0000202 & 11943 & $6,94 \%$ & 1.056 & $9,12 \%$ & 0,0012625 \\
\hline$\ldots$ & $\ldots$ & & $\ldots$ & $\cdots$ & $\ldots$ & & $\cdots$ \\
\hline Vurr & 1,0000000 & $0,0000000^{\circ}$ & 12834 & $0,00 \%$ & 1.162 & $0,00 \%$ & 0,0000000 \\
\hline
\end{tabular}

custo foi de $27,09 \%$ e $24,44 \%$, em termos de número de mutantes gerados e número de mutantes equivalentes, respectivamente. Usando somente 15 operadores, um escore de mutação superior a 0,99 é obtido com uma redução de custo em termos de número de mutantes gerados de $87,92 \%$ e de $93,80 \%$ em relação ao número de mutantes cquivalentes.

\subsubsection{Estratégia ESECIS: Teste de Integração}

Considerando o teste de integração, o mesmo processo descrito anteriormente foi realizado para definir a estratégia $E S E C I S$, considerando os 33 operadores implementados na ferramenta 
Tabela 4.9: Aplicação da Lstratégia ESECUS: Último Passo

\begin{tabular}{|c|c|c|c|c|c|c|c|}
\hline Operadores & $E M$ & Inc & $C C$ & $R C$ & $C C E$ & $R C E$ & $S E C$ \\
\hline OLSN & 0,7704806 & 0.7704806 & 54 & $99,58 \%$ & 1 & $99, \overline{1 \%}$ & 142,6815926 \\
\hline OABA & 0,8505766 & 0,0800960 & 90 & $90,30 \%$ & 2 & $99,83 \%$ & 22,2488889 \\
\hline SMTC & 0,9075436 & 0.0569670 & 123 & $99,04 \%$ & 3 & $99,74 \%$ & 17,2627273 \\
\hline OBNG & 0,9185092 & 0,0109656 & 138 & $98.92 \%$ & 4 & $99,66 \%$ & 7,3104000 \\
\hline STRI & 0,9669142 & 0,0484050 & 298 & $97,68 \%$ & 5 & $99.57 \%$ & 3,0253125 \\
\hline SSWM & 0,9701248 & 0,0032106 & 321 & $97,50 \%$ & 6 & $99,48 \%$ & 1,3959130 \\
\hline SWDD & 0,9708530 & 0,0007282 & 339 & $97,36 \%$ & 8 & $99,31 \%$ & 0,2022778 \\
\hline OASN & 0,9717226 & 0,0008696 & 421 & $96,72 \%$ & 9 & $99,23 \%$ & $0,1060488^{\circ}$ \\
\hline Varr & 0,9750402 & 0.0033176 & 590 & $95,40 \%$ & 12 & $98,97 \%$ & 0.0654359 \\
\hline OLRN & 0,9823772 & 0,0073370 & 752 & $94,14 \%$ & 22 & $98,11 \%$ & 0,0452901 \\
\hline SMVB & 0.9826386 & 0.0002614 & $78 \overline{1}$ & $93.91 \%$ & 25 & $97,85 \%$ & 0,0300460 \\
\hline$O \wedge \Lambda \Lambda$ & 0,9826892 & 0.0000506 & 831 & $93,53 \%$ & 25 & $97,85 \%$ & 0,0101200 \\
\hline VTWD & 0,9893484 & 0,0066592 & 1253 & $90,24 \%$ & 48 & $95.87 \%$ & 0.0068609 \\
\hline Oido & 0.9894788 & 0,0001304 & 1344 & $89,53 \%$ & 51 & $95,61 \%$ & 0,0047766 \\
\hline ORLN & 0,9905128 & 0,0010340 & 1550 & $87,92 \%$ & 72 & $93,80 \%$ & 0,0023902 \\
\hline VSIr & 0.9970402 & 0,0065274 & 3171 & $75,29 \%$ & 100 & $90,88 \%$ & $0,001] 843$ \\
\hline SSDL & 0,9975146 & 0,0004744 & 3617 & $71.82 \%$ & 124 & $84,33 \%$ & 0,0005909 \\
\hline OEBA & 0,9981108 & 0.0005962 & 3872 & $69,83 \%$ & 205 & $82,36 \%$ & 0,0002886 \\
\hline ORRN & 0,9985798 & 0,0004640 & 4387 & $65,82 \%$ & 271 & $76,68 \%$ & 0,0001380 \\
\hline Ciss & 0,9986372 & 0,0000574 & 5780 & $54,96 \%$ & 275 & $76,33 \%$ & 0,0001030 \\
\hline SRSR & 0,9987282 & 0,0000910 & 6264 & $51,19 \%$ & 298 & $74,35 \%$ & 0,0000817 \\
\hline ORAN & 0.9989404 & 0.0002122 & 6754 & $42,44 \%$ & 670 & $42,34 \%$ & 0,0000480 \\
\hline ORBN & 0,9999558 & 0,0000696 & 7681 & $40,15 \%$ & 725 & $37,61 \%$ & 0,0000430 \\
\hline Cecr & 1.0000000 & 0,0000442 & 9357 & $27,09 \%$ & 878 & $24,44 \%$ & 0,0000017 \\
\hline
\end{tabular}

PROTEM/IM. No primeiro passo da aplicaçào da estratégia, 32 operadores foram necessários para obter um conjunto Ml-adequado e a redução de custo em termos do número de mutantes gerados foi de $0,30 \%$, não obtendo redução de custo em relação ao número de mutantes equivalentes, como mostra a Tabela 4.10.

Os operadores de integração, sofreram cinco rcordenações até que a estratégia final fosse estabelecida. O resultado é apresentado na Tabela 4.11. Nota-se que um conjunto de casos teste IM-adequado é obtido aplicando-se 19 opcradores, 13 operadores a menos dos que foram necessário no primeiro passo, reduzindo o custo em $16,91 \% \mathrm{~cm}$ termos do número de mutantes gerados e $20.48 \%$ cm relação ao número de mutantes equivalentes. Com 6 operadores de mutação un escore superior a 0,99 é obtido com uma redução de custo de 78,32\% e 86,53\% em relação ao número de mutantes gerados e equivalentes, respectivamente.

De fato, existem várias formas de estabclecer uma ordem de aplicação dos opcradores de mutação para o teste de unidade e integração ou para selecionar um subconjunto de operadores que mantenha as características mínimas exigidas para a aplicação do teste baseado em mutação. Uma abordagem promissora é a determinação de um conjunto de operadores de mutação essencial. Um conjunto essencial de operadores de mutação pode ser definido como um subconjunto $S C$ de operadores de mutação de forma que, conseguindo-se um conjunto de teste $T$ capaz de distinguir os mutantes gerados pelos operadores de $S C$ (conjunto $T S C$-adequado), $T$ ' seja capaz de distinguir, idealmente, todos os mutantes não equivalentes gerados pelo conjunto total de operadores de mutação definido. 
Tabela 4.10: Aplicação da Estratégia ESECIS: Primeiro Passo

\begin{tabular}{|c|c|c|c|c|c|c|c|}
\hline Operadores & $E M$ & Inc & $C C$ & $R C$ & $C C E$ & $R C E$ & $S E C$ \\
\hline$I I-\Lambda r_{b} S t c l$ if & 0,3141262 & 0.3141262 & 43 & $99,69 \%$ & 0 & $100,00 \%$ & 73,0526047 \\
\hline I-DirVarRepCon & 0,9546916 & 0,6405654 & 1423 & $89,85 \%$ & 87 & $94,79 \%$ & 0,0533538 \\
\hline 1-IndVarRepCon & 0,9854254 & 0,0307338 & 3978 & $71,63 \%$ & 432 & $74,13 \%$ & 0,0003487 \\
\hline II-ArgStcAli & 0,9854254 & 0,0000000 & $3999^{\circ}$ & $71,48 \%$ & 438 & $73,77 \%$ & 0.0000000 \\
\hline 1-I)irVarRepLoc & 0.9860472 & 0.0006218 & 4487 & $68,00 \%$ & 472 & $71,74 \%$ & $0,00037 \overline{48}$ \\
\hline I-DirVarReplat & 0.9870268 & 0,0009796 & 4872 & $65,26 \%$ & 520 & $68,86 \%$ & 0,0005301 \\
\hline Il-ArgAriveg & 0,9871312 & 0.0001044 & 4898 & $65,07 \%$ & 520 & $68,86 \%$ & 0,0401538 \\
\hline II-ArgBitNeg & 0,9871312 & 0,0000000 & $4 \overline{924}$ & $64,89 \%$ & 520 & $68,86 \%$ & 0,0000000 \\
\hline II-ArglogNeg & 0,9871312 & 0.0000000 & $4950^{\circ}$ & $64,70 \%$ & 520 & $68,86 \%$ & 0,0000000 \\
\hline 1-DirVarAriNeg & 0,9871312 & $0,0000000^{\circ}$ & 5104 & $63,61 \%$ & 565 & $66,17 \%$ & 0,0000000 \\
\hline I-DirVarBitNeg & 0,9871758 & 0,0000446 & 5258 & $62.51 \%$ & 582 & $65,15 \%$ & 0,0001704 \\
\hline [-DirVarRepReq & 0,9871758 & 0,0000000 & 6028 & $57,02 \%$ & 661 & $60,42 \%$ & 0,0000000 \\
\hline 1-DirVarLogNeg & $0,987 \overline{1758}$ & 0,0000000 & 6182 & $55,92 \%$ & 674 & $59,64 \%$ & 0,0000000 \\
\hline I-Ind VarRepLoc & 0.9914516 & 0,0042758 & 6800 & $51.51 \%$ & 751 & $55,03 \%$ & 0.0008985 \\
\hline I-I)irvarlneloec & 0,9940118 & $0,002560) 2$ & 7336 & $47.60 \%$ & 792 & $52.57 \%$ & 0,0011650 \\
\hline I-IndVarAriNeg & 0,9940118 & 0,0000000 & 7642 & $45,51 \%$ & 908 & $45,63 \%$ & 0,0000000 \\
\hline II-^rgDel & 0,9940118 & 0.0000000 & 7734 & $44.85 \%$ & 908 & $45,63 \%$ & 0,0000000 \\
\hline I-CovAllNod & 0,9959582 & 0,0019464 & 8172 & $41,73 \%$ & 928 & $44,43 \%$ & 0,0022219 \\
\hline $11-\wedge$ rglncDec & $0,995 \overline{9582}$ & 0,0000000 & 8372 & $40,30 \%$ & 943 & $43,53 \%$ & 0,0000000 \\
\hline 1-J)irVarRepGilo & 0.9960932 & 0,0001350 & 8542 & $39,09 \%$ & 968 & $42,04 \%$ & 0,0003176 \\
\hline I-IndVarlncDec & 0,9963018 & 0,0002086 & 9226 & $34,21 \%$ & 1.053 & $36,95 \%$ & 0,0000359 \\
\hline I-IndVarRepl'ar & 0,9966648 & 0.0003630 & 9898 & $29,42 \%$ & 1.141 & $31,68 \%$ & 0,0000614 \\
\hline I-CovAlltidg & 0,4966772 & 0,0000124 & 10288 & $26,64 \%$ & 1.171 & $29,88 \%$ & 0,0000106 \\
\hline I-DirVarkepExt & 0,9975090 & 0,0008318 & 10782 & $23,12 \%$ & 1.205 & $27.84 \%$ & 0,0004952 \\
\hline I-IndVarRepkeq & 0,9975612 & 0,0000522 & 12173 & $13.20 \%$ & 1.413 & $15,39 \%$ & 0,0000018 \\
\hline I-IndVarBitNeg & 0,9975834 & 0,0000222 & 12479 & $11,02 \%$ & 1.451 & $13,11 \%$ & 0,0000191 \\
\hline [I-Fun( all]el & 0.9976452 & $0,0000618^{\circ}$ & 12733 & $9,21 \%$ & 1.480 & $11,38 \%$ & 0,0000839 \\
\hline 1-Ind VarLogNeg & 0.9976452 & 0,0000000 & 13039 & $7,02 \%$ & 1.519 & $9,04 \%$ & 0,0000000 \\
\hline 1-RetStaDel & 0,9976452 & 0.0000000 & 13104 & $6,56 \%$ & 1.531 & $8.32 \%$ & 0,0000000 \\
\hline 1-IndVarRepcilo & 0.9980332 & 0.0003880 & 13416 & $4,34 \%$ & 1.610 & $3,59 \%$ & 0,0001574 \\
\hline II-ArgRepReq & 0,9980332 & 0,0000000 & 13471 & $3.94 \%$ & 1.610 & $3,59 \%$ & 0.0000000 \\
\hline 1-IndVarkeptixl & 1,00000000 & $0.0019668^{\circ}$ & 13982 & $0,30 \%$ & 1.670 & $0,00 \%$ & 0,0006415 \\
\hline
\end{tabular}

Tabela 4.11: Aplicação da Estratégia ESLCIS: Último Passo

\begin{tabular}{|c|c|c|c|c|c|c|c|}
\hline Operadores & $E M$ & $\ln c^{2}$ & $C C$ & $R C$ & $C C E$ & $R C E$ & $S E C$ \\
\hline II-ArgStcDif & 0,3141262 & 0,3141262 & 43 & $99,69 \%$ & 0 & $100.00 \%$ & 73,0526047 \\
\hline Il-ArgAriNeg & $0 . 3 \longdiv { 1 7 9 1 7 2 }$ & 0,0037910 & 69 & $99,51^{\%} \%$ & 0 & $100,00 \%$ & 1,4580769 \\
\hline 1-DirVarRepCon & 0,9554886 & 0.6375714 & 1449 & $89,67 \%$ & 87 & $94,79 \%$ & 0,0531044 \\
\hline I-CovAllNod & 0,9746970 & 0,0192084 & 1887 & $86,54 \%$ & 107 & $93.59 \%$ & 0,0219274 \\
\hline 1-DirVarlncDec & 0,9840092 & 0,0093122 & 2423 & $82,72 \%$ & 148 & $91,14 \%$ & 0,0042374 \\
\hline I-IndVarRepL $\overline{o c}$ & 0,9942372 & 0,0102280 & 3041 & $78.32 \%$ & $22 \overline{5}$ & $86.53 \%$ & 0,0021494 \\
\hline I-IndVarRepFxt & 0,9974862 & 0,0032490 & 3552 & $74,67 \%$ & 285 & $82,93 \%$ & 0,0010597 \\
\hline I-JirVarRepGlo & 0,9975972 & 0,0001110 & 3722 & $73,46 \%$ & 310 & $81,44 \%$ & 0,0002612 \\
\hline l-DirVarRepLxt & 0,9980194 & 0,0004222 & 4216 & $69,94 \%$ & 344 & $79,40 \%$ & 0,0002514 \\
\hline 1-DirVarkepPar & 0,9983328 & 0,0003134 & 4601 & $67,19 \%$ & 392 & $76,53 \%$ & 0,0001696 \\
\hline I-IndVarRepGlo & 0,9987352 & 0,0004024 & 4913 & $64,97 \%$ & 471 & $71,80 \%$ & 0,0001633 \\
\hline I-IndVarkepPar & 0,9995338 & 0,0007986 & 5585 & $60,18 \%$ & 559 & $66,53 \%$ & 0,0001350 \\
\hline Il-FunCalDel & 0,9995956 & 0,0000618 & 5839 & $58,36 \%$ & 588 & $64,79 \%$ & 0,0000839 \\
\hline I-IndVarkitNeg & 0,9996850 & 0,0000894 & 6145 & $56.18 \%$ & 626 & $62.51 \%$ & 0,0000769 \\
\hline I-CovAllEdg & 0,9996974 & 0,0000124 & 6535 & $53,40 \%$ & 656 & $60,72 \%$ & 0,0000106 \\
\hline I-IndVarlnc Dec & 0,9997346 & 0,0000372 & 7219 & $48,52 \%$ & 741 & $55,63 \%$ & 0,0000064 \\
\hline I-DirVarRepl.oc & 0,9997420 & 0,0000074 & 7707 & $45,04 \%$ & 775 & $53,59 \%$ & 0,0000045 \\
\hline I-IndVarkepCon & 0,9999776 & 0,0002356 & 10262 & $26,83 \%$ & 1.120 & $32,93 \%$ & 0,0000027 \\
\hline I-IndVarRepReq & 1,0000000 & 0,0000224 & 11653 & $16,91 \%$ & 1.328 & $20,48 \%$ & 0,0000008 \\
\hline
\end{tabular}

Para determinação desse subconjunto, Barbosa (1998) definiu um procedimento chamado Essencial, que visa à determinação de um conjunto essencial de operadores de mutação. Em seu traballho Barbosa aplicou o procedimento nos operadores de mutação implementados na ferramenta Proteum, com o qual se obteve um conjunto essencial de operadores que determinavam 
um alto grau de adcquação em relação ao critério Análisc de Mutantes $(0,996)$ com uma redução de custo da ordem de 65\%. Para os programas 5-UNIX, em nível de unidade, o conjunto de operadores essenciais (AM-essencial) obtido foi:

1. SMTC - Multiple Trip continue;

2. SSDL - Statement Deletion;

3. OEBA - Plain by Bitwise Assignment Replacement;

4. ORRN - Relational Operator Replacement;

5. VTWD - Twiddle Mutations; e

6. VDTR - Domain Traps.

Com o objetivo de verificar se os mesmos resultados se confirmavam para os operadores de mutação de interface, Vincenzi (1998) aplicou o procedimento definido por Barbosa (1998) no contexto do teste de integração, utilizando os operadores implementados na ferramenta PROTEM $/ 2 M$ obtendo um escore de mutação de 0,998 com uma redução de custo de aproximadamente $73 \%$. O conjunto de opcradores essenciais para o teste de integração (Ml-essencial) para os programas 5-UNIX é:

1. ArgAriNeg - Inscrts Arithmetic Negation at Arguments;

2. COVA.1.1Node - Coverage of All Nodes;

3. DirVarBitNeg - Inserts Bit Negation at Interface Variable;

4. IndVarBitNeg - Inserts Bit Negation at Non Interface Variable;

5. IndVarRepGlob - Replaces Non Interface Variable by Set G;

6. IndVarRepExt - Replaces Non Interface Variable by Set E;

7. IndVarRepLoc - Replaces Non Interface Variable by Set L; e

8. IndVarRepReq - Replaces Non Interface Variable by Sct R.

Em relação à estratégia incremental de unidade definida na Seção 4.2.1 (Tabela 4.9), observa-se que, para obter um escore de mutação próximo a 0,998 , deveriam ser utilizados os 17 primeiros operadores e a redução de custo proporcionada scria em torno de $71,82 \%$, aproximadamente $10,23 \%$ a menos do que seria obtido com a utilização do conjunto essencial. Para 
a estratégia incremental de integração definida na Seção 4.2.2 (Tabela 4.11), os resultados obtidos são semelhantes, para se obter um escore de mutação próximo de 0,998 , deveriam ser utilizados os 8 primeiros operadores e a redução de custo scria em torno de $73,22 \%$, aproximadamente $9,68 \%$ a menos do que scria obtido com a utilização do conjunto essencial para o teste de integração. Desse modo, uma estratégia incremental que inicie com a aplicação dos operadores essenciais mostra-se melhor em termos de redução de custo do que as estratégias apresentadas nas Tabelas 4.9 e 4.11. Como, em geral, apenas a utilização dos conjuntos cssenciais não produziram conjuntos de casos de teste adequados, foi definida uma seqüência para a aplicação dos demais operadores baseada em uma relação entre escore de mutação, custo de aplicação em termos do número de mutantes gerados, custo $\mathrm{cm}$ termos do número de equivalentes e a dificuldade de se matar mutantes geradores por um determinado operador como nas estratégias ESECUS e ESECIS.

Assim sendo, nas próximas seções, as estratégias incrementais de aplicação dos operadores de mutação serão reavaliadas considerando que os operadores essenciais tenham prioridade em relação aos demais operadores.

\subsection{Estratégias para Aplicação dos Operadores de Mu- tação Priorizando os Operadores Essenciais}

Para estabelecer uma ordem inicial de aplicação dos opcradores de mutação, priorizando o conjunto de operadores AM-essencial e Ml-essencial, os operadores foram classificados da seguinte forma:

1. Operadores AM-essencial e Ml-essencial respeitando a ordem de aplicação incremental estabelecida pelo próprio procedimento Essencial (Barbosa, 1998); e

2. Demais operadores respeitando a ordem estabelecida nas Tabelas 4.5 e 4.6 , ou seja, operadores que geram mutantes mais dificcis de serem mortos.

As estratégias para o teste de unidade c para o teste de integração são denominadas Sufficient Estochastical-Score-Equivalent-Cost Incremental Unit Testing Strategy (SESECUS) e Sufficient Estochastical-Score-Equivalent-Cost Incremental Interface Testing Strategy (SESECIS), respectivamente, e são descritas a seguir.

\subsubsection{Estratégia SESECUS: Teste de Unidade}

Para garantir que os operadores do conjunto essencial sejam aplicados primeiro, somente os operadores não pertencentes a AM-essencial são reordenados de fornła decrescente pela relação 
$S E C$ definida na Seção 4.2. Novamente o processo termina quando todos os operadores não pertencentes ao conjunto AM-essencial estiverem ordenados de forma decrescente pela relação $S E C$. Para isso foram necessárias mais quatro itcrações e o resultado final obtido é apresentado na Tabela 4.12.

Tabela 4.12: Aplicação da Estratégia SESECUS: Último Passo

\begin{tabular}{|l|r|r|r|r|r|r|r|}
\hline Operadores & $E M$ & InC & $C C$ & $R C$ & $C C E$ & $R C E$ & $S E C$ \\
\hline \hline SMTC & 0,8275636 & 0,8275636 & 33 & $99,74 \%$ & 1 & $99,91 \%$ & 250,7768485 \\
\hline SSDL & 0,9663604 & 0,1387968 & 479 & $96,27 \%$ & 19 & $98,36 \%$ & 0,1728909 \\
\hline OEBA & 0,9705834 & 0,0042230 & 734 & $94,28 \%$ & 100 & $91,39 \%$ & 0,0020445 \\
\hline ORRN & 0,9893462 & 0,0187628 & 1249 & $90,27 \%$ & 166 & $85,71 \%$ & 0,0055201 \\
\hline VTWD & 0,9950028 & 0,0056566 & 1671 & $86,98 \%$ & 189 & $83,73 \%$ & 0,0058279 \\
\hline VDTR & 0,9974806 & 0,0024778 & 2304 & $82,05 \%$ & 500 & $56,97 \%$ & 0,0001259 \\
\hline OASN & 0,9980654 & 0,0005848 & 2386 & $81,41 \%$ & 501 & $56,88 \%$ & 0,0713171 \\
\hline SWDI & 0,9981408 & 0,0000754 & 2404 & $81,27 \%$ & 503 & $56,71 \%$ & 0,0209444 \\
\hline OLSN & 0,9982450 & 0,0001042 & 2458 & $80,85 \%$ & 504 & $56,63 \%$ & 0,0192963 \\
\hline Varr & 0,9986126 & 0,0003676 & 2627 & $79,53 \%$ & 507 & $56,37 \%$ & 0,0072505 \\
\hline Oido & 0,9987550 & 0,0001424 & 2718 & $78,82 \%$ & 510 & $56,11 \%$ & 0,0052161 \\
\hline OLRN & 0,9993938 & 0,0006388 & 2880 & $77,56 \%$ & 520 & $55,25 \%$ & 0,0039432 \\
\hline STRI & 0,9994142 & 0,0000204 & 3040 & $76,31 \%$ & 521 & $55,16 \%$ & 0,0012750 \\
\hline SRSR & 0,9995288 & 0,0001146 & 3524 & $72,54 \%$ & 544 & $53,18 \%$ & 0,0001029 \\
\hline Virr & 0,9998816 & 0,0003528 & 5145 & $59,91 \%$ & 578 & $50,26 \%$ & 0,0000640 \\
\hline ORBN & 0,9999512 & 0,0000696 & 5439 & $57,62 \%$ & 633 & $45,52 \%$ & 0,0000430 \\
\hline Cesr & 0,9999558 & 0,0000046 & 6832 & $46,77 \%$ & 637 & $45,18 \%$ & 0,0000083 \\
\hline Cecr & 1,0000000 & 0,0000442 & 8508 & $33,71 \%$ & 790 & $32,01 \%$ & 0,0000017 \\
\hline
\end{tabular}

Analisando-se a Tabela 4.12, um conjunto de casos de teste AM-adequado é obtido com a aplicação de 18 opcradores de mutação, 27 operadores a menos do que eram neccssários no primeiro passo e a redução de custo foi de $33,71 \%$ e $32,01 \% \mathrm{~cm}$ termos do número de mutantes gcrados e número de mutantes equivalentes, respectivamentc. Observa-se que com apenas 5 operadores de mutação, um escore superior a 0,995 é obtido com uma redução de custo em termos do número de mutantes gerados de $86,98 \%$ e de $83,73 \%$ em relação ao número de mutantes equivalentes.

Se comparado com a estratégia aplicada anteriormente para o teste de unidade (ESECUS), observa-se que SESECUS obteve uma maior redução de custo, tanto em termos do número de mutantes gerados $(6,62 \%)$ quanto $\mathrm{cm}$ tcrmos do número de mutantes equivalentes $(7,57 \%)$.

\subsubsection{Estratégia SESECIS: Teste de Integração}

No teste de integração (Tabela 4.13), observa-se que, para se obter um conjunto de casos de teste Ml-adequado, 16 operadores de mutação devem ser aplicados $\mathrm{c}$ a redução de custo obtida é de $25,96 \%$ e $24,67 \%$ em termos do número de mutantes gerados c mutantes equivalentes, respectivamente. Com a prioridade de aplicação do conjunto de operadores IM-essencial, uma maior redução, se comparado com a estratégia anterior ( $E S E C I S)$, é obtida, tanto em relação do número de mutantes gerados $(9,05 \%)$ quanto ao número de mutantes equivalentes $(4,19 \%)$. 
Tabela 4.13: Aplicação da Estratégia SESECIS: Último Passo

\begin{tabular}{|l|r|r|r|r|r|r|r|}
\hline Operadores & $E M$ & Inc & $C C$ & $R C$ & $C C E$ & $R C E$ & $S E C$ \\
\hline \hline II-ArgAriNeg & 0,2997898 & 0,2497898 & 26 & $99,81 \%$ & 0 & $100,00 \%$ & 115,3037692 \\
\hline I-CovAlINod & 0,8488350 & 0,5490452 & 464 & $96,69 \%$ & 20 & $98,80 \%$ & 0,6267639 \\
\hline I-DirVarBitNeg & 0,9086880 & 0,0598530 & 618 & $95,59 \%$ & 37 & $97,78 \%$ & 0,2286211 \\
\hline I-IndVarBitNeg & 0,9817834 & 0,0730954 & 924 & $93,41 \%$ & 75 & $95,51 \%$ & 0,0628615 \\
\hline I-IndVarRepGio & 0,9858078 & 0,0040244 & 1236 & $91,19 \%$ & 154 & $90,78 \%$ & 0,0016327 \\
I-IndVarRepExt & 0,9943990 & 0,0085912 & 1747 & $87,54 \%$ & 214 & $87,19 \%$ & 0,0028021 \\
\hline I-IndVarRepLoc & 0,9975594 & 0,0031604 & 2365 & $83,14 \%$ & 291 & $82,57 \%$ & 0,0006641 \\
\hline I-IndVarRepReq & 0,9981328 & 0,0005734 & 3756 & $73,22 \%$ & 499 & $70,12 \%$ & 0,0000198 \\
\hline I-DirVarRepExt & 0,9985340 & 0,0004012 & 4250 & $69,69 \%$ & 533 & $68,08 \%$ & 0,0002389 \\
\hline I-DirVarRepPit & 0,9958892 & 0,0003552 & 4635 & $66,95 \%$ & 581 & $65,21 \%$ & 0,0001922 \\
\hline I-IndVarRepPar & 0,9996448 & 0,0007556 & 5307 & $62,16 \%$ & 669 & $59,94 \%$ & 0,0001278 \\
\hline II-FunCalDel & 0,9997066 & 0,0000618 & 5561 & $60,35 \%$ & 698 & $58,20 \%$ & 0,00008339 \\
\hline I-DirVarRepGio & 0,9997312 & 0,0000246 & 5731 & $59,13 \%$ & 723 & $56,71 \%$ & 0,0000579 \\
\hline I-DirVarIncDec & 0,9998280 & 0,0000968 & 6267 & $55,31 \%$ & 764 & $54,25 \%$ & 0,0000440 \\
\hline I-CovAlIEdg & 0,9998404 & 0,0000124 & 6657 & $52,53 \%$ & 794 & $52,46 \%$ & 0,0600106 \\
\hline I-DirVarRepLoc & 0,9998478 & 0,0000074 & 7145 & $49,05 \%$ & 828 & $50,42 \%$ & 0,0000045 \\
\hline I-IndVarIncDec & 0,9998702 & 0,0000224 & 7829 & $44,17 \%$ & 913 & $45,33 \%$ & 0,0000039 \\
\hline I-IndVarRepCon & 1,0000000 & 0,0001298 & 10384 & $25,96 \%$ & 1.258 & $24,67 \%$ & 0,0000015 \\
\hline
\end{tabular}

Desejando-se atingir um escore de mutação superior a 0,99 são necessários somente 6 operadores de mutação obtendo uma redução de custo do número de mutantes gerados de $87,54 \%$ e de $87,19 \% \mathrm{~cm}$ relação ao número de mutantes equivalentes.

A seguir os resultados obtidos com a aplicação das 4 estratégias apresentadas são comparados com outras estratégias definidas por Vincenzi et al. (2001).

\subsection{Comparação com Outras Estratégias}

Para verificar o quanto as estratégias propostas foram satisfatórias, faz necessário a comparação destas com outras já definidas. As estratégias a serem comparadas são:

- SCUS e SCIS (Vincenzi et al., 2001) com as estratégias ESECUS e ESECIS; e

- SUS e SIS (Vincenzi et al., 2001) com as cstratégias SESECUS e SESEC'IS.

A primeira comparação, se deve pelo fato de ambas as estratégias não priorizarem a aplicação dos operadores de mutação essenciais. SCUS c SCIS levam em consideração apenas o incremento no escore de mutação que um conjunto de casos de teste adequado para um determinado operador tem sobre o conjunto de todos os outros operadores e o número de mutantes gerados por este operador. Já as estratégias ESECUS e ESECIS, além de considerar as características como o incremento e o número de mutantes gerados, clas priorizam a aplicação dos operadores que geram um menor número de mutantes equivalentes $\mathrm{c}$ os que são mais dificeis de serem mortos.

A segunda comparação se deve ao fato das estratégias priorizarem a aplicação dos operadores essenciais. Os dados utilizados para comparação entre essas estratégias são apresentados nas Tabelas 4.14 e 4.15 . 
Tabela 4.14: Conjunto de Casos de Teste Quase Adequado - (Escore de Mutação maior ou igual a 0,99 )

\begin{tabular}{|c|c|c|c|c|}
\hline \multicolumn{5}{|c|}{ Unidade } \\
\hline Estratégias & Custo Estratégia (CC) & Score $(E M)$ & Reduçâo Custo (RC) & Reduçâo Equivalentes (RCE) \\
\hline ESECUS & 1550 & 0,991 & $87,92 \%$ & $93,80 \%$ \\
\hline SCUS & 925 & 0.991 & $92,79 \%$ & $97.82 \%$ \\
\hline SWSECW & 1671 & 0,995 & $86.98 \%$ & $83,73 \%$ \\
\hline SUS & 1671 & 0,995 & $86.98 \%$ & $83,73 \%$ \\
\hline \multicolumn{5}{|c|}{ Interface } \\
\hline Estratégias & Custo Estratégia (CC) & Score $(E M)$ & Redução Custo (RC) & Redução Equivalentes (RCE) \\
\hline ESECIS & 3041 & 0.994 & $78,32 \%$ & $86.53 \%$ \\
\hline$S C / S$ & 1801 & 0,991 & $87,16 \%$ & $86,86 \%$ \\
\hline SESECIS & 1747 & 0,994 & $87,54 \%$ & $87,19 \%$ \\
\hline S/S & 1747 & 0,994 & $87,54 \%$ & $87.19 \%$ \\
\hline
\end{tabular}

Tabela 4.15: Conjunto de Casos de Teste Adequado - (Escore de Mutação igual a 1,00)

\begin{tabular}{|c|c|c|c|}
\hline \multicolumn{4}{|c|}{ Unidade } \\
\hline Estratégias & Custo Estratégia (CC) & Reduçâoo Custo (RC) & Redução Equivalentes (RCE) \\
\hline ESEC CSS & 9357 & $27,09 \%$ & $24,44 \%$ \\
\hline$S C U S$ & 8684 & $32,34 \%$ & $13,03 \%$ \\
\hline SESECLS & 8568 & $33,71 \%$ & $32,01 \%$ \\
\hline SUS & 7642 & $40,46 \%$ & $21,83 \%$ \\
\hline \multicolumn{4}{|c|}{ Interface } \\
\hline Estratégias & Custo Estratégia $(\bar{C} \bar{C})$ & Redução Custo (RC) & Redução Equivalentes ( $R C E$ ) \\
\hline ESLCIS & 11653 & $16,91 \%$ & $20,48 \%$ \\
\hline$S C I S$ & 10606 & $24,37 \%$ & $23,98 \%$ \\
\hline SESECIS & 10384 & $25,96 \%$ & $24,67 \%$ \\
\hline SiS & 10384 & $25,96 \%$ & $24,67 \%$ \\
\hline
\end{tabular}

Considerando o teste de unidade, para gerar conjuntos de testc que determinam escores de mutação superiores a 0,99 (Tabela 4.14), SCUS apresenta-se melhor que ESECUS tanto na redução do número de mutantes gerados quanto na redução do número de equivalentes: 4,87 e 4,02 pontos percentuais a mais do que ESLCUS, respectivamente. Para o teste de integração, SCIS obteve uma maior redução de custo que ESECIS em relação ao número de mutantes gerados ( $\mathrm{cm}$ torno de 9 pontos percentuais), entretanto, considerando-se o número de mutantes equivalentes, ESECIS e SCIS obtiveram praticamente a mesma redução de custo $(86 \%)$. Como pode ser observado na Tabela 4.14, os dados referentes as estratégias de unidade, SUS e SESECUS, e de integração, SIS e SESECIS, são idênticos visto que somente a aplicação dos operadores essenciais já determina escores de mutação superiores a 0,99.

Desejando-se obter conjuntos de teste adequados (Tabela 4.15) observa-se que SCUS determinou um menor custo no número de mutantes gerados, 5,25 pontos percentuais a mais que ESECUS. No que se refere ao número de mutantes equivalentes, ESECUS determinou uma redução de 24,44 c 11,41 pontos percentuais a mais que SCUS. Para a detcrminação de conjuntos de teste Ml-adequados, SCIS obteve uma maior redução de custo do que $E S E C I S, 7,46$ pontos percentuais a mais em termos do número de mutantes gerados e 3,5 pontos percentuais $\mathrm{cm}$ relação ao númcro de mutantes equivalentes. 
Em relação as estratégias que priorizam a aplicação dos operadores de mutação cssenciais, para o teste de unidade, SUS obteve uma maior redução $\mathrm{cm}$ termos do número de mutantes gerados, 6,75 pontos percentuais a mais que SESECUS. Porém, SESECUS obteve uma maior redução em rclação ao número de mutantes cquivalentes, 10,18 pontos percentuais a mais que SUS. Em relação ao teste de integração, ambas as estratégias definiram o mesmo subconjunto de operadores de mutação, ou seja, a redução tanto $\mathrm{em}$ relação ao número de mutantes gerados como ao número de mutantes equivalentes foram a mesma. Vale ressaltar que, apesar do subconjunto de operadores ser o mesmo a seqüencia de aplicação ć diferente.

Dc forma geral o que pode ser observado é que em nível de unidade ESECUS e SESECUS determinam uma maior redução no número de mutantes equivalentes do que SCUS e SUS para obtenção de conjuntos de casos de teste adequados. Por outro lado, SCUS e SUS são melhores no que se refere à redução de custo em termos do número dc mutantes gerados e na obtenção de conjuntos de casos de teste que determinam escores de mutação superiores a 0,99 .

Em nível de integração, observa-se que SCIS obteve melhor resultados que ESECIS nos dois aspectos, porém levando em consideração a prioridade de aplicação dos operadores essenciais, tanto SESECIS como SIS obtiveram os mesmos resultados. O fato de SCUS e SCIS apresentarem, em termos do número de mutantes equivalentes, uma maior redução de custo do que ESECUS e ESECIS se explica devida a primeira ordenação dos operadores de mutação para aplicação das estratégias ESECUS e ESECIS não considerarem o número de mutantes equivalentes.

Tendo cm vista que, cm geral, a execução dos mutantes é feita de forma automática c a análise dos mutantes vivos requerer a intervenção do testador, por ser o problema de determinar a cquivalência de um mutante uma questão indecidível, uma redução 11,41 pontos percentuais no número de mutantes equivalentes pode ser considerada mais significativa do que uma redução de 5,25 pontos percentuais no número de mutantes gerados, devido ao esforço requerido na análise dos mutantes vivos. Com isso pode-se concluir que as estratégias que priorizam a aplicação dos operadores de mutação essenciais são menos custosas que as demais, ou seja, SESECUS para o teste de unidade e SESECIS para o teste de integração foram as que apresentaram os mclhores resultados.

\subsection{Considerações Finais}

Neste capítulo, foram apresentadas algumas abordagens para a determinação de estratégias incrementais para aplicação dos operadores de mutação para o teste de unidade $c$ integração. Utilizando tais abordagens, inicialmente, uma seqüência de aplicação dos operadores foi estabelecida considerando os seguintes fatores: opcradores que determinavam o maior incremento no escore de mutação em relação aos demais, operadores que gcravam o menor número de mu- 
tantes e mutantes equivalentes e os operadores que geravam mutantes mais dificeis de serem mortos. Priorizando os operadores de mutação que correspondem as características acima citadas, a obtenção de conjuntos AM-adequado e MI-adequado, possibilitou uma redução de custo em termos do número de mutantes gerados de $27,09 \%$ e $16,91 \%$ e cm termos do número de mutantes equivalentes de $24,44 \%$ c $20,48 \%$, respectivamente.

$\Lambda$ partir dos conjuntos essenciais de operadores de mutação obtidos por Barbosa (1998) e Vincenzi et al. (2001), uma nova estratégia incremental de aplicação dos operadores foi estabelecida. Observou-se que, a estratégia que priorizou a aplicação dos operadores de mutação essenciais possibilitou uma melhor redução do custo tanto $\mathrm{cm}$ termos do número de mutantes gerados quanto $\mathrm{cm}$ tcrmos do número de mutantes equivalentes. Para o teste de unidade, a redução foi de 33,71\% e 32,01\% e para o teste de integração a redução foi de 25,96\% e 24,67\%, respectivamente. A partir dos resultados obtidos, demonstrou-se que somente a utilização dos conjuntos essenciais de operadores de mulação é suficiente para se construir conjuntos de casos de teste que determinam escores de mutação superiores a 0,99 .

No geral, resultados demonstram que podem existir inúmeros subconjuntos de operadores de mutação capazes de selecionar conjuntos de casos de teste adequados e, para se obter o melhor conjunto, o ideal seria que todas as combinações possiveis de operadores de mutação fossem consideradas. Entretanto, visto que o critério Análise de Mutantes possui 71 opcradores e o Mutação de Interface possui 33 operadores, o número de combinações que deveriam scr investigadas é de $2^{71}$ para o teste de unidade e $2^{33}$ para o teste de integração, o que dificulta tal análise devido ao alto custo computacional envolvido para a aplicação de todas as combinações possiveis.

As abordagens apresentadas procuram fornecer alternativas pragmáticas para selecionar conjuntos de operadores de mutação que possibilitam uma redução no custo de aplicação dos critérios e ainda assim a seleção de conjuntos de casos de teste adequados ou próximos da adequação para ambos os critérios. 


픈

\section{Conclusões e Trabalhos Futuros}

$\mathrm{O}$ OBJETIVO principal da atividade de teste é aumentar a confiabilidade e garantir a qualidade do software para que este seja liberado com o mínimo de erros possível. Essa atividade, no entanto, consome grande parte dos custos envolvidos durante o desenvolvimento e, apesar disso, não garante um produto completamente sem erros.

Um dos pontos fundamentais na atividade de teste é a necessidade de critérios de adequação que auxiliem no projeto de casos de teste, fornecendo indicação de sua qualidadc. Critćrios Funcionais, Estruturais e Baseados em Erros devem, sempre que possível, ser utilizados $\mathrm{em}$ conjunto, aumentando as chances de que possíveis defeitos possam ser revelados. Ressalta-se ainda a relevância de estudos empíricos, conduzidos no contexto de teste de software, para o estabelecimento de estratégias de teste de baixo custo e alta eficácia. Os resultados desses estudos motivam a transferência tecnológica de critérios de teste, emergentes no meio acadêmico, para ambientes comerciais e industriais.

Dois dos critérios de teste que têm se destacado devido à alta eficácia em revelar a presença de erros são o critério Análise de Mutantes e o critério Mutação de Interface. No entanto, ambos apresentam limitações de custo para sua aplicação. O primciro aspecto deste problema está diretamente relacionado com o grande número de mutantes que pode ser gerado mesmo para programas simples. O segundo aspecto restritivo quando ao custo de aplicação do critério refere-se ao esforço para a determinação dos mutantes equivalentes que, em geral, requer a intervenção do testador ou a elaboração de heurísticas. Assim, a definição de estratégias incrementais para aplicação dos operadores de mutação deve levar em consideração não somente 
aspectos de cobertura e eficácia mas também o custo associado à probabilidade de criação de mutantes equivalentes.

Neste trabalho foi aplicado um estudo analítico e empírico sobre os operadores de mutação implementados nas ferramentas Proteum e $\mathcal{T R O T E M} / \mathrm{DM}$, considerando os aspectos de equivalência. A partir dessa análise foram determinadas heurísticas para determinação de mutantes equivalentes tanto pela semântica do operador como para o domínio de aplicação. Também foi feita uma análise estatística sobre os operadores de mutação com o objetivo de fornecer guidelines ao testador para auxiliá-lo na atividade de análise dos mutantes vivos, ou seja, determinar quais operadores têm maior probabilidade de gerar mutantes equivalentes e quais aqueles que geram mutantes que morrem facilmente. Observou-se que, apesar de não ser uma regra geral, seis opcradores de mutação referentes ao teste de unidade e sete referentes ao teste de integração estão entre os 10 operadores mais custosos, tanto em termos do número de mutantes gerados quanto no número de mutantes equivalentes e q-equivalentes. Com isso, deve-se procurar aplicar opcradores menos custosos que incluam esses operadores.

Procurando reduzir o número de operadores de mutação e o número de mutantes equivalentes, foram estabelecidas, a princípio, duas estratégias de teste denominadas EstochasticalScore-Equivalent-Cost Incremental Unit Testing Strategy (ESECUS) e Estochastical-ScoreEquivalent-Cost Incremental Interface Testing Strategy (ESECIS), para aplicação dos critérios Análise de Mutantes c Mutação de Interface, respectivamente. Tais estratégias avaliam cada operador de mutação segundo os aspectos de escore de mutação, número de mutantes gerados e número de mutantes equivalentes estabelecendo uma ordem incremental para a aplicação dos mesmos, contribuindo para viabilizar a aplicação do Teste de Mutação tanto para o teste de unidade quanto de integração. Também foram estabelecias duas estratégias nas quais, além de considerar as características acima citadas, priorizou-se a aplicação dos operadores de mutação essenciais para aplicação da estratégia. Essas estratćgia foram denominadas Sufficient Estochastical-Score-Equivalent-Cost Incremental Unit Testing Strategy SESECUS) e Sufficient Estochastical-Score-Equivalent-Cost Incremental Interface Testing Strategy (SESECIS).

De um modo geral, para os programas utilizados, observou-se que as estratégias de teste permitem, mesmo utilizando um subconjunto dos operadores de mutação, determinar conjuntos de casos de teste adequados ao conjunto total de operadores com uma redução de custo acima de $16 \%$ (tanto em número de mutantes equivalentes como de mutantes gerados) para se obter um conjunto de casos de teste adequado. Além disso, reduções no custo da aplicação dos critérios superiores a 78\% podem ser obtidas para se atingir escores de mutação acima de 0,99 , diminuindo consideravelmente o número de mutantes gerados e o número de mutantes a serem analisados como é apresentado no Capítulo 4. 


\subsection{Contribuições}

Pode-se destacar como contribuições deste trabalho:

- Análise empírica dos operadores de mutação referentes aos critérios Análise de Mutantes e Mutação de Interface, avaliando o custo tanto em relação ao número de mutantes gerados como cm relação ao número de mutantes equivalentes;

- Coleta de dados sobre causas e padrões de equivalência de mutantes, fundamentais para o desenvolvimento de heurísticas que automatizem esse processo;

- Estabelecimento de heuristicas para determinação de mutantes equivalentes, facilitando a vida do testador na fase de análise dos mutantes vivos;

- Redução do custo de aplicação dos critérios Análise de Mutantes e Mutação de Interface, através da utilização de um subconjunto de operadores de mutação, contribuindo para a aplicação do critério em ambientes comerciais e industriais; e

- Adaptação do Modelo Matemático de Newton Raphson (McCullagh, 1989) para determinação dos operadores de mutação que geram mutantes difíceis de serem distinguidos;

- Produção de dados históricos a respeito dos critérios Análise de Mutantes e Mutação de Interface.

\subsection{Trabalhos Futuros}

Dentre as atividades que devem ser realizadas como continuidade deste trabalho, pode-se destacar:

- Reproduzir os experimentos apresentados neste trabalho em outros domínios de aplicação com o objetivo de obter informações mais abrangentes a respeito dos operadores de mutação de unidade c interface;

- Com base na análise aplicada para estabelecimento das estratégias definidas nesse trabalho, implementar e integrar às ferramentas Proteum e PROTZMM/LM algoritmos que determinam uma seqüência de aplicação dos opcradores de mutação, visando uma redução no custo de aplicação dos critérios;

- A partir dos dados coletados neste trabalho, implementar e integrar às ferramentas Proteum c PROTZMM/LM algoritmos que determinem automaticamente a equivalência de mutantes; 
- Reimplementar os operadores de mutação evitando a geração de mutantes que não comprometerá a eficácia dos critério Análise de Mutantes e Mutação de Interface, diminuindo assim o custo de aplicação dos mesmos; $\mathrm{c}$

- Redefinir os operadores cssenciais levando-se em consideração os mutantes equivalentes.

- Modificar e melhorar o algoritmo matemático utilizado para determinação dos operadores de mutação que geram mutantes difíceis de serem distinguidos procurando estabelecer uma melhor classificação dos opcradores.

- Nesse sentido, vem sendo desenvolvido um trabalho (Jorge et al., 2002a) no qual o algoritmo de Newton-Raphson, utilizado neste trabalho, será melhor adaptado ao problema em questão, procurando uma melhor classificação dos operadores de mutação. 


\section{Referências Bibliográficas}

Acree, A.; Budd, T.; Demillo, R.; Lipton, R.; Sayward, F. Mutation analysis. Rel. Téc. GIT-ICS-79/08, Georgia Institute of Technology, Atlanta, GA, 1979.

Agrawal, H.; Demillo, R. A.; Hathaway, R.; Hsu, W.; Krauser, E. W.; Martin, R. J.; MAThUR, A. P.; SPAFFORD, E. II. Design of mutant operators for the $C$ programming language. Rcl. Téc. SERC-TR41-P, Software Engineering Research Center, Purdue University, West Lafayette, IN, 1989.

BARBos^, E. F. Uma contribuição para a determinação de um conjunto essencial de operadores de mutação no teste de programas $C$. Dissertação de Mestrado, ICMC-USP, São Carlos SP, 1998.

Barbosa, E. F.; Maldonado, J. C.; Vincenzi, $\Lambda$. M. R. Towards the determination of sufficient mutant operators for C. Software Testing, Verification and Reliability, v. 11, n. 2, p. $113136,2001$.

BLDD, T. A. Mutation analysis: Ideas, example, problems and prospects, cáp. Computer Program Testing North-Holand Publishing Company, 1981.

Budd, T. A.; DeMillo, R. A.; Lipton, R. J.; SAyward, F. G. Theoretical and empirical studies on using program mutation to test the functional correcteness of programs. In: $7 \mathrm{th}$ ACM Symposium on Principles of Programming Languages, New York, NY, p. 220-233, 1980 .

Chaim, M. L. Poke-tool - uma ferramenta para suporte ao teste estrutural de programas baseado em análise de fluxo de dados. Dissertação de Mestrado, DCA/FEEC/UNICAMP, Campinas, SP, 1991.

Chol, B. J.; DeMillo, R. A.; Krauser, E. W.; Mathur, A. P.; Martin, R. J.; Offutt, A. J.; PAN, H.; SPAFrord, E. H. The mothra toolset. In: Twenty-Second Annual Hawaii International Conference on System Sciences, HI, 1989.

Cowari, P. A review of software testing. Infomation and Software Technology, v. 30, n. 3, p. $189-198,1988$. 
Delamaro, M. E. Proteum: Um ambiente de teste baseado na análise de mutantes. Dissertação de Mestrado, ICMC/USP, São Carlos - SP, 1993.

Delamaro, M. E. Mutação de interface: Um critério de adequação inter-procedimental para o teste de integraçấo. Tese de Doutoramento, Instituto de Física de São Carlos Universidade de São Paulo, São Carlos, SP, 1997.

Delamaro, M. E.; Maldonado, J. C. Uma visão sobre a aplicação da análise de mutantes. Rel. Téc. 133, ICMC/USP, São Carlos - SP, 1993.

Dilamaro, M. E.; Maldonado, J. C. Interface mutation: A case study. In: Workshop do Projeto de Validação e Teste de Sistemas de Operação, Águas de Lindóia - SP, p. 191-202, $1997 \mathrm{a}$.

DElamaro, M. L.; MALDONADO, J. C. Interface mutation: An approach to integration testing. In: Workshop do Projeto de Validação e Teste de Sistemas de Operação, Águas de Lindóia - SP. p. 177-189, 1997b.

Delamaro, M. E.; MALDONADO, J. C. Interface mutation: Assessing testing quality at interprocedural level. In: 19th International Conference of the Chilean Computer Science Society (SCCC'99), Ialca - Chile, p. 78-86, 1999.

Delamaro, M. E.; Maldonado, J. C.; Mathur, A. P. Proteum-a tool for the assesment of test adequacy for C programs - user's guide. Rel. Téc. SERC-TR168-P, Software Engineering Research Center, Purdue University, 1996.

Delamaro, M. E.; Maldonado, J. C.; Mathur, A. P. Interface mutation: An approach for integration testing. IEEE Transactions on Software Engineering, v. 27, n. 3, p. 228-247, 2001.

Delamaro, M. E.; Maldonado, J. C.; Vincenzi, A. M. R. Proteum/IM 2.0: An integrated mutation testing environment. In: Mutation 2000 Symposium, San Jose, CA, p. 124-134. 2000.

DEMILLO, R. A. Mutation analysis as a tool for software quality assurance. In: COMPSAC80, Chicago, IL, 1980.

Demili.o, R. A. Software testing and evaluation. The Benjamin/Cummings Publishing Company Inc, 1987.

DeMillo, R. A.; Gwind, D. S.; King, K. N.; McKraken, W. N.; Offutt, A. J. An extended overvicw of the mothra testing environment. In: Software Testing, Verification and Analysis, Banfr, Canadá, 1988.

DeMillo, R. A.; Lipton, R. J.; SAYward, F. G. Hints on test data selection: Help for the practicing programmer. IEEE Computer, v. 11, n. 4, p. 34 43, 1978.

DeMillo, R. A.; Mathur, A. P.; WoNG, W. E. Some critical remarks on a hierarchy of fault-detecting abilities of test methods. IEEE Transactions on Software Engineering, v. SE-21, n. 10, p. 858-860, 1995. 
DeMillo, R. A.; Offutt, А. J. Constraint based automatic test data generation. IEEE Transactions on Software Engineering, v. SE-17, n. 9, p. 900-910, 1991.

DeMillo, R. A.; Offutt, A. J.; Mathur, A.; Wong, E. Some critical remarks on a hierarchy of the fault-deteting ability of test methods. IEEE Transactions on Software Engineering, v. SE-21, n. 10, p. 858-863, 1993.

FABRri, S. C. P. F. A análise de mutantes no contexto de sistemas reativos: Uma contribuição para o estabelecimento de estratégias de teste e validação. Tese de Doutoramento, IFSCUSP, São Carlos - SP, 1996.

Fabbri, S. C. P. F.; Maldonado, J. C.; Masiero, P. C.; Delamaro, M. E. Análise de mutantes baseada em máquinas de estado finito. In: XI SBRC - Simpósio Brasileiro de Redes de Computadores, Campinas, SP, p. 407-425, 1993.

Fabbri, S. C. P. F.; Maldonado, J. C.; Masiero, P. C.; Delamaro, M. E. Mutation analysis testing for finite state machines. In: 5th International Symposium on Soffware Reliability Engineering (ISSRE'94), Monterey - CA, p. 220-229, 1994.

FAbrri, S. C. P. F.; Maldonado, J. C.; Masiero, P. C.; Delamaro, M. E. Mutation analisys applied to validate specifications based on petri nets. In: FORTE'95 - 8th IFIP Conference on Formal Descriptions Techniques for Distribute Systems and Communication Protocols, Montreal, Canadá, p. 329-337, 1995.

Fondazzı, L. A. Estudo de técnicas de teste de regressão baseado em mutação seletiva. Disscrtação de Mestrado, 1CMC/USP, São Carlos, SP, 1999.

FRANKL, F. G. The use of data flow information for the selection and evaluation of software test data. Tese de Doutoramento, Universidade de New York, New York, NY, 1987.

Franki, P. G.; WEyUker, E. J. An applicable family of data flow testing criteria. IEEE Transactions on Software Engineering, v. 14, n. 10, p. 1483-1498, 1988.

HALEY, A.: ZWEBEN, S. Development and application of a white box approach to integration testing. The Journal of Systems and Software, v. 4, p. 309-315, 1984.

Harman, M.; Hierons, R.; Danicic, S. The relationship between program dependence and mutation testing. In: Mutation 2000 Symposium, San Jose, CA, p. 15-23, 2000.

HARROLD, M. J. Testing: A roadmap. In: 22th International Conference on Software Engineering, painel sobre o futuro da engenharia de software, 2000.

HARrold, M. J.: SOFfa, M. L. Selecting and using data for integration test. IEEE Software, v. 8, n. 2, p. 58-65, 1991.

HIFRONS, R. M.; HARMAN, M.; DANICIC, S. Using program slicing to assist in the detection of equivalent mutants. Software Testing, Verification and Reliability, v. 9, p. 233-262, 1999.

Horgan, J. R.; MAThur, P. Assessing testing tools in research and education. IEEE Software, v. 9, n. 3, p. 61-69, 1992. 
HOWDFN, W. E. Theoretical and empirical studies of program testing. IEEE Transactions on Software Engineering, v. 4, n. 4, p. 293-298, 1978.

HOWDEN, W. E. Weak mutation testing and completeness of test sets. IEEE Transactions on Software Engincering, v. SE-8, n. 4, p. 371-379, 1982.

Jin, Z.; OffuT, A. J. Integration testing based on software couplings. In: X Annual Conference on Computer Assurance (COMPASS 95), Gaithersburg, Maryland, p. 13 23, 1995.

JorgF, R. F.; PiNTo, D. L.; Delamaro, M. E. Ordenação estocástica aplicada ao teste de mutação para o estabelccimento de estratégias de teste. In: SINAPE - Simpósio Nacional de probabilidade e Estatística, artigo em desenvolvimento, 2002a.

JorGle, R. F.; Vincenzi, A. M. R.; Delamaro, M. E.; Maidonado, J. C. Teste de mutação: Estratégias baseadas em equivalência de mutantes para redução do custo de aplicação. In: CLEI - XXVII Latin-American Conference on Informatics, Venezuela, artigo completo cm CD-ROM, p. 83, 2001.

Jorge, R. F.; Vincenti, A. M. R.; Delamaro, M. F.; Maldonado, J. C. Relatório dos operadores de mutação implementados nas ferramentas proteum e proteum/im. Rel. Téc., ICMC/USP, a ser publicado, $2002 \mathrm{~b}$.

Krause, A.: Olson, M. The basics of s and s-plus. 2nd ed. New York: Springer-Verlag, 2000.

Linnenkljgel, U.; Müllerburg, M. Test data selection criteria for (software) integration testing. In: First International Conference on Systems Integration, Morristown, NJ, p. 709717,1990 .

Maldonado, J. C. Critérios potenciais usos: Uma contribuição ao teste estrutural de software. Tese de Doutoramento, DCA/FEE/UNICAMP, Campinas, SP, 1991.

Maidonado, J. C.; Barbosa, E. F.; Vinclenzi, A. M. R.; Delamaro, M. E. Evaluation $\mathrm{N}$-selective mutation for $\mathrm{C}$ programs: Unit and integration testing. In: Mutation 2000 Symposium, San Jose, CA, p. 32-44, 2000.

Maldonado, J. C.; Chaim, M. L.; Jino, M. Arquitetura de uma ferramenta de teste de apoio aos critérios potenciais usos. In: XXII Congresso Nacional de Informática, São Paulo, SP. 1989.

MAThuR, A. P. Performance, effectiveness and reliability issues in software testing. In: 15th Annual International Computer Software and Applications Conference, Tokio, Japan, p. $604-605,1991$.

Mathlr, A. P.; WONG, W. E. Evaluation of the cost of alternative mutation strategies. In: VII Simpósio Brasileiro de Engenharia de Software, Rio de Janeiro, RJ, Brazil, p. 320-335, 1993.

MCCullagh, P. Regression models for ordinal data. Jornal P. Statist Soc., v. 42, n. 2, p. 109-142, 1989 . 
MCCullagh, P.; Nelder, J. A. Generalized linear models. 2nd ed. New York: Chapman and Hall, 1990.

MYERS, G. J. The art of software testing. Wilcy, New York, 1979.

OfFutT, A. J.; CRAFT, W. M. Using compiler optimization technique to detect equivalent mutants. The Journal of Software Testing, Verification, and Reliability, v. 4, n. 3, p. 131-154, 1994.

Offutt, A. J.; Lee, A.; Rothermel, G.; UnTCH, R. H.; Zapf, C. An experimental determination of sufficient mutant operators. ACM Transactions on Software Engineering Methodology. v. 5, n. 2, p. 99-118, 1996 a.

OfFUTT, A. J.; LEL, S. An empirical evaluation of weak mutation. IEEE Transactions on Software Engineering, v. SE-20, n. 5, p. 337--344, 1994.

Offutt, A. J.; PAN, A. J. Automatically detecting mutants and inseasibl paths. The Journal of Software Testing, Verification, and Reliability, v. 7, n. 3, p. 165-192, 1997.

OfFUTT, A. J.; PAN, A. J.; TEWARY, K.; ZHANG, T. An experimental evaluation of data flow and mutation testing. Software Practice and Experience, v. 26, n. 2, p. 165-176, 1996b.

Offutt, A. J.: Rothermel, G.; ZAPF, C. An experimental evaluation of selective mutation. In: I5th International Conference on Sofiware Engineering, Baltimore, MD, p. 100-107. 1993.

Pressman, R. S. Software engineering - a practitioner's approach. 5 ed. McGraw-Hill, 2000 .

RAPPS, S.; WfyUKER, E. J. Data flow analysis techniques for program test data selection. In: 6th International Conference on Software Engineering, Tokio, Japan, p. 272-278, 1982.

RAPPS, S.; WEYLKER, E. J. Selecting software test data using data flow information. IEEE. Transactions on Software Engineering, v. SE-11, n. 4, p. 367-375, 1985.

SimÃo, A. S. Proteum-RS/PN: Uma ferramenta para a validação de redes de petri baseada na análise de mutantes. Dissertação de Mestrado, ICMC/USP, São Carlos, SP, 2000.

Soliz^. S. R. S. Avaliação do custo e eficácia do critério análise de mutantes na atividade de teste de programas. Dissertação de Mestrado, ICMC/USP, São Carlos - SP, 1996.

Sridhanan, B.; Mundkur, S.; Mathur, A. P. Non-intrusive testing, monitoring and control of distributed corba objects. In: TOOLS'33 - 33rd International Conference on Technology of Object-Oriented Languages, Mont-saint-Michel, France, p. 195-206, 2000.

SugETA, T. Proteum-rs/st: Uma ferramenta para apoiar a validação de especificações statecharts baseada na análise de mutantes. Dissertação de Mestrado, ICMC-USP, São Carlos, SP, 1999.

Vilela, P. R. S.; Maldonado, J. C.; JinO, M. Data flow based integration testing. In: VI Simpósio Brasileiro de Engenharia de Software, Florianópolis, SC, p. 393-409, 1999. 
Vincenzl, A. M. R. Subidios para o estabelecimento de estratégias de teste baseadas na técnica de mutação. Dissertação de Mestrado, ICMC/USP, São Carlos - SP, 1998.

Vincenzl, A. M. R.; Maldonado, J. C.; Barbosa, E. F.; Delamaro, M. E. Unit and integration testing strategies for $\mathrm{C}$ programs using mutation-based criteria. Software Testing, Verification and Reliability, v. 11, n. 4, p. 249-268, (Special Issue: Mutation 2000 A Symposium on Mutation Testing. Issue Edited by W. Eric Wong), 2001.

WAH, K. S. H. T. Theoretical insights into the coupling effect. In: Mutation 2000 Symposium, San Jose, CA: Kluwer Academic Publishers, p. 84-92, 2000.

WONG, W. E. On mutation and data flow. Tese de Doutoramento, Department of Computer Science, Purdue University, W. Lafayette, IN, 1993.

Wong, W. E.; Maldonado, J.; Delamaro, M.; Souza, S. A comparison of selective mutation in $\mathrm{C}$ and fortran. In: Workshop do Projeto Validação e Teste de Sistemas de Operação, Águas de Lindóia, SP, p. 71-80, 1997.

Wong, W. E.; Maldonado, J. C.: Dlilamaro, M. E.; Mathur, A. P. Constrained mutation in C programs. In: Sth Brazilian Symposium on Software Engineering, Curitiba, PR, Brazil, p. 439-452, $1994 \mathrm{a}$.

WONG, W. E.; MATiIUR, A. P. Fault detection effectiveness of mutation and data flow testing. Software Quality Journal, v. 4, n. 1, p. 69-83, 1995 a.

WONG, W. E.; MAriuUR, A. P. Reducing the cost of mutation testing: An empirical study. The Journal of Systems and Software, v. 31, n. 3, p. 185-196, $1995 \mathrm{~b}$.

Wong, W. E.; Mathur, A. P.; Maldonado, J. C. Mutation versus all-uses: An empirical evaluation of cost, strength, and effectiveness. In: International Conference on Software Quality and Productivity, Hong Kong, p. 258-265, 1994 b.

WOODWard, M. R. Mutation testing - its origin and evolution. Information and Software Technology, v. 35, n. 3, p. 163-169, 1993.

WOODWARD, M. R.; HALEWOOD, K. From weak to strong, dead or alive? an analysis of some mutation testing issues. In: Second Workshop on Software Testing, Verification and Analvsis, Banff, Canadá, 1988. 